AUTARQUIA ASSOCIADA À UNIVERSIDADE DE SÃO PAULO

EMPREGO DE SIMULAÇÃO COMPUTACIONAL PARA AVALIAÇÃO DE OBJETOS SIMULADORES IMPRESSOS 3D PARA APLICAÇÃO EM DOSIMETRIA CLÍNICA

\author{
CAIO CÉSAR SANTOS VALERIANO
}

Dissertação apresentada como parte dos requisitos para obtenção do Grau de Mestre em Ciências na Área de Tecnologia Nuclear - Aplicações

Orientadora:

Profa. Dra. Letícia Lucente Campos Rodrigues 
INSTITUTO DE PESQUISAS ENERGÉTICAS E NUCLEARES

Autarquia associada à Universidade de São Paulo

EMPREGO DE SIMULAÇÃO COMPUTACIONAL PARA AVALIAÇÃO DE OBJETOS SIMULADORES IMPRESSOS 3D PARA APLICAÇÃO EM DOSIMETRIA CLÍNICA

\section{CAIO CÉSAR SANTOS VALERIANO}

Dissertação apresentada como parte dos requisitos para obtenção do Grau de Mestre em Ciências na Área de Tecnologia Nuclear - Aplicações

Orientadora:

Profa. Dra. Letícia Lucente Campos Rodrigues 


\section{DEDICATÓRIA}

Aos meus avós Neilde Maria (in memorian) e João Meireles, pelo amor e apoio incondicional;

À minha mãe Josélita Valeriano, pela incrível dedicação e amor que foram fundamentais no decorrer dessa jornada;

À minha "tia-madrinha”" Joana D'arc, pelo amor e dedicação de mãe sem os quais não teria sido possivel essa jornada;

Ao meu pai Orlando César, que sempre foi exemplo de leitura e gosto pelo conhecimento.

À minha "mãe de leite" Lindalva, pelo constante carinho e apoio tão importantes nessa jornada; Ao meu afilhado JP, pelo sorriso infantil e doce que foram sempre remédios para o humor. 


\section{AGRADECIMENTOS}

Ao alto eu olho e agradeço. Deus e Nossa Senhora Aparecida foram meu suporte espiritual, meu escudo e minha força para permanecer firme e não desistir. Sem a luz de Deus eu nem estaria digitando esse paragrafo, por isso meu MAIOR OBRIGRADO!

Ao Instituto de Pesquisas Energéticas e Nucleares, na pessoa do Sr. Superintendente Dr. Wilson Aparecido Parejo Calvo, pela infraestrutura e pelo curso de mestrado. financeiro.

Ao Conselho Nacional de Desenvolvimento Científico e Tecnológico (CNPq) pelo suporte

À minha orientadora, Dra. Letícia Lucente Campos Rodrigues, pelo apoio, profissionalismo e dedicação que sempre se fizeram presentes no decorrer do mestrado. Obrigado pela confiança!

À Dra. Linda Caldas V. E. Caldas, pelo apoio quando cheguei ao GMR.

Ao meu mestre e amigo, William Santos, pelo apoio profissional e pessoal, pelas sugestões e debates de resultados e por ter "rodado" as simulações com MCNP5. Sua amizade e apoio sempre foram essenciais desde a época da iniciação científica na graduação.

Ao Dr. Vitor Vívolo, pelo constante apoio e disponibilidade em ajudar.

À Dra. Maria da Penha, por estar sempre disposta a ajudar.

Ao Dr. Orlando Rodrigues, pelas sugestões e dicas dadas em relação a esse trabalho.

Ao Dr. Silas Cardoso por ter agendado e realizado a microscopia eletrônica de varredura.

Ao LCI/GMR/IPEN pelo suporte dado em diversas fases desse trabalho.

Ao Sr. Aldo Ramos, pela ajuda e suporte iniciais nos procedimentos de leitura dos TLD's.

Aos físicos médicos do Hospital Israelita Albert Einstein, Roberto Sakuraba, Vinícius Gonçalves, Bruno Gialluisi, pelo suporte técnico, profissionalismo e sugestões que foram essenciais nesse trabalho.

À dosimetrista do Hospital Israelita Albert Einstein, Carolina Moreno, pelo "curso rápido" no Eclipse $^{\mathrm{TM}}$, pela paciência, profissionalismo e disponibilidade em ajudar.

Ao amigo Tallyson Alvarenga, pela amizade, pelas "filosofias de vida" e pelos conselhos que foram importantes nos dias de mestrado.

Ao amigo Eduardo Correa, pela amizade, pela ajuda na seleção do dosímetros, pelos debates de resultados, de problemas do mestrado e do dia-a-dia.

Ao amigo João Vinícius, pelas conversas sobre objetos simuladores. mestrado.

Ao amigo Lucas Rodrigues pelas "dicas de vida" e amizade que foram essenciais ao período de 
Ao amigo Glauco Veneziani pela ajuda inicial com o uso da impressora 3D.

Ao amigo Julian Maciel ("Dilman"), pela ajuda e amizade.

Ao amigo Carlos Eduardo Mattos (Cadu), pela amizade

À Eletrocell (CIETEC/IPEN), na pessoa do Sr. Adenilson Almeida, pelo apoio na manutenção da impressora 3D. importante.

Aos "amigos da copa do GMR", pela hora do café que era um pequeno momento de descanso

À amiga Shirlane Barbosa, pelas conversas, debates e parceria em uma fase desse trabalho.

À amiga Ana Maria Souza pelo carinho, apoio e amizade.

À amiga Tereza Vasconcelos, pelo carinho, apoio e amizade.

À D. Elza Pereira ("tia”), pelo carinho e conversas descontraídas.

Aos amigos de GMR, Renata Bressane, Lilian Kuahara e Daniel Villani, pela convivência do dia-adia e pela amizade.

Aos amigos de minha mãe e minha tia: Fátima ("tia"), pelas orações e pelo apoio; Silvio ("professor Sílvio"), pelo apoio e "energias positivas"; Maria do Carmo ("tia"), pelas orações; Loreni ("tia), Valdete ("tia”), Goretti ("tia”), Janete ("tia"), Nadja ("tia"), Joanita ("tia"), Ilná ("tia), e Eliana ("Lili") pelas "energias positivas".

À minha tia Dirce Soares, pelo carinho e apoio constante. Sua presença (via Whatsapp) foi essencial para seguir em frente.

Ao primo Aldemi Ramos e sua namorada Ciça Guimarães, pelo carinho, preocupação e pelo acolhimento quando me acidentei.

À amiga Andrea Vera, pelo socorro prestado quando me acidentei.

À Rose Vieira, pelo carinho e mensagens do Whatsapp.

À Solange, pelas "energias positivas".

À minha família, em especial meus "primos-irmãos" (Diogénes, Sarah e Soraya) e o esposo de minha prima, Magno ("olhos castanhos"), pelo apoio e amor que me fizeram suportar a saudade e a distância.

A todos que de qualquer forma contribuíram positivamente, meu obrigado. 
"Mouth so full of lies Tend to block your eyes Just keep them closed Keep praying Just keep waiting”

(Metallica)

"Our father everlasting

The all creating One

God Almighty through your Holy Spirit

Conceiving Christ the Son Jesus our Saviour"

(Hillsong Worship) 


\title{
EMPREGO DE SIMULAÇÃO COMPUTACIONAL PARA AVALIAÇÃO DE OBJETOS SIMULADORES IMPRESSOS 3D PARA APLICAÇÃO EM DOSIMETRIA CLÍNICA
}

\author{
Caio César Santos Valeriano
}

\author{
RESUMO
}

O propósito de um objeto simulador é representar a alteração do campo de radiação provocada pela absorção e espalhamento em um dado tecido ou órgão de interesse. Suas características geométricas e de composição devem estar próximos o máximo possível aos valores associados ao seu análogo natural. Estruturas anatômicas podem ser transformadas em objetos virtuais 3D por técnicas de imageamento médico (p. ex. Tomografia Computadorizada) e impressas por prototipagem rápida utilizando materiais como, por exemplo, o ácido poliláctico. Sua produção para pacientes específicos requer o preenchimento de requisitos como a acurácia geométrica com a anatomia do individuo e a equivalência ao tecido, de modo que se possa realizar medidas utilizáveis, e ser insensível aos efeitos da radiação. $O$ objetivo desse trabalho foi avaliar o comportamento de materiais impressos 3D quando expostos a feixes de fótons diversos, com ênfase para a qualidade de radiotherapia (6 MV), visando a sua aplicação na dosimetria clínica. Para isso foram usados 30 dosímetros termoluminescentes de LiF:Mg,Ti. Foi analisada também a equivalência entre o PMMA e o PLA impresso para a resposta termoluminescente de 30 dosímetros de $\mathrm{CaSO}_{4}$ :Dy. As irradiações com feixes de fótons com qualidade de radioterapia foram simuladas com o uso do sistema de planejamento Eclipse ${ }^{\mathrm{TM}}$, com o Anisotropic Analytical Algorithm e o Acuros $^{\circledR} X B$ Advanced Dose Calculation algorithm. Além do uso do Eclipse ${ }^{\mathrm{TM}}$ e dos testes dosimétricos, foram realizadas simulações computacionais utilizando o código MCNP5. As simulações com o código MCNP5 foram realizadas para calcular o coeficiente de atenuação de placas impressas expostas a diversas qualidades de raios $\mathrm{X}$ de radiodiagnóstico e para desenvolver um modelo computacional de placas impressas 3D. 


\title{
USE OF COMPUTATIONAL SIMULATION FOR EVALUATION OF 3D PRINTED PHANTOMS FOR APPLICATION IN CLINICAL DOSIMETRY
}

\author{
Caio César Santos Valeriano
}

\begin{abstract}
The purpose of a phantom is to represent the change in the radiation field caused by absorption and scattering in a given tissue or organ of interest. Its geometrical characteristics and composition should be as close as possible to the values associated with its natural analogue. Anatomical structures can be transformed into 3D virtual objects by medical imaging techniques (e.g. Computed Tomography) and printed by rapid prototyping using materials, for example, polylactic acid. Its production for specific pacients requires fulfilling requirements such as geometric accuracy with the individual's anatomy and tissue equivalence, so that usable measurements can be made, and be insensitive to the radiation effects. The objective of this work was to evaluate the behavior of $3 \mathrm{D}$ printed materials when exposed to different photon beams, with emphasis on the quality of radiotherapy (6 MV), aiming its application in clinical dosimetry. For this, 30 thermoluminescent dosimeters of $\mathrm{LiF}: \mathrm{Mg}$, Ti were used. The equivalence between the PMMA and the printed PLA for the thermoluminescent response of 30 dosimeters of CaSO4: Dy was also analyzed. The irradiations with radiotherapy photon beams were simulated using the Eclipse TM treatment planning system, with the Anisotropic Analytical Algorithm and the Acuros ${ }^{\circledR}$ XB Advanced Dose Calculation algorithm. In addition to the use of Eclipse ${ }^{\mathrm{TM}}$ and dosimetric tests, computational simulations were realized using the MCNP5 code. Simulations with the MCNP5 code were performed to calculate the attenuation coefficient of printed plates exposed to different radiodiagnosis $\mathrm{X}$-rays qualities and to develop a computational model of $3 \mathrm{D}$ printed plates.
\end{abstract}




\section{SUMÁRIO}

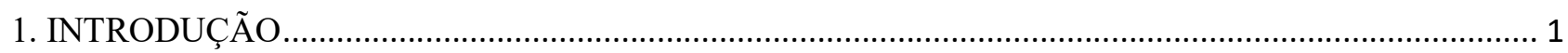

2. OBJETIVOS

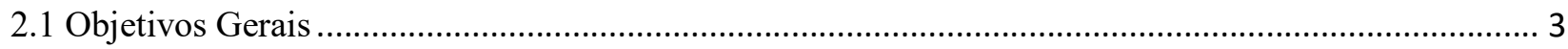

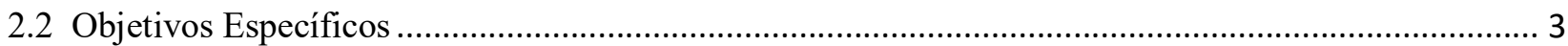

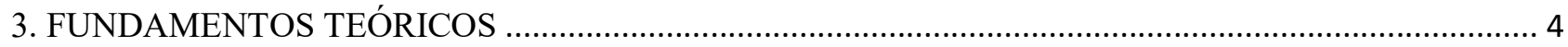

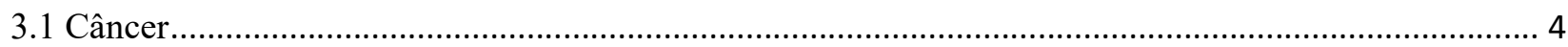

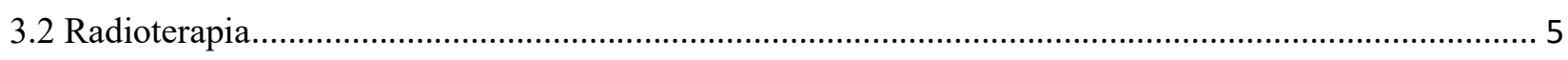

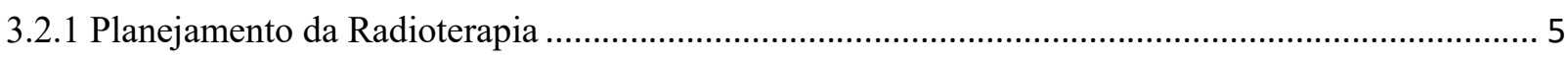

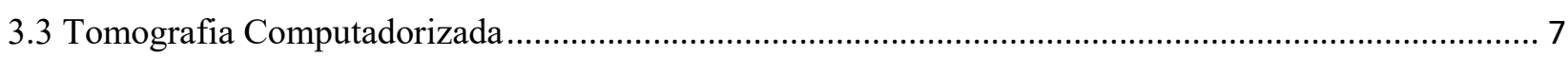

3.3.1 Comunicação de Imagens Digitais em Medicina (DICOM - Digital Imagining and

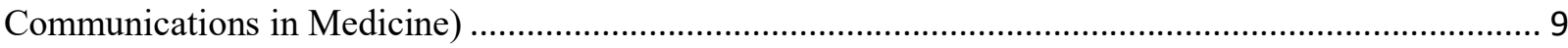

3.4 Sistema de Planejamento de Tratamento (TPS - Treatment Planning System) ................................. 10

3.5 Aceleradores Lineares (LINACs - Linear Accelerators): ................................................................ 11

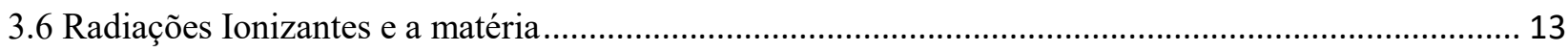

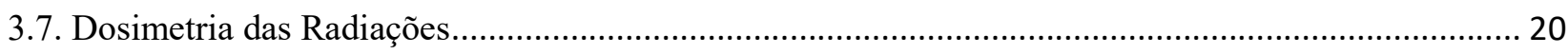

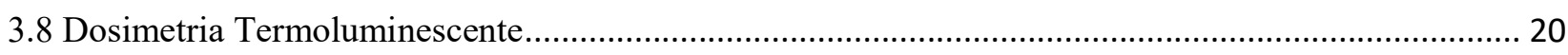

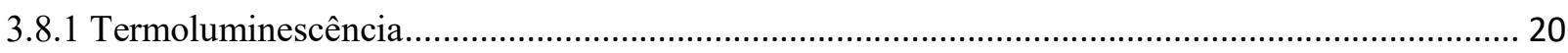

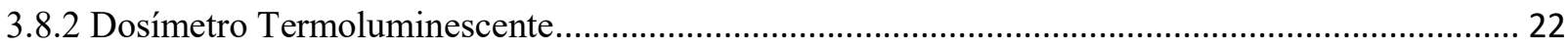

3.8.3 Fluoreto de lítio dopado com magnésio e titânio (LiF:Mg,Ti) .................................................... 25

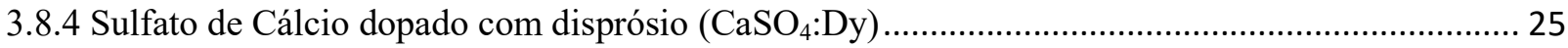

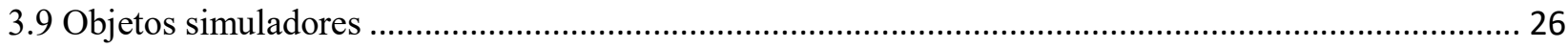

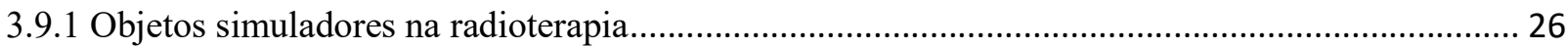

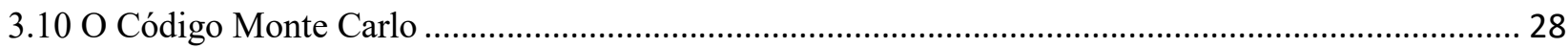

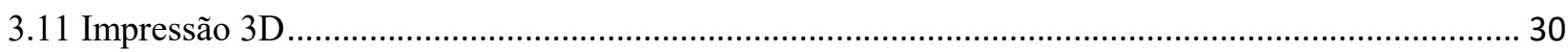

3.11.1 Modelagem por fusão e deposição .................................................................................... 30

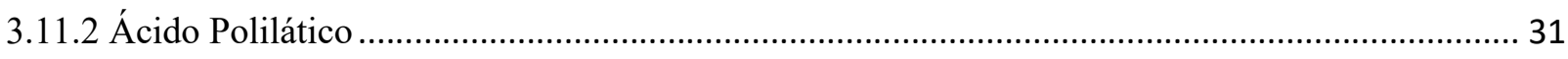

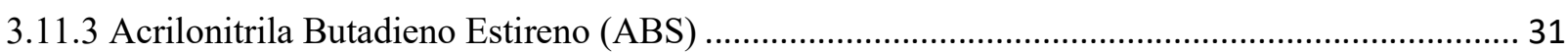




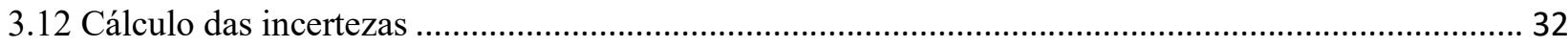

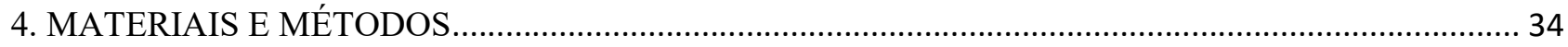

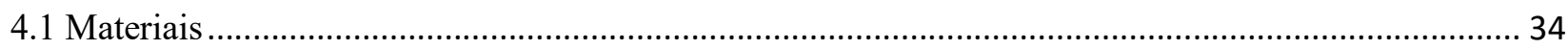

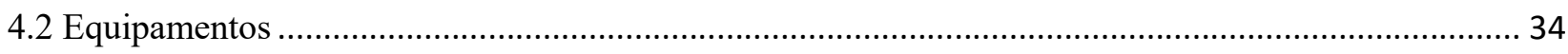

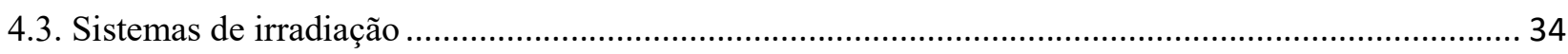

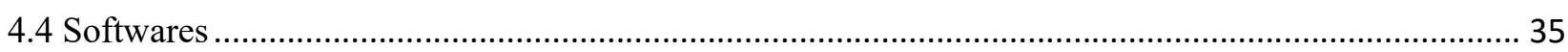

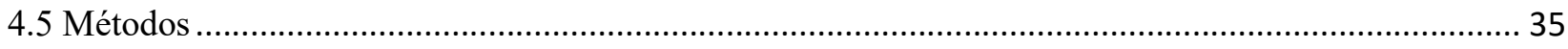

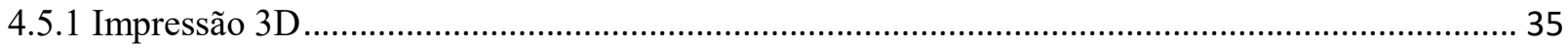

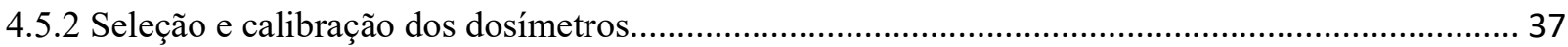

4.5.3 Verificação da calibração - LiF:Mg,Ti .................................................................................... 38

4.5.4 Calibração com o acelerador linear Varian 6 EX - LiF:Mg, Ti ................................................... 39

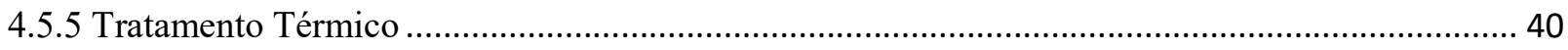

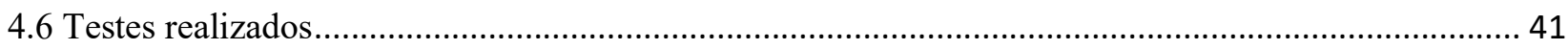

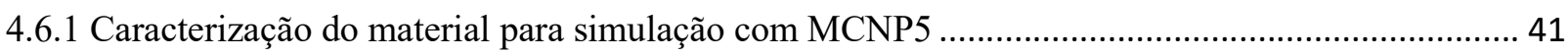

4.6.2 Cálculo dos coeficientes de atenuação para PLA e ABS com MCNP5 ……….............................. 43

4.6.3 Desenvolvimento de modelo computacional da placa impressa "quase-sólida" ............................ 45

4.6.4 Resposta termoluminescente do $\mathrm{CaSO}_{4}$ :Dy, empregando placas de PLA e de PMMA................. 47

4.6.5 Cálculo de dose para Água Sólida, PLA e ABS - Dosimetria termoluminescente e Eclipse ${ }^{\mathrm{TM}}$..... 48

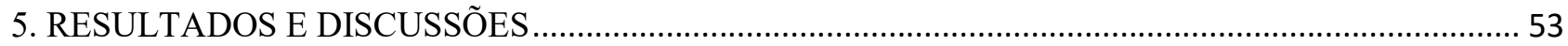

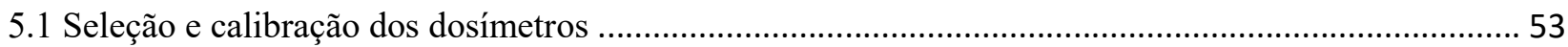

5.2 Composição e densidade do material para simulação com MCNP5 ………….................................... 55

5.3 Coeficientes de Atenuação para PLA e ABS ….................................................................................... 55

5.4 Validação do modelo computacional da placa impressa "quase-sólida" ............................................. 56

5.5 Fatores de correção para dependência energética do $\mathrm{CaSO}_{4}$ :Dy - PLA versus PMMA ....................... 57

5.6 Comparativo de doses calculadas - Sistema de planejamento Eclipse ${ }^{\mathrm{TM}}$ versus dosimetria

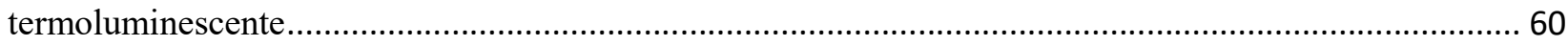

5.6.1 Diferença percentual da dose - PLA versus Água Sólida ........................................................... 61

5.6.2 Percentagem de dose profunda - PLA versus Água Sólida....................................................... 61

5.6.4 Diferença percentual de dose - ABS versus Água Sólida ............................................................ 63

5.6.5 Percentagem de dose profunda - ABS versus Água Sólida ....................................................... 64

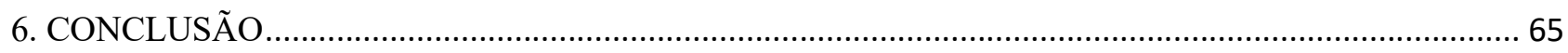

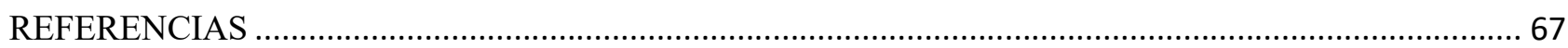




\section{INTRODUÇÃO}

Descoberta há pouco mais de um século, a radiação causou um efeito profundo tanto no ramo industrial quanto no ramo médico. Nos primórdios não havia um consenso quanto aos malefícios do uso da radiação. Muitos acreditavam que a exposição às radiações poderia trazer benefícios, tanto que raios emitidos pelo Rádio eram usados em tratamentos de algumas doenças (p.ex. lúpus e câncer).

Pierre Curie notou que se um indivíduo fosse exposto a alguns centigramas de sal de Rádio por algumas horas, não haveria complicação imediata. No entanto, dias após iria surgir uma vermelhidão seguida de ferimento de difícil cicatrização.

O próprio Curie levantou questões como: quão perigosa seria a radiação em poder de criminosos e quais seriam os benefícios trazidos por tal conhecimento, principalmente para fins bélicos. (Reed, 2011)

A radiação é dita ionizante quando é capaz de retirar um elétron do átomo, podendo ser citadas como exemplos as partículas carregadas (p. ex. alfa e beta), os raios X e os raios gama. No corpo humano, os átomos se unem formando moléculas (p.ex. moléculas de água ou moléculas de DNA).

Quando a radiação ionizante arranca um elétron de um dos átomos de uma dessas moléculas poderá ocorrer a sua quebra. Dentre outros efeitos decorrentes da passagem da radiação pelo organismo, podem ser citados: morte celular, mutação genética e queimaduras. (Okuno, 2013)

Atualmente, existem diversas aplicações das radiações, as quais vão desde fins médicos até usinas nucleares. Na área médica, podem ser citados o seu uso para a visualização de fraturas ósseas por meio de diferentes níveis de sombreamento em um filme fotográfico e também sua utilização para matar células cancerígenas. (USNRC,2014).

Para a destruição de células tumorais uma dose previamente calculada de radiação é aplicada, em um dado período de tempo, a um volume de tecido que circunda a região tumoral, 
causando o mínimo de dano possível às células circunvizinhas que se encontram sadias. A este uso de radiação ionizante para destruição de células tumorais é dado o nome de radioterapia. (INCA, [s.d.])

Segundo a IAEA (International Atomic Energy Agency) as exposições para fins médicos deverão ser justificadas levando-se em conta o balanceamento entre os benefícios (terapêuticos e diagnósticos) esperados e os malefícios decorrentes da radiação. O balanceamento deverá levar em consideração a viabilidade de técnicas alternativas que não envolvam a exposição.

Ainda segundo a IAEA, deverá ser garantido que a exposição, para cada paciente, de regiões que não sejam aquelas que se deseja tratar, devera estar a níveis tão baixos quanto seja possível manter a consistência entre a dose prescrita e a dose planejada, levando em conta os níveis de tolerância. (IAEA, 2014)

É possível dizer que um desvio na dose prescrita pode ter consequências severas ou até mesmo fatais, e que a eficácia de um tratamento radioterápico repousa sob a dose depositada no volume alvo. A sua medição de forma precisa é primordial para a calibração de equipamentos e implementação de novas técnicas na prática clínica, não devendo variar mais que $5 \%$ do valor prescrito. (Bueno, 2007)

A medição pode ser realizada utilizando-se os dosímetros termoluminescentes (TL), que têm sido aplicados na dosimetria das radiações de diversas qualidades e tipos, variando desde os fótons de baixas e altas energias, as partículas carregadas pesadas (p. ex. partículas beta) e nêutrons. (Campos, 1998)

Estruturas anatômicas podem ser transformadas em objetos virtuais 3D por meio de técnicas de imageamento médico (p. ex. Tomografia Computadorizada) e impressas por prototipagem rápida utilizando materiais como, por exemplo, o ácido poliláctico. Variando os materiais utilizados e suas densidades é possível obter o contraste radiográfico ou a equivalência ao tecido desejado.

Esses modelos são utilizáveis como objetos simuladores para a radioterapia (para o controle de qualidade de um tratamento específico, ou em casos que envolvam dosimetria complexa). Sua produção para pacientes específicos requer o preenchimento de requisitos como a acurácia geométrica com a anatomia do individuo e a equivalência ao tecido, de modo que se possa realizar medidas utilizáveis, e ser insensível aos efeitos da radiação. (Kairn, Crowe \& Markwell, 2015) 


\section{OBJETIVOS}

\subsection{Objetivos Gerais}

Avaliar o comportamento de materiais impressos 3D quando expostos a feixes de fótons diversos, com ênfase para qualidade de radioterapia, de modo a catalogar materiais alternativos àqueles que são indicados pela publicação 44 da International Comission on Radiation Units \& Measurements (ICRU).

\subsection{Objetivos Específicos}

- Desenvolver protótipos impressos;

- Realizar simulações computacionais, empregando o código MCNP5, de irradiações dos materiais impressos;

- Realizar cálculo de dose, utilizando sistema de planejamento de tratamentos, das irradiações com feixes de radioterapia;

- Avaliar a dose recebida pelos protótipos impressos por meio da técnica de dosimetria termoluminescente empregando os dosímetros de $\mathrm{LiF}: \mathrm{Mg}$, $\mathrm{Ti}$ e $\mathrm{CaSO}_{4}$ :Dy. 


\section{FUNDAMENTOS TEÓRICOS}

\subsection{Câncer}

O crescimento celular de forma controlada (ou não) pode ser observado no organismo. A neoplasia (tumores) é a proliferação anormal de tecido, a qual é caracterizada por não ser controlada (total ou parcialmente) pelo organismo e pela tendência à autonomia e a perpetuação, com efeitos agressivos ao hospedeiro. (SIA/SUS, 2015)

Os tumores podem ser classificados em tumores benignos e malignos. A diferença básica entre os dois tipos é que os tumores benignos apresentam células muito parecidas com aquelas que os originaram, apresentam um desenvolvimento lento e não são capazes de desenvolver metástase. Os malignos, por sua vez, apresentam "agressividade" e com o desenvolvimento do câncer eles tendem a se espalhar para os linfonodos vizinhos, e na metástase para órgãos não contíguos. [(Goitein, 2008); (Hospital Israelita Albert Einstein, 2013)]

$\mathrm{O}$ câncer pode ser definido como o grupo de doenças que se caracterizam pelo rápido crescimento e pela disseminação de células anormais. Tais doenças podem ser causadas por fatores externos como, por exemplo, o tabaco, alguns agentes infecciosos e a radiação, assim como também por fatores internos como, por exemplo, os hormônios, as mutações hereditárias e as mutações que ocorrem a partir do metabolismo. (American Cancer Society, 2014).

Na figura 1 pode ser vista uma ilustração com as diferenças entre os tumores malignos e benignos.

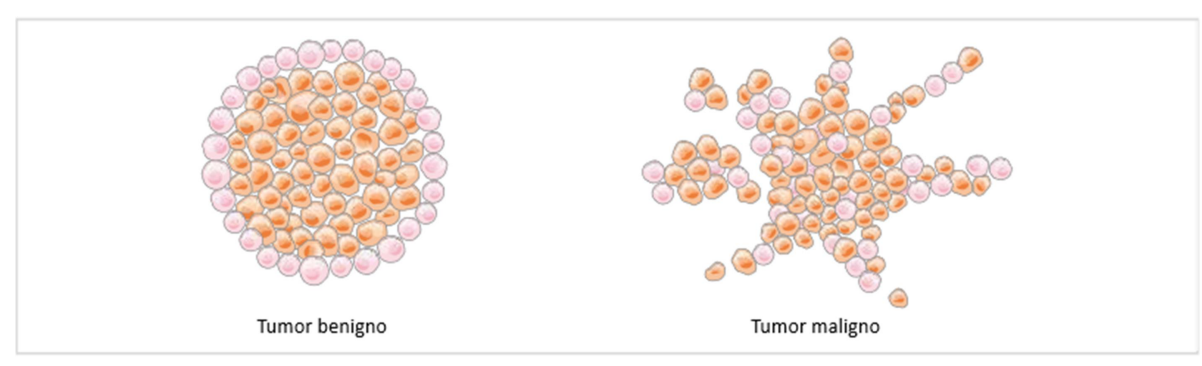

FIGURA 1. Tipos de tumores [Adaptada de (Ministério da Saúde/INCA, 2012)] 
Três modalidades principais de tratamento do câncer podem ser citadas: radioterapia, quimioterapia e cirurgia. Estas modalidades podem ser aplicadas em forma conjunta, variando apenas ao se levar em consideração a susceptibilidade do tumor a cada uma das modalidades e a sequência mais eficaz de sua administração. (Ministério da Saúde/INCA, 2012)

\subsection{Radioterapia}

Este procedimento clínico visa a eliminação parcial ou completa das células tumorais, preservando o máximo possível os tecidos vizinhos, por meio da utilização de feixes de radiação ionizante (radiação gama, X, beta e elétrons). [(Matsushima, 2010)].

A radioterapia pode ser indicada de forma exclusiva ou associada aos outros métodos terapêuticos (cirurgia ou quimioterapia), e, pode ser classificada como: curativa (cura total do tumor); remissiva (redução tumoral); profilática (trata a doença em fase subclínica); e paliativa (amenizar as dores causadas pelo câncer). [(INCA,[s.d.])]

Há duas formas de radioterapia: a teleterapia e a braquiterapia. A teleterapia é normalmente executada com feixe de fótons, os quais são, na maioria das vezes, raios $\mathrm{X}$ de alta energia produzidos por acelerador linear (LINAC - Linear Accelerator). Por sua vez, a braquiterapia é o tratamento que utiliza fontes radioativas seladas inseridas no volume tumoral, cuja finalidade é dar uma dose localizada de modo a reduzir a morbidade aos tecidos sadios vizinhos. [(Okuno \& Yoshimura, 2010); (Williams \& Thwaites, 2000)]

A resposta dos tecidos à interação da radiação com a matéria vai depender de fatores como a localização do tumor, a sensibilidade e seu nível de oxigenação, assim como a qualidade, a quantidade e o tempo total no qual é administrada a radiação. (Matsushima, 2010)

\subsubsection{Planejamento da Radioterapia}

A importância do planejamento da radioterapia se deve ao fato de que os tecidos sadios vizinhos à área tratada devem ser danificados o menos possível, assim como se deve garantir que o alvo receba a dose de tratamento desejada. (Poli, 2007)

O processo de planejamento do tratamento consiste de diversas etapas as quais podem ser citadas: a aquisição dos dados do paciente; definição do alvo; simulação; cálculo de dose e avalição do plano de tratamento.

Primeiramente, no planejamento do tratamento deve ser realizada a aquisição dos dados do paciente. As informações anatômicas do paciente podem ser obtidas por meio de imagens radiográficas ou por meio da tomografia computadorizada ( $\mathrm{CT}$ - computed tomography), sendo o 
uso da CT mais frequente, uma vez que essa técnica oferece informações mais precisas da localização do tumor devido ao contraste em tecidos moles.

Os volumes de interesse podem ser divididos em: volume de tumor visível, volume clínico do alvo, volume alvo interno, volume de planejamento do alvo e os órgãos de risco. O volume de tumor visível (GTV - gross tumor volume) pode ser definido como sendo a massa palpável ou extensão visível do crescimento tumoral.

Quando se leva em conta o GTV e o volume da doença maligna possível é então considerado o volume clínico do alvo, conhecido pelo acrônimo CTV (clinical target volume). O volume alvo interno (ITV - internal target volume) é definido como sendo a soma entre o CTV e uma margem interna para movimentos fisiológicos e variações temporais no tamanho, formato e posição do CTV. [ (Gointein, 2008);(Poli,2007)]

$\mathrm{O}$ volume de planejamento de tratamento (PTV - planning target volume) é compreendido como o volume que abrange o ITV acrescido a uma margem cuja finalidade é considerar a incerteza no posicionamento do paciente e no alinhamento do posicionamento do mesmo. (Gointein, 2008)

Todo órgão ou porção de tecido sadio que possa vir a ser significativamente afetado pela radiação ministrada é classificado com órgãos de risco (OAR - organs at risk). [(Gointein, 2008)]. Uma representação gráfica dos volumes de interesse encontra-se na figura 2.

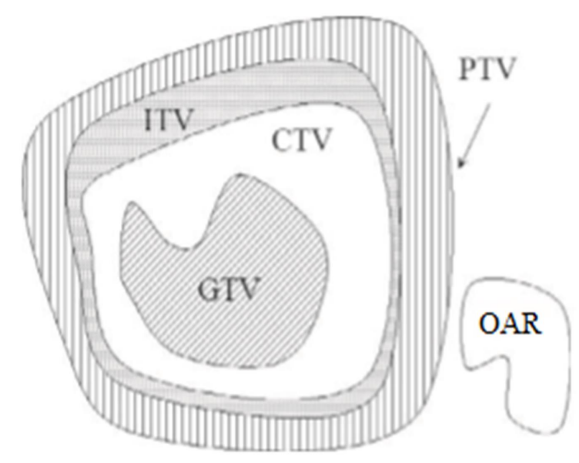

FIGURA 2. Representação gráfica dos volumes de interesse. [Adaptada de (Podgorsak, 2005)]

Com os dados do paciente já adquiridos e os alvos localizados, é possível determinar os parâmetros do feixe necessários ao tratamento. No caso da geometria do feixe ter sido obtida a partir de radiografia convencional são usadas estruturas ósseas como referência para delimitar os campos de tratamento. Se os dados partirem de imagens de CT é possível realizar simulação virtual por meio das radiografias planas reconstruídas digitalmente (DRR - digitally reconstructed 
radiograph), pelas quais podem ser sobrepostas as delineações dos campos de tratamento. Essa técnica permite que os feixes de radiação sejam determinados relativamente às estruturas de tecido mole que foram delineadas nas imagens de CT. (Poli, 2007)

Após ser executada a seleção dos campos, é possível realizar o cálculo de dose para os alvos e os órgãos de risco. Em casos de campos com formato de um quadrado, retângulo ou de uma esfera, em meio homogêneo, podem ser utilizadas tabelas com dados dosimétricos dos feixes para cálculo manual. Para aqueles casos onde há distribuições heterogêneas, são utilizados algoritmos de cálculo de dose que podem incluir formas de correção de tecidos heterogêneos dentro do paciente.

Após a realização do cálculo da dose, o médico responsável pelo tratamento irá avaliar fatores como a uniformidade da dose e o limite de dose nos órgãos críticos. Estando o planejamento de acordo com o tratamento desejado, o mesmo será validado.

Uma vez tendo sido validado o plano de tratamento, a etapa de entrega do tratamento (entrega da dose ao paciente) será iniciada. Devido a problemas como modificações no procedimento de posicionamento e/ou mobilização do paciente e as alterações anatômicas que ocorrem em decorrência a flutuações no peso e na doença, deverá ser realizada a verificação periódica por meio de imagem portal. (Bueno, 2007)

\subsection{Tomografia Computadorizada}

A tomografia computadorizada pode ser entendida como sendo a técnica na qual imagens são produzidas por meio de feixes de raios $\mathrm{X}$ estreitos. Esses feixes são direcionados para $\mathrm{o}$ paciente e, enquanto rotacionam o corpo, produzem sinais que são processados e se transformam em imagens de cada seção transversal (conhecidas como "fatias").

Quando fatias sucessivas são coletadas, elas são agrupadas digitalmente em uma imagem tridimensional. Essa imagem permite a identificação e a localização de estruturas básicas e de tumores ou estruturas anormais. (NIH/NIBIB,[s.d.])

Cada fatia representa um plano específico na anatomia do paciente. A espessura de cada fatia esta relacionada com o eixo $\mathrm{Z}$ e é especificada pelo operador do equipamento de tomografia; a limitação se da por meio de colimadores que se ajustam de acordo com o tamanho da fatia selecionada. Uma ilustração da espessura de uma fatia de imagem tomográfica pode ser vista figura 3. 


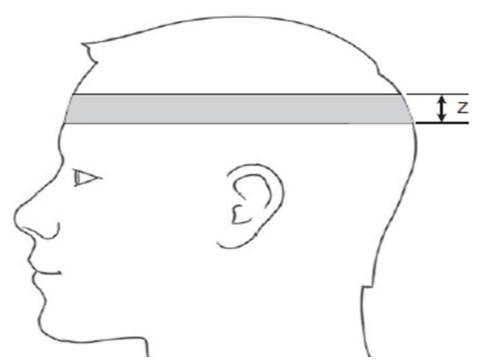

FIGURA 3. Ilustração da espessura de um corte transversal no eixo Z. (Romans, 2011)

Uma imagem tomográfica é representada por meio da variação de tons de cinza. À medida que o feixe de raios $\mathrm{X}$ emitido atravessa a anatomia do paciente, ele vai sendo registrado por detectores. Pode ser dito, portanto, que a quantidade de raios $\mathrm{X}$ que atravessa a anatomia do paciente será determinante para formação da escala de tons de cinza que irá compor a imagem.

Em regiões nas quais o feixe de raios $\mathrm{X}$ é capaz de atravessar livremente será formada uma área preta na imagem, para tais regiões há uma baixa atenuação. Por outro lado, regiões nas quais o feixe de raios X é completamente absorvido, serão representadas por áreas brancas na imagem; esse fato é decorrente da não detecção do feixe de raios X nessas regiões. (Romans, 2011)

A escala de tons de cinza que compõe a imagem tomográfica recebe o nome de Unidades Hounsfield (HU - Hounsfield Units). As HU pode ser definida por meio da seguinte equação:

$$
H U_{(x, y, z)}=1000 \frac{\left[\mu_{(x, y, z)}-\mu_{w}\right]}{\mu_{w}}
$$

Na equação $1, \mu_{(x, y, z)}$ representa o valor médio do coeficiente de atenuação linear do elemento de volume (chamado de voxel) da região anatômica do paciente na posição (x,y,z); $\mu_{w}$ representa o valor do coeficiente de atenuação linear da água para o espectro empregado; e $H U_{(x, y, z)}$ representa a escala de cinza, na imagem tomográfica formada, da região localizada no ponto $(\mathrm{x}, \mathrm{y}, \mathrm{z})$. A partir dessa mesma equação, é possível verificar que, para o caso no qual um dado voxel represente a água, o valor da HU atribuído ao mesmo será zero.

Para um dado voxel que represente o ar $\mu_{(x, y, z)}$, a razão contida a esquerda da equação 1 , será igual a -1. Esse valor fará com que o voxel de ar seja representado pelo valor de HU igual a -1000. Portanto a escala de HU é definida entre esses dois pontos - água e ar. (Bushberg et al, 2012) 
3.3.1 Comunicação de Imagens Digitais em Medicina (DICOM - Digital Imagining and Communications in Medicine)

A Organização Internacional para Padronização (ISO - International Organization for Standardization) definiu o Sistema Aberto de Intercomunicação (OSI - Open System Interconnection) como modelo de referência a ser usado como estrutura para comunicação de rede. O OSI descreve a forma como dados em um serviço são transportados para outro serviço via meio eletrônico. (Schlegel, Bortfeld \& Grosu 2006)

Em um ambiente hospitalar com sistemas digitais de variados fabricantes a comunicação de dados está propensa a falhas, podendo ocorrer comprometimento de dados quando estes são reformatados para os formatos de um dado equipamento.

Nos anos 1980 surgiu a necessidade de uma padronização que mantivesse a conectividade e interoperabilidade. Foi desenvolvido então o padrão DICOM, cuja finalidade era criar padrões industriais onde todos os fornecedores de equipamentos médicos pudessem se adaptar.

O padrão definiu fundamentos das interações em rede, tais como a transferência de imagens, a troca de dados e a comunicação entre ambientes médicos. Respectivamente, estes fundamentos possibilitaram a troca e manejo remoto de objetos, bem como a comunicação de diferentes instituições. (Schlegel, Bortfeld \& Grosu 2006)

O processo de geração de estruturas DICOM no processo radioterápico pode ser descrito como um processo que envolve o "escaneamento" do paciente que resulta na criação de uma imagem DICOM. Por meio da imagem DICOM gerada é produzida uma estrutura contendo estruturas como o tumor e órgãos de risco. É criado também um plano que contém informações acerca da geometria do feixe.

O sistema de planejamento do tratamento (TPS - Treatment Planning System) lê então as imagens, o plano e a estrutura criada. São adicionados modeladores e modificadores do feixe para que o TPS calcule os parâmetros dosimétricos referentes ao planejamento. Um sistema de gravação e verificação gera então o plano completo que será utilizado para iniciar o tratamento.

Durante o decorrer do tratamento, podem ser gerados dados acerca de cada sessão de tratamento. Ao final do tratamento, todos os objetos DICOM são compactados para um arquivo DICOM dedicado. (Schlegel, Bortfeld \& Grosu 2006) 


\subsection{Sistema de Planejamento de Tratamento (TPS - Treatment Planning System)}

Para cálculos de dose absorvida nos pacientes é utilizada uma ferramenta computacional denominada Sistema de Planejamento Computadorizado, capaz de realizar os cálculos dosimétricos por meio de diversos algoritmos. (Barbosa, 2011)

O TPS possibilitou, além de avanços no cálculo da dose, avanços na análise final do planejamento, pois, o programa de planejamento possui ferramentas de visualização como: BEV (beam eye view), a qual permite visualizar o campo conformado para diferentes cortes tomográficos do paciente; histograma dose-volume (DVH - dose-volume histogram), ferramenta que permite a análise da dose depositada no volume alvo e em estruturas críticas; DRR (digitally reconstructed radiograph), radiografia digital do paciente, na qual podem ser inseridas informações do campo conformado, importante ferramenta de verificação do posicionamento do paciente para inicio do tratamento. (Barbosa, 2011)

Como exemplos de TPS comerciais podem ser citados: Pinnacle $e^{3}$ da Philips Healthcare, Monaco $^{\circledR}$ e $\mathrm{XiO}^{\circledR}$ ambos da Elekta e o Eclipse ${ }^{\mathrm{TM}}$ da Varian. [(Phillips,[s.d.]);(Elekta, [s.d.]);(Varian Medical Systems (b)) $]^{1}$

O Eclipse ${ }^{\mathrm{TM}}$ é um sistema de planejamento integrado que abrange diversas modalidades de tratamento com radiação: feixes externos de fótons, prótons e elétrons; braquiterapia de baixa taxa de dose; e cobalto. Esse sistema é destinado para a visualização de imagens tridimensionais; definição do tumor e de outras estruturas anatômicas; parâmetros do campo; simulação virtual; cálculo da dose e avaliação do plano.

As informações contidas em uma imagem de tomografia computadorizada (CT - Computed Tomography) são manipuladas de modo diferenciado em cada algoritmo de cálculo de dose. As unidades Housenfield (HU - Housenfield Unit) das imagens de CT são convertidas tanto em densidade eletrônica, quanto em densidade de massa ou poder de fretamento (stopping power) para prótons, dependendo do tipo de planejamento e algoritmo utilizado.

A conversão é realizada empregando as curvas de calibração da CT que foram implementadas na configuração do feixe. Das curvas disponíveis (para cada tomógrafo) a curva de densidade eletrônica é empregada (pelo algoritmo AAA) para converter as HU para densidade eletrônica relativa e a curva de densidade de massa é empregada (pelo algoritmo Acuros XB) para

\footnotetext{
${ }^{1} \mathrm{Na}$ instituição onde foram realizados os teste com raios $\mathrm{X}$ empregando qualidade de radioterapia o sistema de planejamento de tratamento disponível é o Eclipse ${ }^{\mathrm{TM}}$, por esse motivo será descrito apenas esse sistema de planejamento de tratamento, bem como os algoritmos de cálculo de dose AAA e Acuros XB, implementados no já referido sistema. $\mathrm{O}$ autor ressalta que não há conflito de interesse e divulgação do sistema Eclipse ${ }^{\mathrm{TM}}$ bem como de sua fabricante.
} 
converter as HU em densidade de massa [(Varian Medical Systems (a));(Varian Medical Systems(c))].

O Anisotropic Analytical Algorithm (AAA) representa (anisotropicamente) a heterogeneidade do tecido em toda região tridimensional vizinha ao sítio de interação. A implementação clínica desse algoritmo é dividida: na descrição dos parâmetros físicos fundamentais (p. ex. espectro de energia) e na deposição da dose baseando-se nos parâmetros físicos que representam a fluência e os espectro de energia (para fótons e elétrons) que representam o feixe clínico.

No Acuros $^{\circledR}$ XB Advanced Dose Calculation algorithm (Acuros XB), o transporte da radiação no paciente consiste de quatro passos: modelo da fluência da fonte; cálculo da fluência dos fótons espalhados no paciente; cálculo da fluência dos elétrons espalhados no paciente; e cálculo de dose. A fonte do acelerador linear é modelada como uma fonte externa e os raios X são rastreados de modo que seja calculada a distribuição da fluência de fótons e elétrons que não sofreram colisões.

Para calcular a dose o Acuros XB necessita de um mapeamento do material existente na imagem da CT. A biblioteca de materiais desse algoritmo possui diversos materiais biológicos ( $\mathrm{p}$. ex. pulmão) e não biológicos (p. ex. aço). [(Varian Medical Systems (a));(Varian Medical Systems(c))]

\subsection{Aceleradores Lineares (LINACs - Linear Accelerators):}

Os aceleradores lineares são equipamentos que aceleram partículas carregadas (p. ex. elétrons), utilizando ondas eletromagnéticas de alta frequência, através de um tubo linear. Os elétrons acelerados podem ser, de forma direta, empregados no tratamento de tumores superficiais, ou postos a colidir em um alvo de modo a produzirem raios $\mathrm{X}$ que vão ser empregados no tratamento de tumores mais profundos. (Khan, 2003)

Os LINACs de uso médico aceleram os elétrons até energias cinéticas, que variam de 4 à $25 \mathrm{MeV}$, por meio do uso de micro-ondas, cujas frequências variam de $10^{3} \mathrm{~Hz} \mathrm{a} 10^{4} \mathrm{~Hz}$. Um modelo típico de LINAC moderno é capaz de gerar fótons de duas energias (6 e $18 \mathrm{MV}$ ) e elétrons de várias energias (p. ex. 9, 16 e $22 \mathrm{MeV}$ ). (Podgorsak, 2005)

Os elétrons provenientes do aquecimento do cátodo vão ser focados e acelerados por campos eletrostáticos em direção ao anodo, através do qual entram no guia de onda e são acelerados. $\mathrm{Na}$ figura 4 pode ser visto um acelerador linear modelo Varian $6 \mathrm{EX}$. 


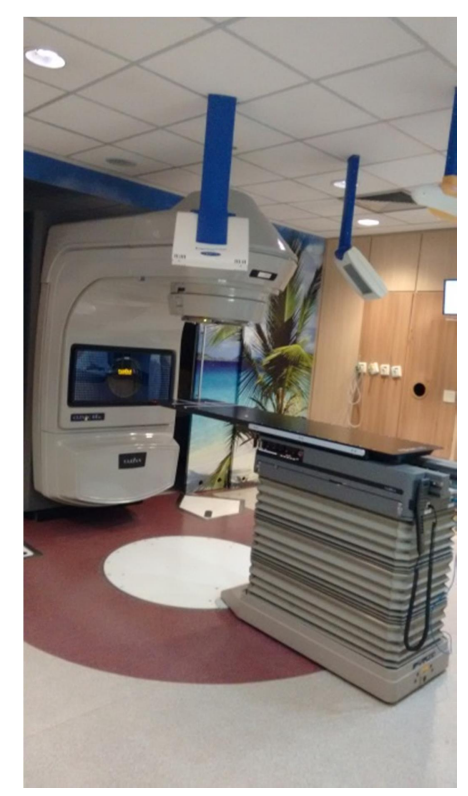

FIGURA 4. Acelerador Linear Varian 6EX

O guia de onda (acelerador) é caracterizado como sendo um tubo de cobre com interior dividido em espaços circulares (ou retangulares), de espaçamento e aberturas variados, os quais estão em vácuo. Estes espaços servem para a união e distribuição das micro-ondas dos espaços adjacentes e para promover um padrão de campo elétrico propício para a aceleração dos elétrons. (Giglioli, 2012)

No cabeçote de um LINAC existem várias estruturas que influenciam a produção, o formato, a localização e a monitoração dos feixes clínicos de fótons e elétrons, sendo exemplos: alvo móvel, filtros aplanadores, colimador primário fixo e colimadores secundários móveis.

O feixe de fótons é gerado por Bremsstrahlung devido à passagem de elétrons pelo alvo e pelo colimador primário, o qual é responsável pela definição do maior tamanho do campo circular disponível.

O colimador primário consiste de uma abertura cônica em um bloco de tungstênio cujos lados de abertura são projetados para as bordas do alvo em uma extremidade do bloco e para o filtro aplanador na outra extremidade.

A intensidade dos raios $\mathrm{X}$ gerados pelos LINACs devido à megavoltagem é maior na região central do que na periferia do feixe, pois o espalhamento dos elétrons segue a mesma direção do feixe de fótons. Para tornar o feixe plano é utilizada a estrutura conhecida como filtro aplanador. 
Um determinado feixe de fótons é gerado em uma combinação própria de alvo e filtro aplanador. Para elétrons com energia inferior a $15 \mathrm{MeV}$, deve ser usado um material com alto número atômico (p. ex. tungstênio) e para elétrons com energia superior aos $15 \mathrm{MeV}$, é utilizado material de menor número atômico. Referente ao material do filtro aplanador, podem ser citados, dentre outros, materiais como o cobre, o aço e o alumínio.

A colimação secundária é feita por meio de quatro blocos de tungstênio, sendo dois localizados na direção $\mathrm{X}$ e superior aos outros dois que se localizam no eixo $\mathrm{Y}$. Os dois superiores recebem o nome de upper jaws e os inferiores de lower jaws. Os colimadores combinados geram campos quadrados ou retangulares que podem ir de $0 \mathrm{~cm}$ x $0 \mathrm{~cm}$ à $40 \mathrm{~cm}$ x $40 \mathrm{~cm}$ (Giglioli, 2012).

\subsection{Radiações Ionizantes e a matéria}

O modo como a radiação interage com o meio é dependente do tipo da radiação. Os mecanismos de interação podem ocorrer por partículas carregadas que atravessam o meio e o ionizam de modo direto e por partículas neutras, as quais ionizam o meio de forma indireta, através da radiação secundária.

Dentre as partículas diretamente ionizantes é possível ainda dividir as radiações em partícula carregadas pesadas (p. ex. partículas alfa) e partículas carregadas leves (p. ex. elétrons). No tocante as partículas neutras podem ser citados fótons e nêutrons. (Leroy, 2010)

Devido ao fato dos elétrons incidentes e os elétrons presentes no meio material possuírem mesma massa, as colisões entre eles podem resultar em grandes perdas de energia e desvios bruscos de trajetória, desta forma, para um grupo de elétrons (com mesma energia inicial), a penetração de cada partícula no meio pode variar.

Outro processo de interação dos elétrons se dá com os núcleos atômicos, o qual pode resultar na emissão de raios X e recebe o nome de Bremsstrahlung. Neste processo, um elétron incidente vai se aproximar do núcleo do átomo que constitui o meio, ao sofrer a atração do núcleo o elétron vai sofrer uma brusca desaceleração, emitindo um fóton de raios $\mathrm{X}$. (Okuno \& Yoshimura, 2010)

Os fótons, por sua vez, geralmente sofrem poucas interações ou simplesmente não interagem. Os principais processos de interação dos fótons em um dado meio são o efeito fotoelétrico, o efeito Compton e a produção de pares. (Dance et. al, 2014)

O efeito fotoelétrico ocorre quando um fóton incidente interage com um elétron (geralmente da camada mais interna) presente no meio material. Caso a energia do fóton seja superior àquela 
com a qual o elétron se encontra ligado, haverá a ejeção do elétron de sua respectiva camada e um desaparecimento do fóton incidente devido à transferência de energia para o elétron.

O elétron ejetado terá energia correspondente à diferença entre a energia do fóton incidente e a energia de ligação do elétron. Uma figura representativa do efeito fotoelétrico pode ser vista na figura 5 .

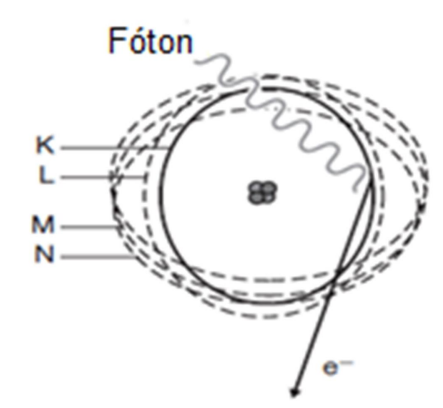

FIGURA 5. Efeito fotoelétrico. [Adaptada de (Symonds et al., 2012)]

No efeito Compton, o fóton incidente vai interagir com um elétron classificado como "livre". Neste processo, o elétron recebe parte da energia do fóton incidente e é emitido com um ângulo $\Phi$, enquanto que o fóton incidente (com energia reduzida) sofrerá espalhamento com ângulo $\theta$. (Dance et. al, 2014). Uma ilustração do efeito Compton pode ser vista na figura 6.

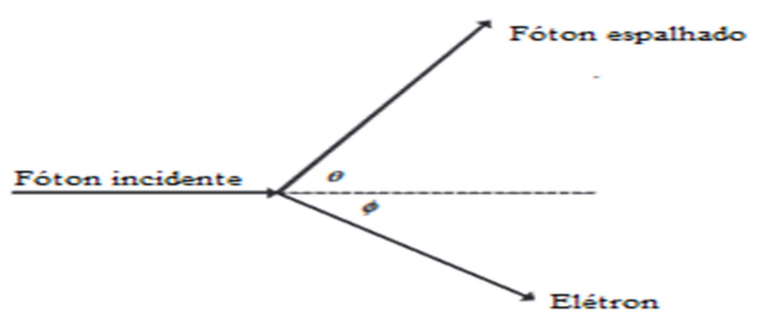

FIGURA 6. Ilustração do Efeito Compton [Adaptada de (Dance et. al, 2014)].

O montante de energia transferido para o elétron do meio pelo fóton incidente será dependente de sua energia. Esta é uma característica relevante para a radioterapia e para a dosimetria das radiações, uma vez que os elétrons secundários gerados por fótons de menor energia (kilovoltagem) depositam sua energia em regiões muito próximas àquelas onde foram gerados. Porém, os elétrons originários da interação de fótons de alta energia (megavoltagem) são capazes de percorrer distâncias consideráveis.

Se o fóton incidente possuir, no mínimo, energia de 1,022 MeV ocorrerá a formação de 
pares. Neste processo, o fóton incidente irá interagir com o núcleo atômico, transferindo totalmente sua energia, produzindo desta maneira um par elétron-pósitron.

Para a água (e tecido mole) sua importância passa a ser considerável para fótons com energia superior a $10 \mathrm{MeV}$, contribuindo desta forma muito pouco para a dose absorvida pelo paciente que é submetido à radioterapia.

A relação existente entre os três principais fenômenos de interação dos fótons com a matéria, o número atômico do meio e a energia do fóton incidente pode ser vista na figura 7 .

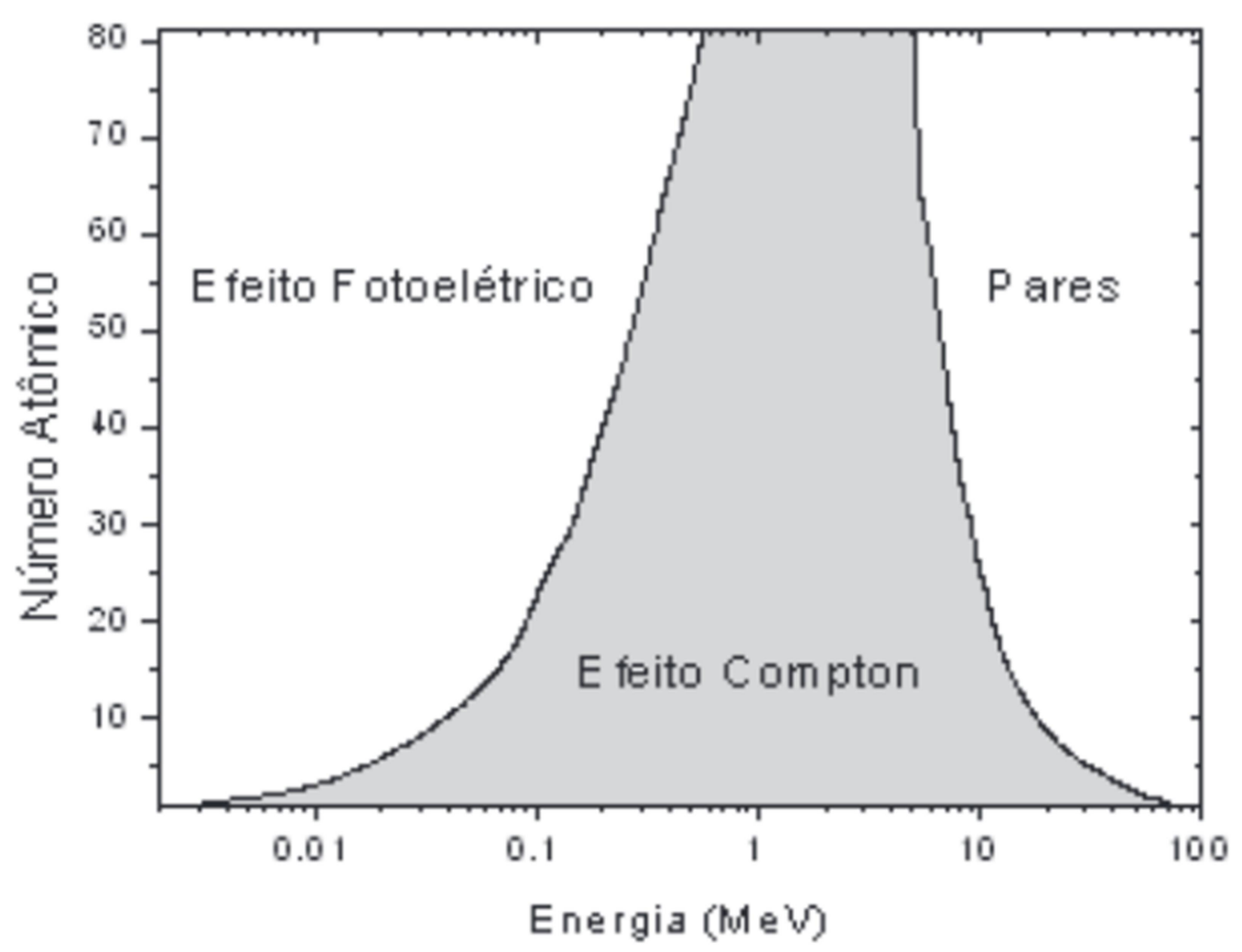

FIGURA 7 Relação entre os processos de interação dos fótons com a matéria, o número atômico do meio e a energia do fóton incidente. [Adaptada de (YOSHIMURA,2009)]

Quando um feixe de fótons atravessa um determinado meio, este sofre atenuação devido aos processos de interação dos fótons com o material do meio. Há em cada processo uma probabilidade de ocorrência, a qual é dada pelo valor da seção de choque. Este valor vai depender da energia do fóton incidente e do número atômico do meio. 
A seção de choque pode ser definida dessa forma, como sendo a probabilidade apresentada por um determinado átomo de provocar em um fóton (com dada energia) um determinado processo de interação. (Pereira, 2011)

A porção dos fótons que são removidos de um feixe monoenergético por unidade de comprimento do material é definida como coeficiente de atenuação linear, cuja unidade é $\mathrm{cm}^{-1}$. O número de fótons que são removidos de um dado feixe que atravessa uma porção muito fina $(\Delta x)$ de um determinado material poderá ser expresso por meio da equação 2.

$$
n=\mu N \Delta x(2)
$$

Onde: $\mathrm{n}$, representa o número de fótons removidos do feixe;

$\mathrm{N}$, representa o número de fótons que incidem no meio;

$\mu$, representa o coeficiente de atenuação linear.

No entanto, não haverá linearidade na remoção de fótons quanto maior for a espessura de um dado material. Sendo assim, deverá ser empregada uma relação exponencial entre o número de fótons incidentes $\left(\mathrm{N}_{0}\right)$ e aqueles que ultrapassam um meio material, de espessura $\mathrm{x}$, sem sofrer interação. (Bushberg et al, 2012). Esta relação pode ser escrita por meio da seguinte equação:

$$
\mathrm{N}=\mathrm{N}_{0} \mathrm{e}-{ }^{\mathrm{ux}}(3)
$$

O coeficiente de atenuação linear total será a o somatório dos coeficientes de atenuação linear para cada tipo de interação, como pode ser visto na equação 4:

$$
\mu=\left(\mu_{\text {efeito fotoelétrico })}+\left(\mu_{\text {Efeito Compton })}+\left(\mu_{\text {Produção de Pares }}\right)\right.\right.
$$

Para uma determinada espessura de um dado material, há a proporcionalidade entre a probabilidade de interação e o número de átomos por unidade de volume. No entanto, pode ser possível solucionar tal dependência por meio da divisão do coeficiente de atenuação linear pela densidade $(\rho)$ do material.

Para a relação $\mu / \rho$ é dado o nome de coeficiente de atenuação mássico, cuja unidade será $\mathrm{cm}^{2} / \mathrm{g}$. Desta forma, a equação 3, deverá ser reescrita da seguinte forma (Bushberg et al, 2012): 


$$
N=N_{0} e^{-\left(\frac{\mu}{\rho}\right) \rho x}
$$

Uma determinada espessura de material que seja capaz de reduzir a intensidade inicial do feixe de fótons para a metade é definida como sendo a camada semirredutora (HVL - Half Value Layer). A HVL se caracteriza por ser a medição indireta da energia do feixe, sob condições de feixe estreito (configuração desenvolvida para evitar a medição dos fótons espalhados pelo detector). É possível relacionar o coeficiente de atenuação linear e a HVL por meio da relação:

$$
\mathrm{HVL}=\frac{\ln (2)}{\mu}(6)
$$

Onde: $\mu$, representa o coeficiente de atenuação linear.

$\mathrm{Na}$ prática, devido à interação de elétrons acelerados com um alvo de alto número atômico, haverá feixes de fótons com um espectro de energias. À medida que o espectro (feixe polienergético) segue atravessando o meio material, haverá (preferencialmente) a remoção daqueles fótons de energia mais baixa, pois estes possuem um alto coeficiente de atenuação, de modo a que eles não atravessem toda a espessura do meio material.

A remoção provoca o aumento da energia média do feixe e a diminuição do coeficiente de atenuação médio. Como resultante dessa mudança no coeficiente de atenuação, a transmissão medida já não terá um comportamento exponencial verdadeiro, pois os valores para as espessuras das HVLs vão ser dependentes do montante já filtrado no feixe incidente. [(Symonds et al., 2012); (Bushberg et al., 2012)]

Os tecidos expostos às radiações ionizantes apresentam mudanças químicas e biológicas e isto se deve à energia que é depositada pela radiação. Duas grandezas são utilizadas no intuito de descrever esta deposição: a dose absorvida e a KERMA.

A KERMA (acrônimo para Kinetic Energy Released per unit of Mass.) é definida como sendo a energia média transferida da radiação indiretamente ionizante para partículas carregadas (elétrons) em um meio por unidade de massa $\mathrm{dm}$. A sua unidade é o $\mathrm{J} / \mathrm{kg}$ e sua fórmula pode ser vista na equação 7 :

$$
K=\frac{d \overline{E_{t r}}}{d m}
$$


A dose absorvida poder ser definida como sendo a energia média transmitida pela radiação ionizante para a matéria de massa m. A energia média $(\bar{E})$ transmitida é caracterizada por ser o somatório de toda a energia que adentra o volume de interesse menos todas as energias que saem deste volume. A unidade de dose absorvida é o $\mathrm{J} / \mathrm{kg}$ e sua equação pode ser vista na equação 8:

$$
D=\frac{d \bar{E}}{d m}(8)
$$

Devido ao fato dos elétrons depositarem energia ao longo de suas trajetórias no meio é dito que essa deposição não ocorre no mesmo local aonde é descrito a KERMA. [(Symonds et al.,2012); (Podgorsak,2005); (Pawlicki, Scanderbeg \& Starkschall, 2016)]

Um feixe de fótons ao se propagar pelo vácuo ou pelo ar é regido pela lei do inverso do quadrado da distância. Porém, a propagação dos fótons no corpo do paciente será regida pela lei do inverso do quadrado da distância, bem como pela atenuação e pelo espalhamento ocorrido no mesmo.

Na superfície de entrada o feixe vai depositar certa dose. Abaixo da superfície ocorrerá um rápido aumento da dose, até que seja alcançado um valor máximo na profundidade de dose máxima $\left(\mathrm{Z}_{\max }\right)$, e então vai ocorrer uma redução (praticamente) exponencial, até que seja alcançado o valor da dose de saída no ponto de saída do corpo do paciente.

As (relativamente) baixas doses na superfície para feixes de fótons de alta energia são de grande importância no que diz respeito ao tratamento de lesões profundas, pois é possível poupar a pele (tanto quanto for possível) concentrando a dose em grandes profundidades.

A região de dose existente entre a superfície e a profundidade onde haverá a dose máxima $\left(\mathrm{z}_{\max }\right)$ é conhecida como região de build-up. A região de build-up compreende a porção do paciente na qual haverá o aumento na deposição da dose em função da profundidade devido ao alcance dos elétrons secundários (liberados pelos fótons).

$\mathrm{O}$ valor de $\mathrm{Z}_{\max }$ é proporcional à energia do feixe, sendo $0,5 \mathrm{~cm}$ para feixes de cobalto-60; 1,5 cm para feixes de $6 \mathrm{MV}$; e $4 \mathrm{~cm}$ para feixes de $22 \mathrm{MV}$ (Podgorsak, 2010). A figura 8 representa a deposição de dose de um feixe de megavoltagem em um paciente. 


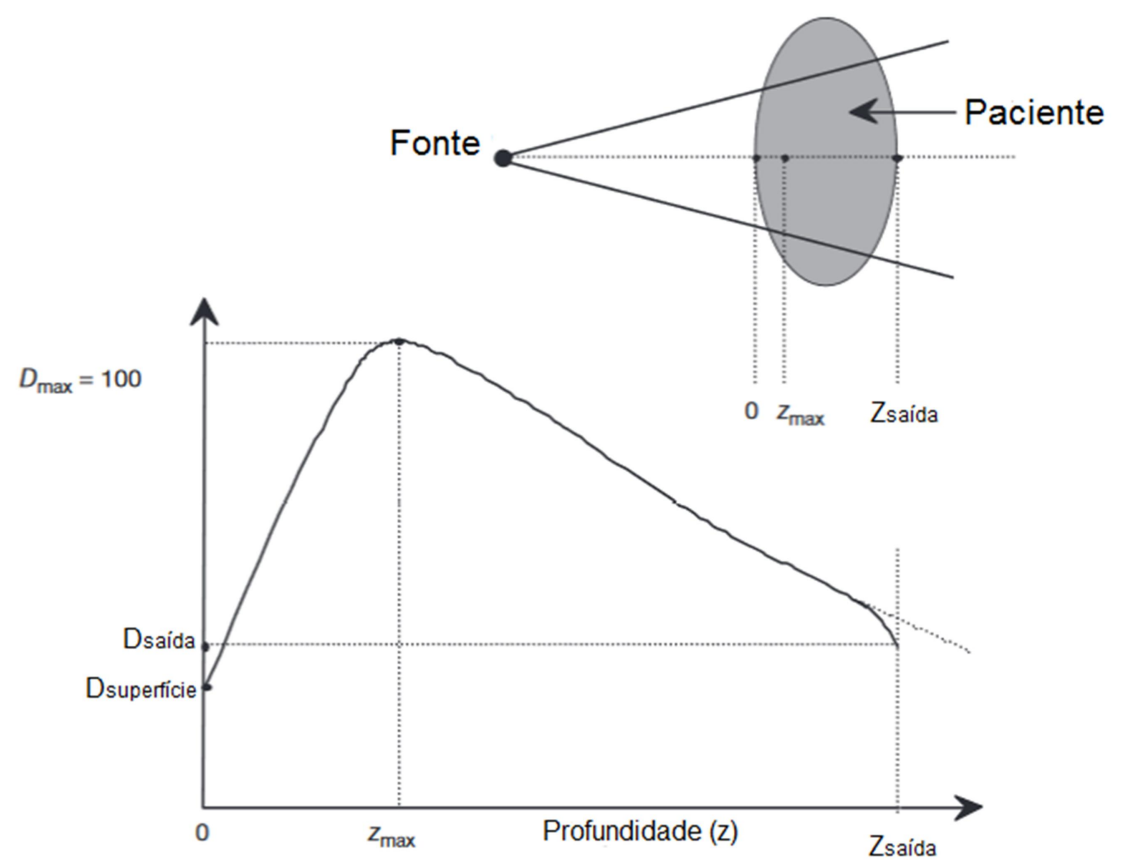

FIGURA 8. Região de build-up da dose [Adaptada de (Podgorsak, 2005)]

Os elétrons (secundários) produzidos pela interação do feixe de fótons (megavoltagem) seguem (principalmente) em direção do avanço do feixe. O primeiro ponto de interação será a superfície, deste modo a dose será entregue na mesma direção na qual o feixe avança. Ignorando suaves alterações na fluência dos fótons com a profundidade, é possível dizer que haverá (na camada de material abaixo da superfície) uma distribuição retilínea similar à da superfície.

Os elétrons formados na superfície se somam com aqueles gerados na camada inferior, e assim o fazem com os elétrons gerados nas demais camadas inferiores. Este efeito somatório eleva a dose de um modo rápido, porém não linear.

Devido ao alcance dos elétrons ser finito, haverá um ponto no qual o efeito somatório dos elétrons é máximo. Neste ponto o número de elétrons produzidos se iguala ao número dos elétrons absorvidos, havendo o chamado equilíbrio eletrônico e a máxima dose é então depositada no meio.

O número de fótons no feixe vai diminuindo, devido à atenuação, de modo que os elétrons secundários produzidos vão diminuindo quão maior for a profundidade. Apesar de simultâneos, o processo de build-up é mais veloz que a atenuação e, dessa maneira, ocorre o aumento da dose (Bogart et al., 2016).

Para feixes de fótons de energia alta, o valor de $z_{\max }$ é alto devido ao maior alcance dos elétrons secundários. Além do valor de $z_{\max }$, a atenuação dos fótons resulta em um equilíbrio 
eletrônico transiente (a energia que entra é levemente maior que a energia que sai) e uma consequente diminuição da dose com a profundidade. (Bogart et al., 2016)

\subsection{Dosimetria das Radiações}

A dosimetria das radiações é a área de estudo que tenta relacionar de forma quantitativa medições físicas feitas em campos de radiação às mudanças físicas, químicas e biológicas que a radiação pode provocar em um alvo, sendo fundamental para a quantificação da chamada relação dose-efeito, que é caracterizada pela incidência de várias mudanças biológicas em função da quantia de dose recebida. (Turner, 2007)

Os dosímetros usados na medição de radiação ionizante são aparelhos ou sistemas que medem, de forma direta ou indireta, as grandezas: exposição, KERMA e dose, ou seus valores por unidade de tempo (taxa de exposição, KERMA ou dose). Associado ao dosímetro, normalmente, existe um equipamento de leitura, o conjunto forma o sistema de medida.

O material a ser empregado como dosímetro de radiação é escolhido a partir de algumas propriedades, entre as quais podem ser citadas [(Scaff, 2010);(Silva, 2010)]:

- Resposta linear com a dose absorvida;

- Resposta independente da taxa de dose;

- Resposta independente da energia da radiação incidente;

- Exatidão e precisão.

\subsection{Dosimetria Termoluminescente}

\subsubsection{Termoluminescência}

É possível definir a termoluminescência (TL) como sendo a propriedade que alguns materiais apresentam de emitir luz visível quando são aquecidos, caso tenham sido irradiados anteriormente. Geralmente, existe proporcionalidade entre a quantidade de luz e a dose absorvida pelo material termoluminescente. (Okuno \& Yoshimura, 2010)

Materiais termoluminescentes são, geralmente, cristais nos quais a banda de valência se encontra repleta de elétrons e a banda de condução vazia, ambas separadas por uma faixa larga de estados energéticos não permitidos aos elétrons, sendo denominada de banda proibida. (Campos, 1998) 
Uma descrição tradicional da TL remonta da absorção da energia oriunda de uma fonte ionizante, por um material isolante ou semicondutor. A absorção provoca a excitação de elétrons e buracos livres e posteriores armadilhamentos dos mesmos nos defeitos do material (estados armadilhados).

A termoluminescência (TL) requer a perturbação de um sistema em equilíbrio termodinâmico para um estado metaestável, por meio da absorção de energia externa, seguida de relaxação termicamente estimulada para que o sistema volte para sua condição de equilíbrio. (Mckeever \& Chen, 1997).

Ao realizar o aquecimento, os elétrons (ou buracos) tendo absorvido energia térmica, escapam das armadilhas, indo os elétrons e os buracos, respectivamente, para a banda de condução e para a banda de valência.

Nos casos em que as armadilhas dos elétrons forem mais rasas, os elétrons escapam de suas armadilhas antes que os buracos. Os elétrons migram então para a banda de condução, e possuem mobilidade livre no cristal até a recombinação com os buracos armadilhados. Podendo nesse caso, eventualmente, ocorrer emissão de luz.

Quando as armadilhas de buracos são mais rasas, estes escapam antes que os elétrons. Os buracos seguem para a camada de valência, e, possuem livre mobilidade no cristal até acontecer a recombinação com os elétrons armadilhados. Nesse caso pode haver emissão de luz.

Outro caso possível, é a liberação simultânea de elétrons e buracos. Em casos como esse a recombinação ocorre em centros de recombinação ou centros de luminescência, quando, então ocorre emissão de luz. (Campos, 1998). A figura 9 ilustra o principio de funcionamento dos dosímetros termoluminescentes.

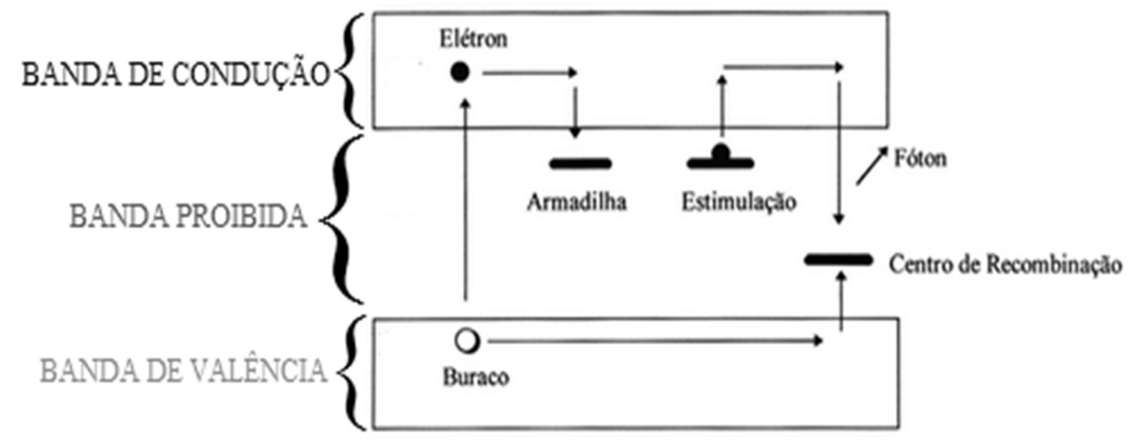

FIGURA 9. Modelo de Bandas da Termoluminescência. [Adaptada de (Campos, 1998)] 


\subsubsection{Dosímetro Termoluminescente}

Existem muitos materiais empregados como dosímetro termoluminescente, os quais se destacam, entre outros, o fluoreto de cálcio (CaF) e o fluoreto de lítio (LiF). (Okuno \& Yoshimura, 2010)

Para ser usado como dosímetro termoluminescente, um material termoluminescente deve apresentar algumas caractarística tais como (Campos, 1998):

- Espectro de emissão termoluminescente (TL) dentro da sensibilidade da fotomultiplicadora afim de que não haja interferência da emissão incandescente, infravermelha, do próprio equipamento. Recomenda-se um espectro com comprimentos de onda de 300 à $500 \mathrm{~nm}$;

- Uma curva de emissão simples, preferencialmente com um único pico, de modo a facilitar a operação e interpretação da leitura;

- $\quad$ Fácil tratamento térmico para reutilização;

- Apresentar resistência a diversos fatores ambientais tais como luz, umidade, solventes orgânicos, poluição e gases;

- $\quad$ Ter baixo custo e ser de fácil obtenção;

- Apresentar uma resposta linear para um amplo intervalo de dose absorvida.

A curva de emissão é obtida através do registro da intensidade luminosa e da temperatura. A formação de um pico de emissão TL se relaciona com a probabilidade de escape do elétron, ou buraco, da armadilha correspondente. Com o aquecimento do cristal, é aumentada a probabilidade de escape, causando um aumento da emissão, que é máxima na temperatura de pico.

Devido à redução de portadores de cargas nas armadilhas há o decrescimo da intensidade. Quando há mais de um pico na curva, existe mais de um tipo de armadilha. (Campos, 1998). Na figura 10 tem-se uma curva típica de emissão do LiF (TLD-700). 


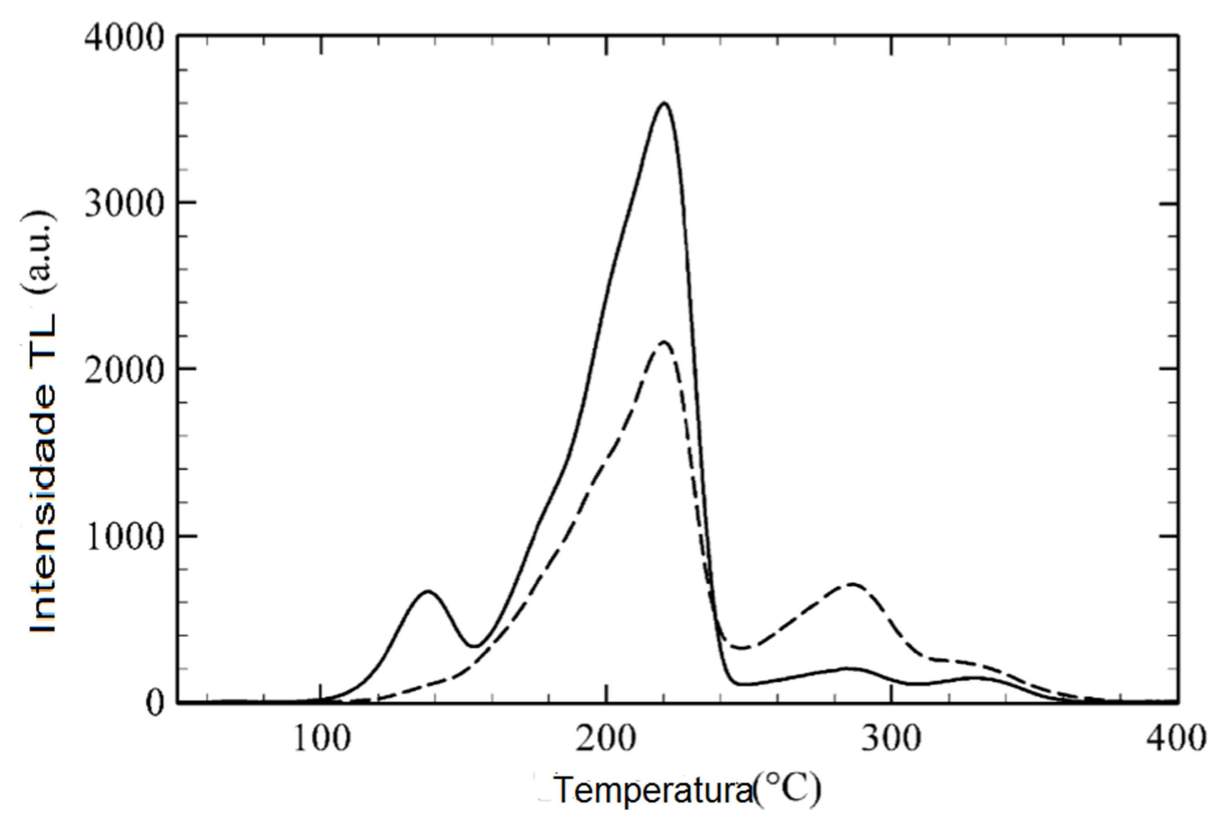

FIGURA 10. Curva de emissão de um TLD-700 após irradiação com 50 mGy de ${ }^{60} \mathrm{Co}$ (linha sólida) e $50 \mathrm{mGy} \mathrm{de}{ }^{20} \mathrm{Ne}$ em $31.6 \mathrm{keV} / \mu \mathrm{m}$. [Adaptada de (Berger \& Hajek, 2007)]

O equipamento de medida da termoluminescência é caracterizado como sendo um dispositivo para aquecimento do dosímetro e uma fotomultiplicadora para captar a luz emitida. Geralmente, utilizam-se dois métodos de aquecimento para um dosímetro TL.

O primeiro consiste em colocar o material sobre uma prancheta metálica e realizar o aquecimento através da passagem de corrente elétrica. No segundo método, o aumento da temperatura é feito por meio de um fluxo de gás inerte aquecido. (Campos, 1998). A figura 11 mostra o esquema de um sistema leitor TL. 


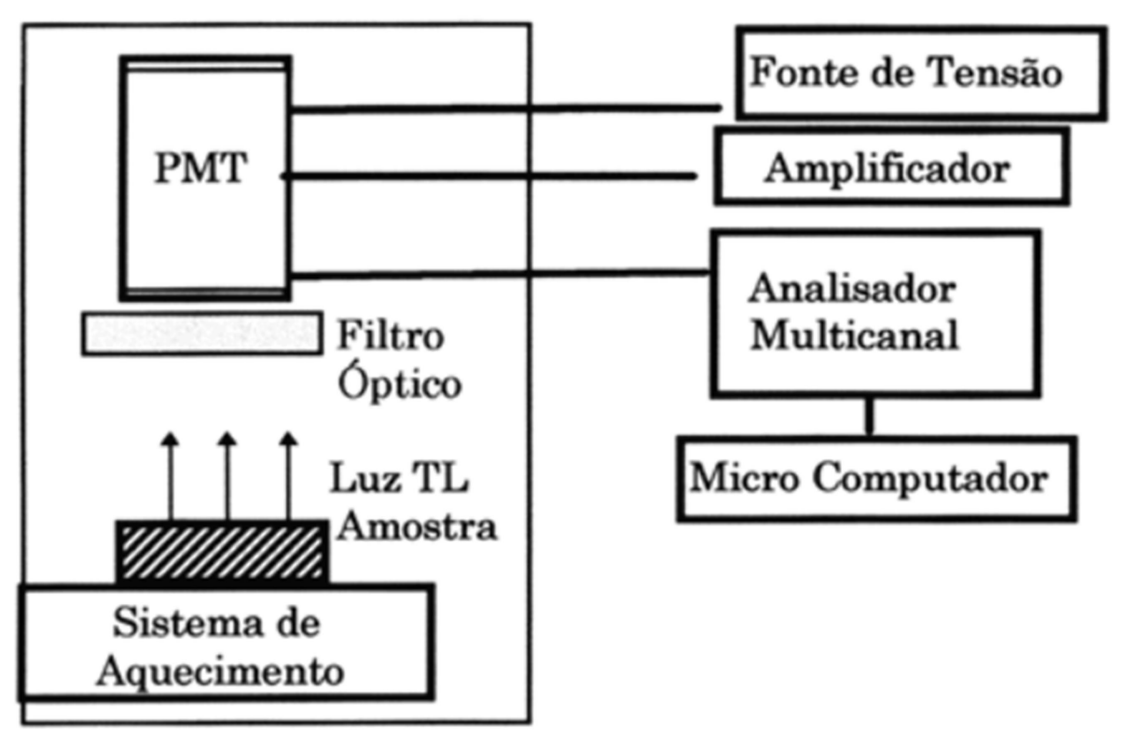

FIGURA 11. Ilustração de um sistema de leitura TL. [Adaptada de (Campos, 1998)]

Anteriormente ao uso de um material TL para fins dosimétricos se faz necessário sua preparação. A preparação significa zerar o material de qualquer informação oriunda de qualquer irradiação prévia e sua finalidade é restaurar as condições iniciais do cristal (condições anteriores a eles serem irradiados).

Para tanto, é necessário realizar um tratamento térmico chamado de annealing, o qual é realizado em um forno e consiste no aquecimento do material TL até um temperatura prédeterminada, mantendo-o nessa temperatura por um determinado período de tempo para então realizar seu resfriamento a temperatura ambiente.

O processo de tratamento térmico pode ser dividio em 3 classes: tratamento de inicialização; tratamento padrão; e o tratamento pré-leitura. Respectivamente, é possível definir essas classes como (Furetta, 2003):

1. O tratamento realizado para amostras TL "virgens", cuja finalidade seja estabilizar os níveis de armadilha (trap levels) de modo a tornar reprodutíveis o background e a sensibilidade;

2. Tratamento utilizado para zerar quaisquer resíduo da irradiação prévia. Seu objetivo principal é fazer voltar as armadilhas as formas que se encontravam após o procedimento de inicialização;

3. Procedimento cuja finalidade é limpar (zerar) os picos de baixa temperatura, caso eles sejam encontrados nas curvas de emissão, de modo a evitar erros na medida da dose. 


\subsubsection{Fluoreto de lítio dopado com magnésio e titânio (LiF:Mg,Ti)}

O Fluoreto de Lítio dopado com magnésio ( $\mathrm{LiF}: \mathrm{Mg}, \mathrm{Ti})$ é o material mais utilizado como dosímetro TL, tal fato se deve à esse material apresentar caracteristicas como: baixo número atômico efetivo; falta de sensibilidade à luz; resistência química e mecânica; facilidade de produção em diferentes versões (TLD-100, TLD-600 E TLD-700 - os quais têm diferentes concentrações de ${ }^{6} \mathrm{Li} \mathrm{e}{ }^{7} \mathrm{Li}$ ) e a disponibilidade em tipos variados (pastilhas, pó e etc.). [(Batista, 2011)]

O TLD-100 apresenta uma concentração de 7,5\% de ${ }^{6} \mathrm{Li}$, enquanto que o TLD-600 é enriquecido com ${ }^{6} \mathrm{Li} \quad(95,6 \%)$ e $\quad$ o $\quad$ TLD-700 é enriquecido com ${ }^{7} \mathrm{Li} \quad(99,93 \%)$. [(Cavalieri, Castro \& Siqueira, 2012)]

O LiF:Mg,Ti foi desenvolvido em colaboração com Cameron pela Harshaw Chemical Company, Inc., USA, a qual o comercializa como TLD-100 e suas variantes isotópicas TLD-600 e TLD-700 em forma de pó, bastões, discos e pastilhas cujas dimensões vão de $(3,15 \times 3,15 \times 0,14) \mathrm{mm}^{3}$ a $(3,15 \times 3,15 \times 0,9) \mathrm{mm}^{3}$, com peso entre 0,3 e $5 \mathrm{mg}$.

A curva de emissão do LiF:Mg,Ti consiste de vários picos de intensidade luminosa, sendo que o pico dosimétrico aparece aproximadamente à $200{ }^{\circ} \mathrm{C}$, apresentando limite mínimo de detecção de aproximadamente $500 \mu \mathrm{Gy}$ e sua resposta apresenta linearidade até doses da ordem de 1 Gy e a saturação do sinal ocorre em uma dose de aproximadamente $10^{3} \mathrm{~Gy}$.

O TLD-100 apresenta pequena dependência energética e pode alcançar uma precisão de 5\% ou menos em suas aplicações. [(Nunes, 2008); (Horowitz \& Moscovitch, 2012)]

\subsubsection{Sulfato de Cálcio dopado com disprósio $\left(\mathrm{CaSO}_{4}: \mathrm{Dy}\right)$}

O Sulfato de Cálcio dopado com disprósio $\left(\mathrm{CaSO}_{4}\right.$ :Dy) é um dosímetro termoluminescente cujo desenvolvimento e produção é vinculado ao Laboratório de Materiais Dosimétricos do IPEN (LMD/IPEN).

Esse dosímetro termoluminescente (TLD) é comercializado na forma de pó e pastilhas de $6 \mathrm{~mm}$ de diâmetro com $0,2 \mathrm{~mm}$ e $0,8 \mathrm{~mm}$ de espessura, com massas (respectivamente) de 10 e $50 \mathrm{mg}$.

O limite inferior de detecção é $1 \mu$ Gy sendo linear até doses de 30 Gy, a saturação ocorre em doses de $1 \mathrm{kGy}$ e apresenta forte dependência energética com energias abaixo de $200 \mathrm{keV}$. [(Campos \& Lima, 1986);(Matsushima, 2010);(Oberhoffer \& Scharman, 1979] 


\subsection{Objetos simuladores}

Um objeto simulador tem como propósito representar a alteração do campo de radiação provocada pela absorção e espalhamento em um dado tecido ou órgão de interesse. Suas características geométricas e de composição devem estar próximos o máximo possível aos valores associados ao seu análogo natural. Os objetos simuladores podem ser classificados de acordo com sua função principal: dosimétricos; de calibração; e para imageamento. (ICRU, 1992)

Os objetos simuladores classificados como dosimétricos são aqueles que são usados para medir a dose absorvida em uma dada geometria. A dose absorvida pode ser medida em profundidade; ou em ponto externo ao objeto simulador.

Os objetos simuladores de calibração são aqueles utilizados para estabelecer a resposta dos detectores de radiação, por sua vez os objetos simuladores classificados como "para imageamento" são utilizados na avaliação da qualidade de imagens. (ICRU, 1992)

Estes objetos podem simular diferentes órgãos, tecidos e estruturas, podendo ser aplicados para elétrons, fótons, partículas pesadas carregadas e nêutrons. (ICRU, 1992). Há uma grande dependência entre as propriedades radiológicas de um material e a energia do feixe de radiação ao qual ele é sujeito.

Alguns materiais podem simular corretamente um tecido em um espectro energético e apresentar diferenças significativas em outro espectro. É comum separar os objetos simuladores em conjuntos que consideram sua utilização, podendo citar diagnóstico (kilovoltagem) e terapia (megavoltagem). [(DeWerd \& Kissick, 2014)]

\subsubsection{Objetos simuladores na radioterapia}

Os objetos simuladores são empregados quando se faz necessário mensurar a dose em ponto(s) de interesse, pois expor um ser humano real é perigoso e logicamente impraticável, assim como a inserção de dosímetros em estruturas orgânicas não é uma opção viável.

Nos primórdios, os objetos simuladores consistiam de placas de cera ou tanques de água, apesar de possuírem aspecto pouco sofisticado ainda continuam sendo empregados na dosimetria. Os simuladores de cera caíram em desuso, no entanto, alguns simuladores formados por compostos de epóxi (p. ex. Solid Water ${ }^{\circledR}$ ) permanecem em uso. (DeWerd \& Kissick, 2014)

O uso destes objetos simuladores tem se mostrado simples e reprodutível. Sua posição no feixe pode ser facilmente repetida, sendo possível realizar medições (sob as mesmas condições) em instituições distintas. Os simuladores do tipo tanque de água permitem uma vasta gama de posições 
para colocação de dosímetros, sendo possível fazer o escaneamento do feixe por meio de câmara de ionização.

A necessidade de objetos simuladores cada vez mais representativos do formato do corpo humano leva ao desenvolvimento dos objetos simuladores conhecidos como antropomórficos. Esses simuladores permitem um melhor estudo da distribuição da dose dentro do corpo humano.

Qualquer objeto simulador dosimétrico deve possuir, ao menos, local para posicionar um dosímetro de modo a medir a dose dentro do simulador, sendo possível citar como dosímetros aplicáveis: as câmaras de ionização, os dosímetros termoluminescentes e os dosímetros de filmes. (DeWerd \& Kissick, 2014)

O emprego eficiente de feixes de radiação de alta energia para fins terapêuticos é ligado fortemente à distribuição espacial da dose dentro do paciente, pois a deposição energética ocorre na natureza, de modo tridimensional, uma vez que as partículas não só interagem localmente, mas também podem interagir em tecidos circunvizinhos de modo a depositar energia no entorno do tecido alvo.

É necessário conhecer a distribuição da dose, possibilitando assim manter os níveis de dose dentro do tolerado pelos tecidos circunvizinhos ao campo tratado. O uso de objetos simuladores para fins terapêuticos possui duas principais funções: caracterizar e calibrar o feixe de radiação empregado na terapia; e validar a modelagem numérica da dose bem como do design do tratamento elaborados pelo sistema de planejamento.

Para que um objeto simulador seja empregado na medição da dose ele deve apresentar algumas características básicas referentes ao material e à geometria. No tocante aos materiais, pode ser dito que devem apresentar similaridade com o tecido de modo que as medições possam ser mapeadas como a dose no tecido, ter composição que possa ser bem caracterizada e de pronta disponibilidade, ser de fácil rastreabilidade para padrões de referência, ser resistente aos danos da radiação e possuir uma resposta reprodutível e bem-conhecida ao tipo de radiação e energia.

Com relação à geometria, os objetos simuladores devem: acomodar os tamanhos e formas dos campos de radiação ao que forem expostos; possibilitar demarcações 3D; possuir praticidade no transporte; e ser de fácil alinhamento e configuração de um modo preciso e eficiente. (DeWerd \& Kissick, 2014)

Dependendo da localização do detector no objeto simulador, este pode ser classificado como ativo ou passivo. Um objeto simulador é considerado ativo quando o detector é localizado dentro do seu corpo (p. ex. uma câmara de ionização dentro de um tanque de água). 
Por sua vez, um objeto simulador passivo pode ser entendido como sendo um objeto que é colocado em um feixe e o detector é colocado externamente ao mesmo, pode ser citado como exemplo os objetos utilizados na calibração de equipamentos eletrônicos de imageamento portal (EPID - Eletronic Portal Imaging Devices).

Outra classificação leva em conta a integração entre o material do objeto simulador e o detector, podendo ser: modular ou integrado. Um objeto simulador modular possibilita ao usuário uma maior flexibilidade de escolha de locais e geometrias de medição, pois os simuladores modulares (p. ex. câmara de ionização em tanques de água) permitem a colocação do detector em diversas localidades pelo meio material.

No tocante aos objetos simuladores integrados pode ser dito que nestes simuladores os detectores (p. ex. diodo planar) estão afixados firmemente dentro do meio material em posições bem-definidas e, com frequência, está contido também todo equipamento eletrônico ligado ao detector. (DeWerd \& Kissick, 2014)

\subsection{O Código Monte Carlo}

O código MCNP (Monte Carlo N-Particle) é um código baseado no método de Monte Carlo, que pode ser utilizado para o transporte de fótons, nêutrons e elétrons, bem como para o transporte acoplado de nêutrons/fótons/elétrons. Para elétrons, o intervalo energético permitido é de $1 \mathrm{keV}$ à $1 \mathrm{GeV}$, para os fótons esse intervalo é de $1 \mathrm{KeV}$ à $100 \mathrm{GeV}$. (X-5 Monte Carlo Team,2003)

É possível descrever o método de Monte Carlo com sendo um método estatístico que emprega uma sequencia de números aleatórios para a realização de uma simulação. No âmbito de transporte de radiação, o processo estocástico é visto como sendo uma família de partículas cujas coordenadas individuais mudam de modo aleatório em cada colisão.

O conjunto de eventos ocorridos com uma dada partícula desde o seu nascimento, ou seja, momento em que ocorre a emissão da mesma da fonte, até o momento em que ela "morre", momento em que a partícula é absorvida ou escapa do sistema, é denominado história da partícula.

Cálculos com Monte Carlo são iniciados a partir de um modelo que representa o sistema real de interesse. O usuário poder criar um arquivo de entrada (input), o qual será lido pelo MCNP. Nesse arquivo de entrada estão contidas informações do problema em estudo, tais como: as especificações geométricas; a localização e características da fonte (nêutron, elétron ou fóton); as composições dos materiais envolvidos e o tipo de resposta (tally) desejado. [(YORIAZ, 2009); (X-5 Monte Carlo Team, 2003)] 
Um arquivo de entrada consiste de 3 blocos (cards) os quais correspondem as células (cell card), superfícies (surface card) e os dados (data card). A geometria de cada célula que compõe o problema é descrita no bloco de células por meio de operadores e sinais nas superfícies que delimitam a célula.

Na primeira coluna do bloco de células vai estar o número que representará uma célula (escolhido pelo usuário); na segunda coluna vai estar o número do material (especificado no bloco de dados) que compõe a célula; a terceira coluna vai conter a densidade do respectivo material, em seguida vão ser designadas as especificações geométricas da célula e o designador de partícula que vai especificar a importância de uma dada partícula na célula.

De modo similar ao bloco das células, a primeira coluna do bloco de superfície vai ser preenchida pelo número representante de uma dada superfície (escolhido pelo usuário) ; em seguida vai ser colocado o respectivo mnemônico da superfície (p. ex. um plano que corta o eixo X vai ser representado por “px”); após o mnemônico da superfície vão ser colocados os coeficientes numéricos da equação da superfície na ordem apropriada. (Pelowitz, 2011)

O bloco de dados vai conter especificações da fonte, composição dos materiais, a informação desejada para a simulação (Tally), o modo que o MCNP vai operar (p.ex MODE P significa apenas transporte de fótons) e os parâmetros que terminam a execução do MCNP (cutoffs) (X-5 Monte Carlo Team, 2008).

Outra forma de declarar células e superfícies em um arquivo de entrada do MCNP é por meio das Estruturas Repetidas (Repeated Structure Cards). O objetivo principal dessa funcionalidade é permitir a descrição, apenas uma única vez, de células e superfícies que apareçam mais de uma vez na geometria.

Com a funcionalidade das estruturas repetidas é reduzido o montante de dados que seria implementado no arquivo de entrada e também a memória do computador, necessários em cenários onde existem diversas reduções geométricas. Um exemplo de aplicação dessa funcionalidade é um núcleo de reator no qual existem dezenas de módulos idênticos de combustível. (X-5 Monte Carlo Team, 2008)

Para especificar o que se deseja calcular empregando o código MCNP é utilizado o "cartão de cálculo" (Tally Card). Dentre outras é possível citar: corrente através de uma superfície, fluxo em um ponto e aquecimento em uma região. Os tallies são especificados por números, ou incrementos de 10 . 
Cada Tally utiliza um designador de partícula. Por exemplo, a entrada "F4:n" vai especificar fluxo de nêutrons em uma dada célula, sendo sua unidade: $\frac{\text { partículas }}{\mathrm{cm} 2}$. (Pelowitz, 2011)

\subsection{Impressão 3D}

A impressão 3D, também conhecida por manufatura aditiva ou prototipagem rápida, se refere à construção de objetos tridimensionais, empregando plástico ou outros materiais, a partir de um modelo digital. (Evans, 2012)

Essa técnica é caracterizada pela flexibilidade e pela capacidade de construir geometrias complexas. Atualmente existem diversas formas de emprego da técnica de manufatura aditiva, dentre as quais se destacam: a modelagem por fusão e deposição (FDM - Fused Deposition Modeling), que emprega fios de polímero como matéria-prima; a Estereolitografia (SLA Stereolithography Aparatus), que realiza a cura de resinas liquidas por meio de luz ultravioleta e a Sinterização Seletiva por Laser (SLS - Selective Laser Sintering), a qual gera objetos 3D utilizando plásticos, cerâmicas e metais em estado granulado. (Marques, 2014)

\subsubsection{Modelagem por fusão e deposição}

Essa técnica é baseada na deposição de material, geralmente termoplástico, por meio de um cabeçote de extrusão. Considerando o plano cartesiano tridimensional e seus eixos XYZ, o cabeçote é movimentado, ao longo de X e de $\mathrm{Y}$, para construir uma camada por meio da adição de filamentos de material.

Depois de terminada uma camada, haverá a elevação da plataforma no sentido do eixo Z, fazendo com que uma nova camada seja construída. Esse processo é repetido até o fim da confecção da peça desejada. (Cunico, 2013)

O processo de fabricação de objetos 3D por FDM pode ser dividido em três fases: préprocessamento, produção e pós-processamento. A etapa de pré-processamento consiste da importação do modelo virtual e da seleção dos parâmetros de cada camada. O software da impressora 3D irá gerar os parâmetros de design de cada camada (variando de 0,127 mm a 0,3302 $\mathrm{mm})$, de modo que a figura desejada seja confeccionada.

A produção pode ser entendida como a confecção do objeto propriamente dito. Nessa etapa, dois materiais são utilizados (um de composição e outro de suporte); há o aquecimento de maneira a derreter os plásticos. 
Esses materiais vão ser "extrudados" em finas faixas (aproximadamente da espessura de um fio de cabelo), sempre fazendo alternância entre o material de composição e o de suporte. A última etapa (pós-processamento) consistirá da separação do objeto da impressora, arrancando ou lavando o mesmo do suporte ao qual está ligado. (Hiemenz, [s.d.])

\subsection{2 Ácido Polilático}

O ácido polilático [PLA - Poly(lactic acid)] advém dos poliésteres, é caracterizado pela alta resistência, pela possibilidade de ser obtido de fontes renováveis e pela biodegradabilidade, possibilitando sua aplicação desde o ramo industrial (produção de embalagens) até aplicações médicas em materiais biocompatíveis, além de ser processado em equipamentos de plástico padrão para a produção de peças moldadas, filmes ou fibras. (Garlotta, 2001). A estrutura química do PLA pode ser vista na figura 12.

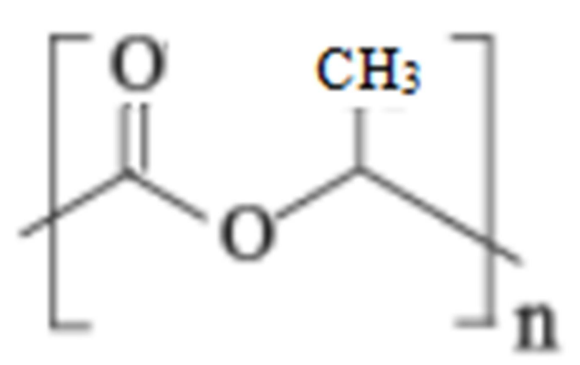

FIGURA 12. Estrutura química do PLA. [Adaptada de (Franchetti \& Marconato, 2006)]

\subsubsection{Acrilonitrila Butadieno Estireno (ABS)}

O ABS é sintetizado a partir de três compostos químicos: acrilonitrila, butadieno e estireno. Seus três componentes atômicos básicos são o carbono, o nitrogênio e o hidrogênio, sendo o carbono a espécie atômica predominante e a acrilonitrila a única fonte de nitrogênio. (Rutkowski \& Levin, 1986)

Podem ser citadas, dentre outras, algumas propriedades dos compostos de ABS, tais como alta rigidez e resistência química. A resistência química tem relação direta com a quantidade de acrilonitrila presente no composto, sendo possível dizer que se trata de uma relação diretamente proporcional. 
Os compostos de ABS são, geralmente, resistentes a outros compostos tais como a agua e soluções salina, sendo atacados por compostos como a acetona. (Landi, 2003) A estrutura química do ABS pode ser vista na figura 13.

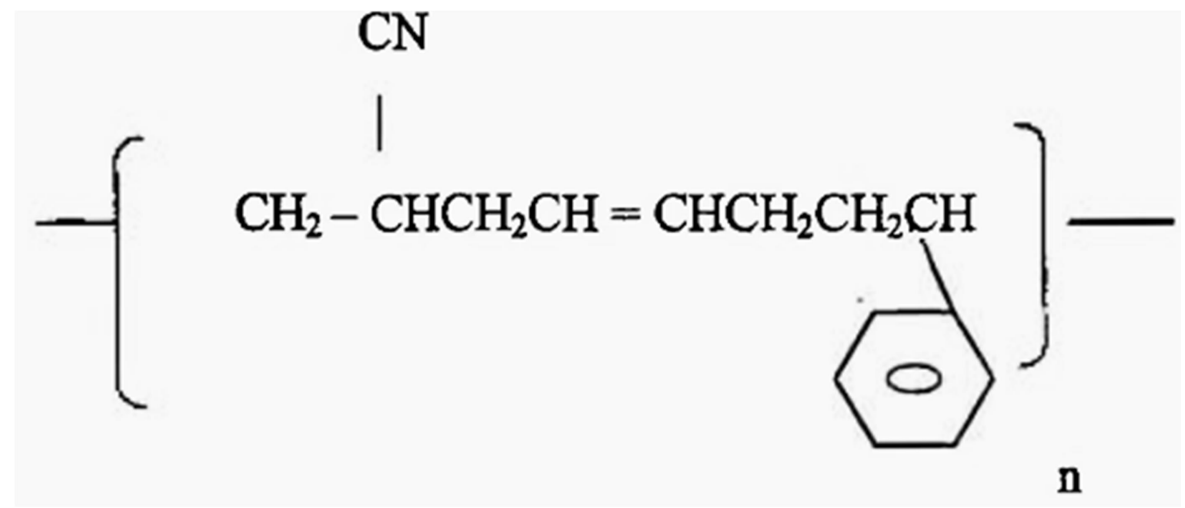

FIGURA 13. Estrutura química do ABS. [Adaptada de (Landi, 2003)]

\subsection{Cálculo das incertezas}

A incerteza de uma dada medição pode ser entendida como um parâmetro que caracteriza a dispersão dos valores que podem ser atribuídos a um mensurando. A incerteza pode ser estimada por métodos estatísticos, para essa categoria de incerteza é dado o nome de incerteza de tipo A. A avaliação da incerteza de tipo A é feita, empregando: o valor médio; desvio padrão da medida; e desvio padrão da média. (Maia et. al, 2016)

Quando medições repetidas de um mesmo mensurando são realizadas, uma estimativa do valor real deste mensurando é dada pelo valor médio das medidas, o qual pode ser calculado por meio da seguinte equação:

$$
\bar{x}=\frac{\sum_{i=1}^{n} x_{i}}{n}(9)
$$

Onde: $\bar{x}$, representa o valor médio das medidas;

$x_{i}$, representa o valor a i-ésima medida;

$\mathrm{n}$, representa o número total de medidas.

A quantificação do grau da dispersão das medidas em relação ao valor médio é feita através do desvio padrão da medida, o qual pode ser calculado através da seguinte equação:

$$
\sigma=\sqrt{\frac{\sum_{i=1}^{n}\left(x_{i}-\bar{x}\right)^{2}}{n-1}}(10)
$$


Onde: $\sigma$, representa o desvio padrão da medida;

$\bar{x}$, representa o valor médio das medidas;

$x_{i}$, representa o valor a i-ésima medida;

$\mathrm{n}$, representa o número total de medidas.

O desvio padrão da média vai estimar a incerteza de tipo A associada a um dado valor médio. Para calcular o desvio padrão da média é utilizada a seguinte equação:

$$
\sigma_{A}=\frac{\sigma}{\sqrt{n}}(11)
$$

Onde: $\sigma_{A}$, representa a incerteza de tipo A associada a um valor médio;

$\sigma$, representa o desvio padrão da medida. 


\section{MATERIAIS E MÉTODOS}

\subsection{Materiais}

Para a realização desse trabalho foram utilizados:

- Filamentos para impressora 3D de PLA e ABS, distribuído pela UP3D (Grupo BCS Tecnologia);

- Objeto simulador de Água Sólida RMI-457, pertencente ao Hospital Israelita Albert Einstein;

- Placa de polimetilmetacrilato (PMMA) com $3 \mathrm{~mm}$ de espessura;

- 30 dosímetros termoluminescentes de LiF:Mg,Ti;

- 30 dosímetros termoluminescentes de $\mathrm{CaSO}_{4}$ :Dy.

\subsection{Equipamentos}

Os equipamentos empregados nesse trabalho foram:

- Forno tipo mufla da Vulcan ${ }^{\circledR}$, modelo 3-550PD;

- Estufa Retilínea da FANEM LTDA., modelo 315/1;

- Leitor Harshaw TLD ${ }^{\mathrm{TM}}$ Modelo 4500;

- Balança de precisão (Instrumentos Científicos C.G. Ltda);

- Microscópio de bancada Hitachi TM3000, pertencente ao Centro de Ciência e Tecnologia de Materiais (CCTM) do IPEN;

- Impressora 3D modelo UP Plus 2;

- Aparelho de tomografia computadorizada GE Medical System LightSpeed RT16 Series, pertencente ao Hospital Israelita Albert Einstein.

\subsection{Sistemas de irradiação}

Foram utilizados os seguinte sistemas de irradiação: 
- Sistema de Raios X Pantak/Seifert, pertencente ao Laboratório de Calibração de Instrumentos (LCI/GMR/IPEN);

- Irradiador panorâmico de ${ }^{137}$ Cs marca Hopewell (atividade de 38,11 GBq em 17/11/2014), pertencente ao Laboratório de Calibração de Instrumentos (LCI/GMR/IPEN);

- Fonte de radiação gama do ${ }^{60} \mathrm{Co}$ (atividade de 0,339 TBq em setembro de 1999), pertencente ao Laboratório de Calibração de Instrumentos (LCI/GMR/IPEN);

- Acelerador Linear Clínico Varian Modelo 6EX, pertencente ao Hospital Israelita Albert Einstein.

\subsection{Softwares}

Os seguintes softwares foram utilizados:

- Sistema de planejamento de tratamento Eclipse ${ }^{\mathrm{TM}}$, pertencente ao Hospital Israelita Albert Einstein (empregando os algoritmos de calculo de dose AAA e Acuros XB);

- Modelador paramétrico 3D FreeCAD;

- Image J - Image Processing and Analysis in Java;

- Wolfram Mathematica 9 Student Edition;

- General Monte Carlo N-Particle (MCNP) Transport Code, versão 5;

- IPEM-78 Catalogue of Diagnostic X-Ray Spectra and other data;

- OriginPro 8.

\subsection{Métodos}

\subsubsection{Impressão 3D}

O processo de impressão dos materiais que foram utilizados em todas as fases desse trabalho foi realizado durante quase toda extensão do mesmo, pois sempre que necessário era realizada a impressão de uma peça com parâmetros específicos. Devido às limitações técnicas da mesa de impressão da impressora 3D (14 cm x $14 \mathrm{~cm}$ x $13.5 \mathrm{~cm})$ [(3D Printing Systems)] as peças impressas não ultrapassaram as dimensões de lado igual a $10 \mathrm{~cm}$. Na figura 14 é mostrada a impressora 3D empregada nesse trabalho. 


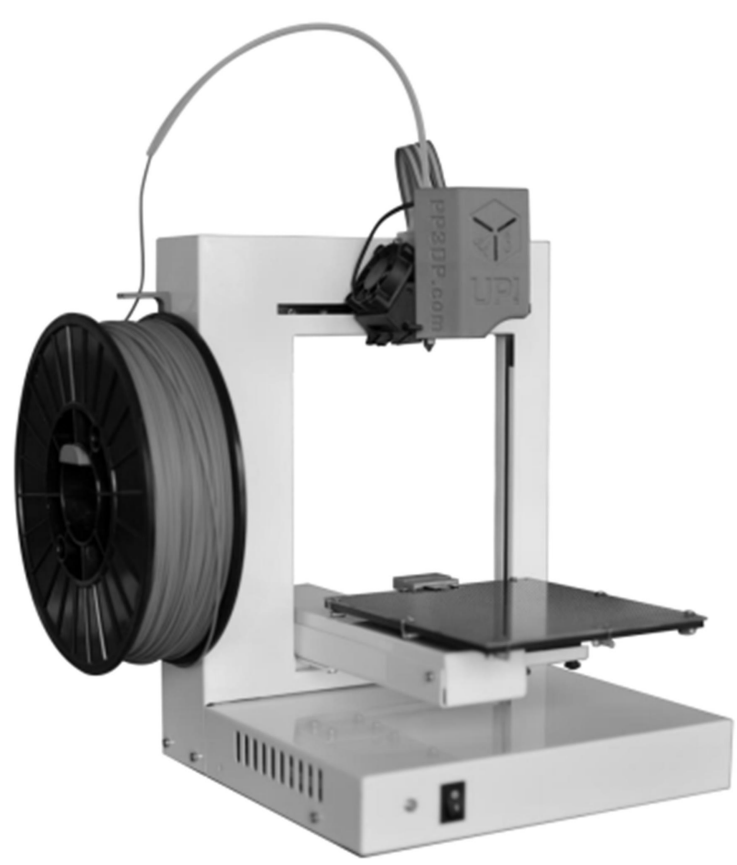

FIGURA 14. Impressora 3D UP Modelo Plus 2 (UPP2). [Adaptada de (UP! 3D Brasil)]

O usuário deve preparar a UPP2 para executar a impressão com o material que deseja utilizar (no presente trabalho foi empregado o PLA e o ABS), para tanto, deve ser selecionado o material no software de utilização da mesma. Na figura 15 é mostrada uma imagem do painel de seleção do software da impressora 3D.

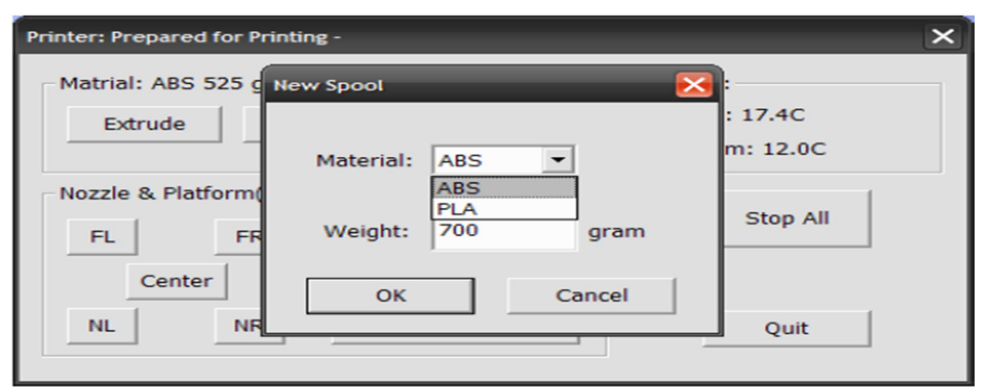

FIGURA 15. Visão do software de utilização da impressora - Escolha do material de impressão. [Adaptada de (3D Printing Systems)]

Essa escolha se faz necessária, pois o PLA e o ABS apresentam características de aquecimento diferenciadas, as quais são apresentadas na tabela 1. 
TABELA 1. Temperatura de Impressão. [Adaptada de (3D Printing Systems)]

\begin{tabular}{cc}
\hline MATERIAL & TEMPERATURA \\
\hline PLA & Bico de Extrusão: $200{ }^{\circ} \mathrm{C}$ \\
& Mesa de impressão: $50{ }^{\circ} \mathrm{C}$ \\
ABS & Bico de Extrusão: 260 à $270{ }^{\circ} \mathrm{C}$ \\
& Mesa de impressão: $100{ }^{\circ} \mathrm{C}$ \\
\hline
\end{tabular}

Após a seleção do material do filamento que será empregado, é necessário realizar a fusão do mesmo. O rolo com o filamento deve ser inserido no suporte (localizado na impressora 3D) e o comando Extrude deve ser acionado. É necessário repetir esse procedimento toda vez que for desejado trocar o material que será utilizado na impressão.

Feita a escolha do material da impressora, deve ser carregado o modelo 3D no software da UPP2. A impressora suporta arquivos em formato .STL que podem ser criados por qualquer software de modelagem 3D capaz de salvar arquivos nesse formato.

\subsubsection{Seleção e calibração dos dosímetros}

Nessa fase do trabalho foi realizada a seleção dos dosímetros de LiF:Mg,Ti (TLD-100) e $\mathrm{CaSO}_{4}$ :Dy a serem utilizados. Para a seleção dos dosímetros de LiF:Mg,Ti foi utilizado o sistema de raios X Pantak/Seifert com a qualidade de raios X T-50b, cujas características podem ser vistas na tabela 2.

TABELA 2. Qualidade de raios X empregada no Pantak-Seifert para seleção dos TLD-100.

[Adaptada de (Oliveira,2015)]

\begin{tabular}{c|c|c|c}
\hline Qualidade & $\begin{array}{c}\text { Tensão } \\
\mathrm{kV}\end{array}$ & $\begin{array}{c}\text { Filtração Adicional } \\
(\mathrm{mmAl})\end{array}$ & $\begin{array}{c}\text { Taxa de Kerma no ar } \\
(\mathrm{mGy} / \mathrm{s})\end{array}$ \\
\hline T-50b & 50 & 1 & $3,860 \pm 0,084$ \\
\hline
\end{tabular}

A seleção consistiu na irradiação dos dosímetros sob as mesmas condições. A cada irradiação realizada foi executada a leitura da resposta termoluminescente (TL) de cada dosímetro. O dosímetro cuja leitura variou acima de $\pm 5 \%$ da média das leituras do lote completo foi excluído.

Esse procedimento foi realizado até que a diferença percentual entre a resposta TL do dosímetro individual e a resposta média do lote chegasse a 3\%. As doses variam de 98.9 mGy até 
4999.2 mGy. A partir da resposta TL foram obtidos a curva da resposta TL em função da dose dos TLD's (LiF:Mg,Ti) e o respectivo fator de calibração.

Os dosímetros $\mathrm{TL}$ de $\mathrm{CaSO}_{4}$ :Dy foram selecionados utilizando a fonte de radiação gama do ${ }^{60} \mathrm{Co}$, sendo o intervalo de doses variando de $0,03 \mathrm{~Gy}$ à $10 \mathrm{~Gy}$. A seleção consistiu na irradiação dos dosímetros sob as mesmas condições.

A cada irradiação realizada foi executada a leitura da resposta termoluminescente (TL) de cada dosímetro. O dosímetro cuja leitura variou acima de $\pm 5 \%$ da média das leituras do lote completo foi excluído. Esse procedimento foi realizado até que a diferença percentual entre a resposta TL do dosímetro individual e a resposta média do lote chegasse a $1 \%$.

A leitura TL dos dosímetros $\left(\mathrm{CaSO}_{4}: \mathrm{Dy}\right.$ e $\left.\mathrm{LiF}: \mathrm{Mg}, \mathrm{Ti}\right)$ foi realizada, após 24 horas da irradiação [(Campos \& Lima, 1986); (ISO/ASTM 51956:2013)] empregando uma leitora TLD Harshaw modelo 4500, mostrada na figura 16.

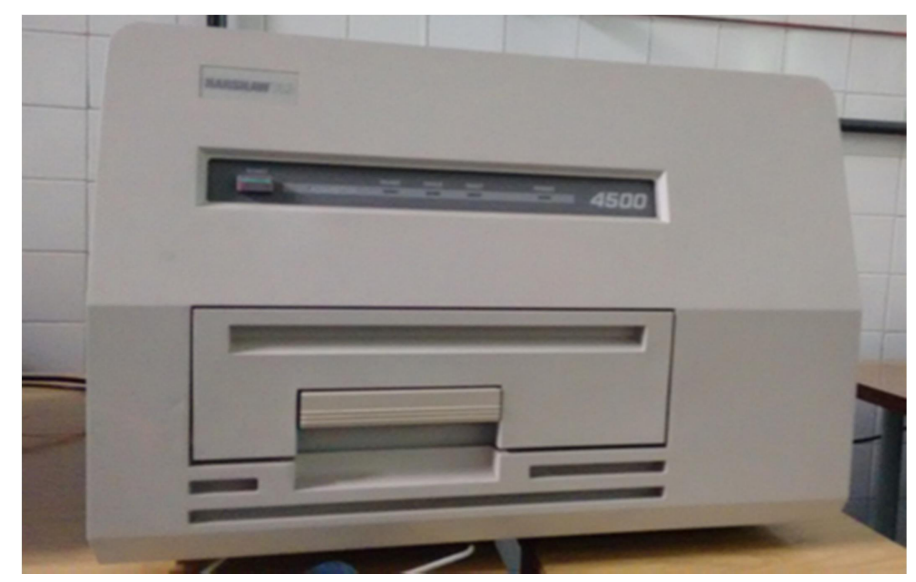

FIGURA 16. Leitora TLD Harshaw - Modelo 4500.

\subsubsection{Verificação da calibração - LiF:Mg,Ti}

Nessa fase foi realizada a verificação da seleção dos TLD's por meio de um “teste-cego". O teste compreendeu de uma irradiação dos 30 TLD's, em um campo quadrado com lado medindo $10 \mathrm{~cm}$ e em condições de feixe aberto (sem adição de filtração adicional).

Uma dose de radiação foi dada empregando um acelerador linear (LINAC) Varian modelo 6EX, não sendo esse valor de dose imediatamente informado pelo físico médico responsável. Foi realizada a leitura TL dos dosímetros e posteriormente foi calculado o valor médio das leituras da resposta TL (em uC) de cada um dos 30 TLD's. 
Utilizando o valor médio da leitura das respostas TL e o fator de calibração foi obtido o valor da dose. Por último, foi realizado o comparativo entre o valor de dose dado e o valor obtido com os dosímetros TL.

\subsubsection{Calibração com o acelerador linear Varian 6 EX - LiF:Mg,Ti}

Essa fase do trabalho consistiu em realizar uma nova calibração dos 30 TLD-100 com o acelerador linear. Para essa calibração foram utilizados diferentes valores de unidades monitoras para irradiação dos dosímetros.

Foi empregada uma placa com $5 \mathrm{~cm}$ de espessura como base para colocação dos dosímetros. As irradiações ocorreram com um campo quadrado com lado $10 \mathrm{~cm}$, sem utilização de filtração adicional. Foi fixado o valor da distância fonte-superfície em $100 \mathrm{~cm}$ para todas as irradiações.

Os dosímetros termoluminescentes (TLD's) foram organizados com o auxílio de uma faixa de esparadrapo comum em linha reta. O campo quadrado (com lado $10 \mathrm{~cm}$ ) foi dividido em porções iguais de modo que os TLD's empregados foram posicionados a mesma distância.

Acima dos TLD's foi colocado uma camada de bolus de cera de abelha com espessura de $1 \mathrm{~cm}$ e acima do bolus uma placa de Água Sólida com $4 \mathrm{~cm}$ de espessura. A organização dos TLD’s para a calibração com o Varian 6EX pode ser vista na figura 17.

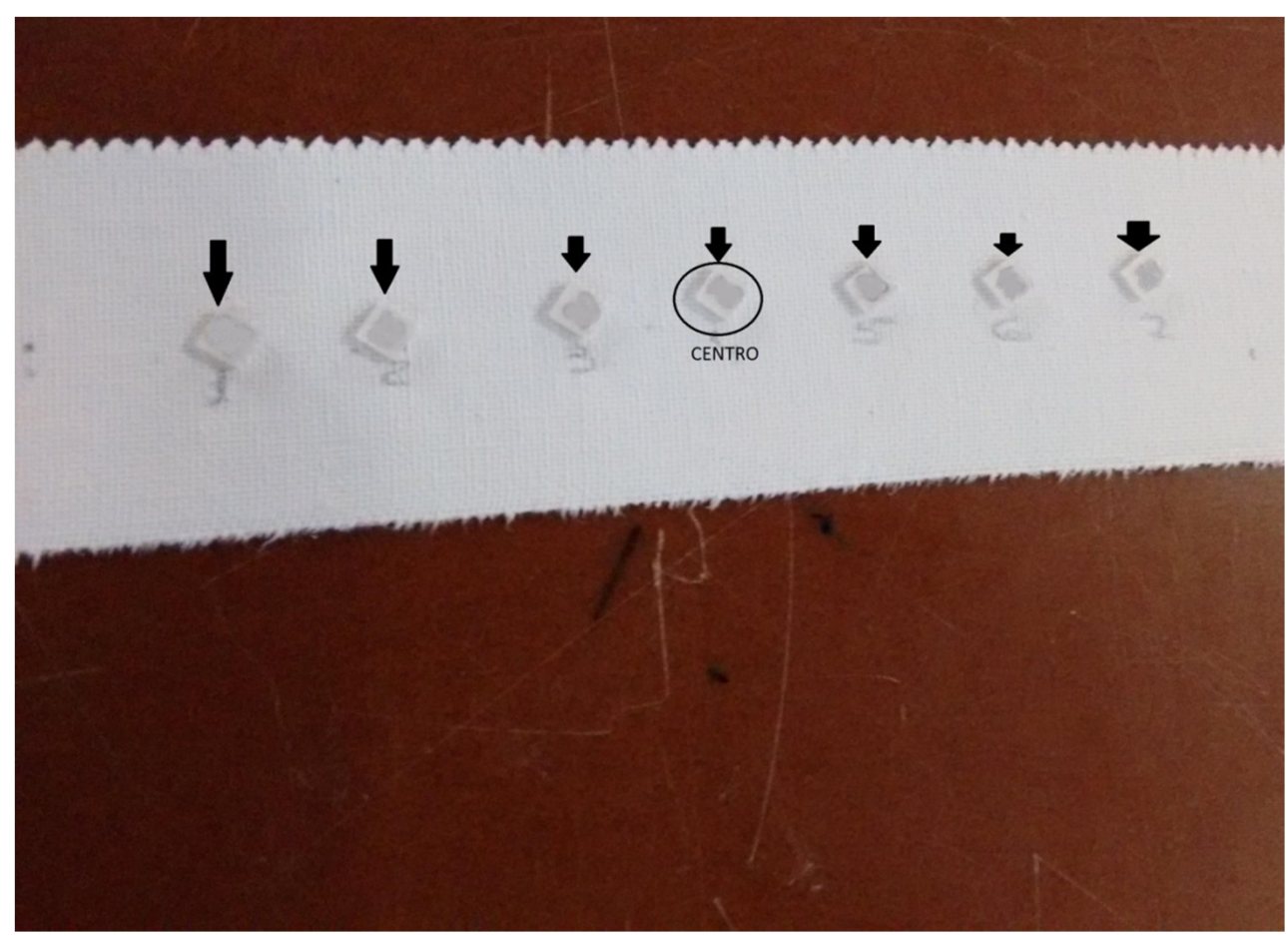

FIGURA 17. Organização dos TLD’s irradiados na calibração com acelerador linear. 
$\mathrm{Na}$ figura 17 é possível notar que 6 TLD's (3 do lado esquerdo e 3 do lado direito) foram posicionados fora do eixo central. Para determinar a dose em alguma posição fora do eixo central do feixe, deve ser levado em consideração o fator conhecido como razão de off-axis (OAR Off-Axis Ratio).

A OAR pode ser entendida como a razão entre a dose medida (em um ponto) no eixo central e a dose medida fora do eixo central, isso considerando ambas na mesma profundidade. (Giglioli, 2012). Essa relação é exposta na equação 12.

$$
\mathrm{OAR}=\frac{\operatorname{Dose}_{(\text {Eixo cenral })}}{\text { Dose }_{(\text {Fora do eixo central })}}
$$

No presente trabalho, as respostas TL obtidas pelos dosímetros fora do eixo central do feixe foram divididas pela resposta obtida pelo TLD posicionado no centro do feixe. Cada leitura foi então multiplicada pelo seu respectivo valor de OAR obtendo assim a leitura corrigida. A média de cada leitura corrigida foi obtida e foi correlacionada a resposta TL (uC) com a dose (Gy) de modo a que fosse obtido o fator de calibração adequado para o LINAC Varian 6 EX.

\subsubsection{Tratamento Térmico}

O tratamento térmico dos dosímetros foi executado sempre antes de ser realizada uma irradiação. Para o tratamento térmico foram utilizados: o forno tipo mufla da Vulcan ${ }^{\circledR}$; a Estufa Retilínea da FANEM LTDA; bandeja de alumínio para acondicionar os TLD’s e pinça cirúrgica para manuseio dos TLDs. Esses materiais podem ser visualizados na figura 18.

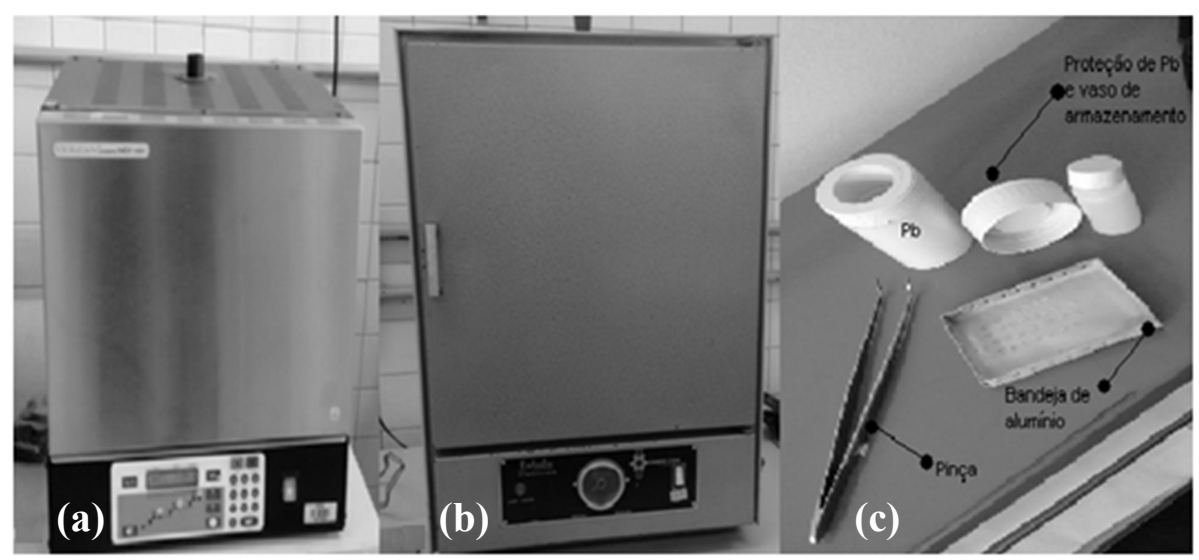

FIGURA 18. Equipamentos utilizados no manuseio, armazenamento e tratamento térmico - (a) forno tipo mufla da Vulcan ${ }^{\circledR}$; (b) Estufa Retilínea da FANEM LTDA.; (c) material utilizado para manuseio, transporte e armazenagem. 
No presente trabalho foram utilizados dois tipos diferentes de dosímetro TL, o LiF:Mg,Ti e o $\mathrm{CaSO}_{4}$ :Dy. Cada dosímetro possui uma forma diferenciada de tratamento térmico. Vale ressaltar que todos os dosímetros de um mesmo tipo foram tratados juntos, de modo que cada dosímetro recebeu o mesmo tratamento por ciclo.

Para o LiF:Mg,Ti o tratamento térmico consistiu de: 1 h à $400{ }^{\circ} \mathrm{C}$ (no forno tipo mufla) e $2 \mathrm{hrs} \mathrm{à} 100{ }^{\circ} \mathrm{C}$ (na estufa). [(Furetta,2003)]. O tratamento térmico realizado para o $\mathrm{CaSO}_{4}: \mathrm{Dy}$ foi de 3 hrs à $300^{\circ} \mathrm{C}$ (no forno mufla Vulcan $\left.{ }^{\circledR}\right)$. [(Campos \& Lima,1986)]

Os TLDs foram sempre manuseados com pinça (para se evitar contaminação) e alocados em bandeja de alumínio. Quando o tratamento térmico foi realizado no dia anterior ao dia da irradiação, os TLD's foram mantidos em proteção de chumbo.

\subsection{Testes realizados}

\subsubsection{Caracterização do material para simulação com MCNP5}

Segundo o manual do usuário (UP! 3D Brasil), existem quatro formas de preenchimento dos objetos impressos. Uma visualização do modo de preenchimento das peças, com suas respectivas aparências quando impressas, pode ser encontrada na figura 19.

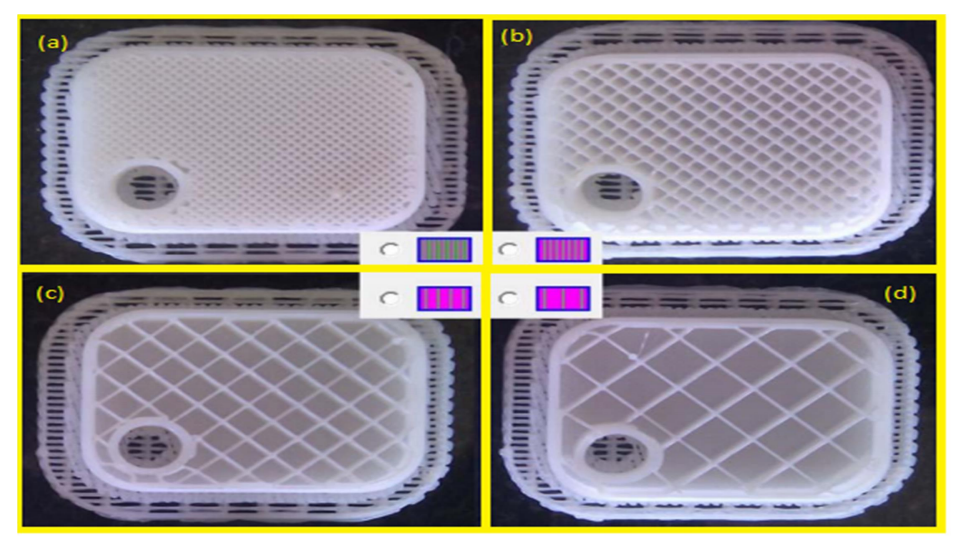

FIGURA 19. Modos de preenchimento de objetos impresso na impressora UP Plus 2. - (a) Solid Honeycomb ("quase sólido"); (b) Semi-solid Honeycomb; (c) Semi-Hollow Honeycomb; (d) Hollow Honeycomb. [Adaptada de (UP! 3D Brasil); (3D Printing Systems)]

Para realizar uma simulação com o código MCNP5 é necessário conhecer informações (p. ex. densidade) dos materiais simulados, no entanto, não foram encontradas, na literatura, 
informações confiáveis a cerca da composição exata e das respectivas densidades do PLA e do ABS.

Tendo como base as fórmulas químicas do PLA e do ABS e utilizando os pesos atômicos convencionais de cada elemento que estão presentes na IUPAC Periodic Table of the Elements (IUPAC, 2016) foram calculadas as frações dos elementos constituintes de cada um dos materiais impressos. Primeiramente foi calculado o peso molecular de cada composto, o cálculo foi desenvolvido por meio da equação 13 .

$$
w_{m}=\sum_{i=1}^{n}\left(N_{i} * w_{i}\right)(13)
$$

Onde: $w_{m}$,representa o peso da molécula em análise.

$N_{i}$, representa o número de átomos do i-ésimo elemento;

$w_{i}$, representa o peso atômico do i-ésimo elemento.

Após a realização do cálculo do peso molecular de cada um dos materiais foi calculado a fração de cada elemento. O cálculo foi desenvolvido por meio da equação 14.

$$
w_{f_{i}}=\sum_{i=1}^{n}\left[\frac{\left(N_{i} * w_{i}\right) * 1}{w_{m}}\right]
$$

Onde: $w_{f_{i}}$, representa a fração elementar do i-ésimo elemento;

$N_{i}$, representa o número de átomos do i-ésimo elemento;

$w_{i}$, representa o peso atômico do i-ésimo elemento.

1 , resultante da regra de três simples.

No tocante à densidade, foi utilizado o Método de Arquimedes. O processo consistiu na medição da massa, utilizando balança de precisão, de um Becker, de cubo (de ABS ou de PLA) e de uma moeda. Devido ao fato dos cubos impressos não submergirem foi necessário adicionar um peso extra. O peso extra consistiu em uma moeda que foi colada, com fita adesiva, na parte superior do cubo impresso.

A massa dos cubos foi medida antes de ser adicionado o peso extra e também foi medida a massa de todo "conjunto de prova" (cubo + moeda + fita adesiva). Foi realizada também a medição do Becker não preenchido e do Becker preenchido com água destilada.

Após o preenchimento do Becker com água destilada foi adicionado o "conjunto de prova". A massa correspondente (Becker preenchido + "conjunto de prova") foi medida. A diferença entre a 
massa do Becker preenchido com/sem o "conjunto de prova" foi atribuída como sendo a massa do "conjunto de prova".

Foi então calculada a massa do cubo quando submerso (massa aparente), para tanto foi subtraída a massa da moeda da massa do "conjunto de prova". Com os valores da massa do cubo, (não submerso) e de sua massa aparente foi calculada a densidade do cubo por meio da equação (Mazali, 2005):

$$
\mathrm{d}_{\mathrm{c}}=\left(\frac{\mathrm{m}_{\mathrm{c}}}{\mathrm{m}_{\mathrm{c}}-\mathrm{m}_{\mathrm{AP}}}\right) * \mathrm{~d}_{\mathrm{L}}(15)
$$

Onde: $d_{c}$, representa a densidade do cubo;

$\mathrm{m}_{\mathrm{c}}$, representa a massa do cubo não submerso;

$\mathrm{m}_{\mathrm{AP}}$, representa a massa aparente do cubo;

$\mathrm{d}_{\mathrm{L}}$, representa a densidade do líquido (água)

\subsubsection{Cálculo dos coeficientes de atenuação para PLA e ABS com MCNP5}

Em um trabalho realizado por Veneziani e colaboradores (2015), foram obtidos experimentalmente os coeficientes de atenuação de placas de diversas espessuras de PLA (Ácido Polilático) e ABS (Acrilonitrila Butadieno Estireno) impressas por uma impressora 3D Modelo UP PLUS 2 (UPP2), irradiadas com o sistema de Raios X Pantak/Seifert empregando qualidades de Raios-X diagnóstico diversas (RQR 3, RQR 5, RQR 8, RQR 10). [(IEC 61627, 2005)]. As placas de PLA e ABS empregadas no trabalho realizado por Veneziani e colaboradores (2015), foram impressas com a qualidade de impressão "quase-sólida". As características das qualidades de RaiosX diagnóstico empregadas por Veneziani e colaboradores (2015) pode ser visto na tabela 3a

TABELA 3a - Qualidades de Raios X do Sistema de Raios X Pantak/Seifert*

\begin{tabular}{cccc}
\hline Qualidade da Radiação & Tensão $(\mathrm{kV})$ & HVL & Energia $(\mathrm{keV})$ \\
\hline RQR3 & 50 & $1,78 \mathrm{mmAl}$ & 29,7 \\
RQR5 & 70 & $2,58 \mathrm{mmAl}$ & 34 \\
RQR8 & 100 & $3,97 \mathrm{mmAl}$ & 38,1 \\
RQR10 & 150 & $6,57 \mathrm{mmAl}$ & 46,5 \\
\hline
\end{tabular}

*Informações gentilmente cedidas pelo Laboratório de Calibração de Instrumentos (LCI/GMR/IPEN)

Com base nos parâmetros experimentais e os resultados obtidos por Veneziani e colaboradores (2015) foi desenvolvida uma simulação computacional utilizando o código MCNP, versão 5. Foi simulado um cenário de irradiação de placas compostas pelos materiais (PLA ou 
ABS) utilizados pela UPP2. Nas simulações realizadas as placas foram consideradas totalmente preenchidas.

Outras informações necessárias foram as características do sistema de raios X Pantak/Seifert (p. ex. ângulo anódico). Ao se elencar todos os parametros necessários, foi desenvolvida a simulação com o MCNP5.

A simulação consistiu de uma fonte de raios $\mathrm{X}$ pontual, colimador de chumbo, atenuador composto de material impresso e uma elipse preenchida de ar que representava o detector. O espectro de emissão da fonte pontual foi gerado através do software IPEM-78. Uma representação (fora de escala) da simulação utilizada neste trabalho pode ser vista na figura 20.

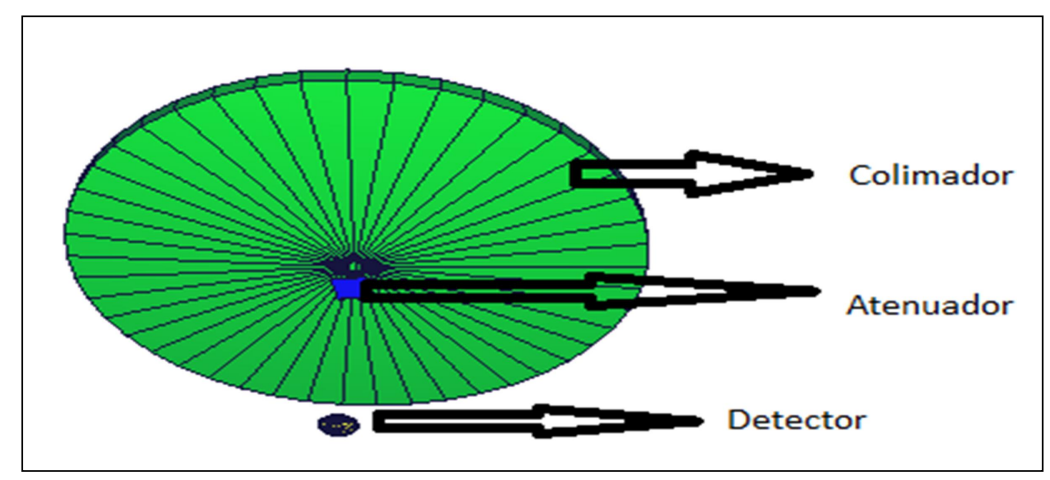

FIGURA 20. Modelo utilizado na simulação com MCNP5 (Imagem fora de escala)

As simulações foram divididas em dois grupos. No primeiro grupo, foi simulada apenas a irradiação do feixe sem a presença das placas do material da impressora (atenuador), de modo a que fosse possível que o detector fornecesse a intensidade inicial (I0) do feixe.

No segundo grupo, diversas simulações foram feitas sendo variada a espessura das placas de cada material (PLA ou ABS), de modo que o detector fornecesse a intensidade (I) do feixe após ser atenuado.

Para todas as simulações realizadas foram utilizadas 3E08 histórias (NPS 3E08) sendo empregado o tally F4 (fluxo médio em uma célula), cuja unidade é $\frac{\text { fótons }}{\mathrm{cm}^{2}}$. (Shultis \& Faw, 2011)

Relacionando os resultados (com e sem atenuador) foi possível calcular os respectivos coeficientes de atenuação por meio da equação $\mathrm{I}=\mathrm{I} 0 \mathrm{e}^{-\mathrm{ux}}$. Em cada cenário foi modificado o valor atribuído à densidade do material atenuador de modo a que os resultados obtidos por simulação fossem melhor adequados aos obtidos experimentalmente (placas "quase sólidas"). 


\subsubsection{Desenvolvimento de modelo computacional da placa impressa "quase-sólida"}

Conforme mostrado anteriormente, no manual do usuário consta que existem quatro formas de preenchimento das peças impressas com a impressora UP Plus 2 (UPP2), sendo possível notar, por meio da figura 19, que existem regiões não preenchidas por material (PLA ou ABS) em uma peça impressa utilizando a UPP2.

Diante da ausência de preenchimento em algumas porções das peças impressas e da aparente influência dessa ausência na atenuação da radiação foi desenvolvido o modelo computacional para MCNP 5 de placas impressas no modo "quase-sólido".

Visando obter características da malha que preenche as peças impressas foi realizada a microscopia do interior de um cubo de PLA e de um cubo de ABS. Para tanto, foi empregada a técnica de microscopia eletrônica de varredura (MEV). Basicamente, a técnica de MEV faz a varredura de amostras, com o uso de um feixe focalizado de elétrons, e forma imagens com informações topográficas das amostras. (ZEISS, [s.d.])

Utilizando cada um dos materiais estudados (PLA e ABS) no presente trabalho, um cubo, com lado medindo $1 \mathrm{~cm}$, foi impresso. Para que fosse possível visualizar o interior do cubo, foi efetuado o corte (em duas fatias) do mesmo. A microscopia eletrônica de varredura foi efetuada com o microscópio de bancada Hitachi TM3000. Uma imagem obtida com o Hitachi TM3000 pode ser vista na figura 21.

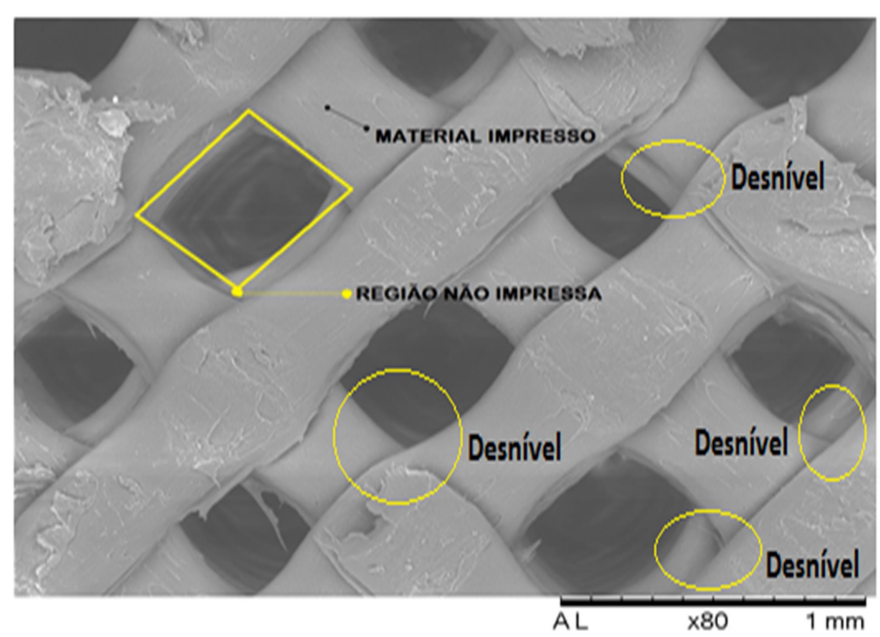

FIGURA 21. Malha interna de um cubo impresso pela UPP2, visualizada por microscopia eletrônica de varredura (no exemplo ABS aumentado 80x)

É possível notar que existem regiões mais altas que outras, provocando desníveis. Por causa desses desníveis existem pontos mais próximos/distantes de um ponto tomado como referência. 
Para a obtenção das dimensões (aproximadas) dos espaços de ar (não preenchidos por material impresso) contidos no cubo foi empregado o software de distribuição livre ImageJ.

Após calibrar a função "measure" do ImageJ com a escala disponibilizada pelo Hitachi TM3000, foi realizada a medição dos espaços. Devido aos desníveis, foi perceptível que a distancia entre um ponto (quando fixo) a outro ponto (localizado no mesmo plano) variava.

Foram encontrados com o software ImageJ valores que variaram entre $0.33 \mathrm{~mm}$ até os $0.6 \mathrm{~mm}$. Foi escolhido um valor que estivesse entre a escala de valores encontrados, sendo o valor de $0.5 \mathrm{~mm}$ o valor escolhido.

O valor de $0.5 \mathrm{~mm}$ foi escolhido, pois foi o ponto (acima do valor médio do intervalo de valores encontrados com o ImageJ) que permitiu desenvolver uma matriz numérica que representasse uma placa (impressa) quadrada de lado $10 \mathrm{~cm}$ (dimensão utilizada nesse trabalho), com mesmo número de divisões. A matriz foi criada usando o software Wolfram Mathematica 9.0 Student Edition.

No software da UPP2 é possível visualizar o número de camadas que vão ser impressas. Visando desenvolver uma matriz para MCNP5 que representasse de forma satisfatória uma placa impressa foram desenhadas placas (com o software FreeCAD) e com os arquivos gerados foram realizadas as impressões.

Com intuito de manter o mesmo número de pontos nos 3 eixos (comprimento, largura e altura) foram escolhidos valores arredondados (sem casas decimais) de camadas.

As camadas na matriz que representavam as bordas superior e inferior da placas foram representadas exclusivamente com o número 1. A matriz que representava a estrutura interna (preenchimento) da placa foi representada pelos números 1 e 2, sendo o 1 atribuído para o material da impressora (PLA ou ABS) e o 2 atribuído para o ar. Um trecho das matrizes criadas pode ser visualizado na figura 22.

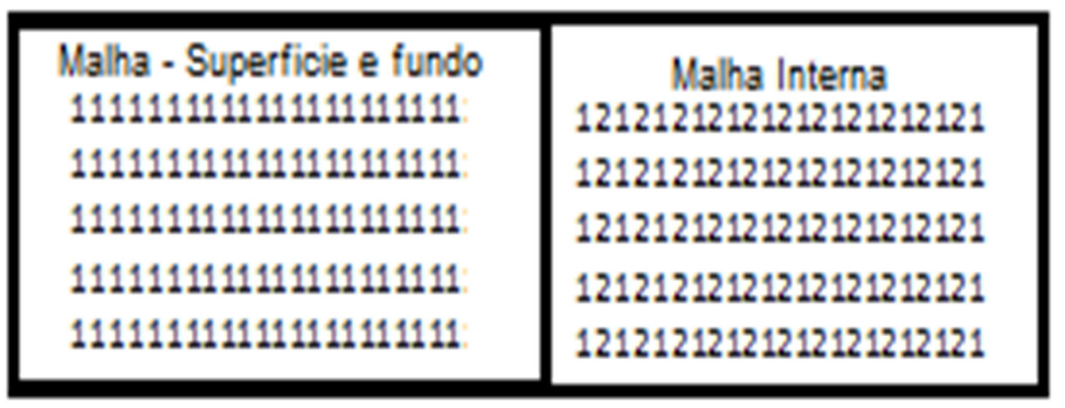

FIGURA 22. Trecho da matriz criada com o software Wolfram Mathematica 9.0 Student Edition 
Com as matrizes criadas foi possível desenvolver um modelo computacional para realizar a simulação com MCNP5 da irradiação das placas. Visando avaliar se o modelo criado para o MCNP5 (aqui chamado "Placa Vazada") representava de forma satisfatória uma placa impressa foi realizado experimentalmente a medição do coeficiente de atenuação das placas.

As irradiações foram feitas empregando o sistema de raios X Pantak-Seifert, usando a qualidade T-50a (tensão de $50 \mathrm{kV}$ com filtração adicional de $4 \mathrm{~mm}$ de alumínio). [(Oliveira,2015)]. Para a medição experimental foi utilizada uma câmara de ionização de placas paralelas PTW 23344.

Na simulação com MCNP5, além de desenvolvido o modelo das placas ("Placa Vazada") foi desenvolvido um modelo de câmara de ionização semelhante à PTW 23344. Foi realizada a simulação da irradiação de placas totalmente preenchidas (aqui chamada de "Placa Cheia"). Para todas as simulações realizadas foram usadas 4E08 histórias (NPS 4E08) e o tally F6 (deposição de energia), cuja unidade é $\mathrm{MeV} / \mathrm{g}$. (Shultis \& Faw, 2011)

\subsubsection{Resposta termoluminescente do $\mathrm{CaSO}_{4}$ :Dy, empregando placas de PLA e de PMMA}

Nessa fase foi avaliada a resposta termoluminescente do $\mathrm{CaSO}_{4}: \mathrm{Dy}$, empregando placas de PLA impressas em 3D e de polimetilmetacrilato (PMMA) de mesma espessura, para obtenção da condição de equilíbrio eletrônico

Foram utilizados 30 dosímetros de $\mathrm{CaSO}_{4}$ :Dy e foram empregadas as fontes de radiação gama de

${ }^{137} \mathrm{Cs}$, de ${ }^{60} \mathrm{Co}$ o sistema de Raios X Pantak/Seifert com as qualidades de radiodiagnóstico RQR 3, RQR 5 e RQR 10 (descritas na tabela 3a) e com a qualidade de radioproteção N150. Características da qualidade de radioproteção N150 podem ser encontrada na tabela $3 b$.

TABELA 3b - Qualidade de radioproteção do Sistema de Raios X Pantak/Seifert*

\begin{tabular}{cccc}
\hline Qualidade da Radiação & Tensão $(\mathrm{kV})$ & HVL & Energia Efetiva (keV) \\
\hline N150 & 150 & $2,4 \mathrm{mmCu}$ & 118 \\
\hline *Informações gentilmente cedidas pelo Laboratório de Calibração de Instrumentos (LCI/GMR/IPEN)
\end{tabular}

Para todas as energias, exceto a qualidade N150, o tempo de exposição foi calculado para uma dose de $30 \mathrm{mGy}$. Esse valor de dose foi escolhido por fazer parte da curva de calibração dos dosímetros utilizados. Em razão das limitações da taxa de dose da qualidade N150, a dose aplicada foi de $10 \mathrm{mGy}$. As doses de radiação gama do ${ }^{137} \mathrm{Cs}$ e ${ }^{60} \mathrm{Co}$ foram também de $30 \mathrm{mGy}$.

Os resultados obtidos (resposta TL) com as placas de PLA de $3 \mathrm{~mm}$ de espessura foram comparados com os resultados obtidos com as placas de $3 \mathrm{~mm}$ de espessura de PMMA (material 
utilizado como espessura de equilíbrio eletrônico na seleção e calibração do $\mathrm{CaSO}_{4}$ :Dy com radiação gama do $\left.{ }^{60} \mathrm{Co}\right)$.

As respostas TL obtidas para as diferentes energias foram relacionadas com a resposta TL obtida para o ${ }^{60} \mathrm{Co}$, de modo a gerar os fatores de correção para dependência energética da resposta, por unidade de dose.

\subsubsection{Cálculo de dose para Água Sólida, PLA e ABS - Dosimetria termoluminescente e Eclipse $^{\text {TM }}$}

Nessa fase do trabalho foram empregados placas impressas em PLA e ABS, placas de água sólida RMI-457 (IAEA, 2005), 30 dosímetros TL de LiF:Mg,Ti (TLD-100) e pinça para manuseio dos dosímetros TL. O objetivo dessa etapa foi avaliar o comportamento da dose em profundidade. Para tanto, foi empregado o acelerador linear Varian 6 EX para irradiar as placas de PLA e ABS e de Água Sólida.

Em todas as irradiações foi mantida uma distância fonte-superfície (SSD - Source to surface distance) de $100 \mathrm{~cm}$; foi dada uma dose com 100 unidades monitoras (MU - Monitor Unit), empregando uma taxa de dose $600 \mathrm{MU} / \mathrm{Min}$. Todas as irradiações foram realizadas com campo aberto. (AAPM, 1999). A medição da dose foi realizada utilizando os TLD-100. Para todos os materiais foram selecionados aleatoriamente 4 espessuras (profundidades) de placas $(1,5 ; 3,5 ; 5 ; \mathrm{e} 7 \mathrm{~cm})$.

As irradiações das placas de PLA e ABS foram realizadas usando a mesma geometria. Em ambos os casos foram empilhadas placas de diferentes espessuras de modo que fosse alcançada a espessura desejada. Abaixo das placas empilhadas foi posicionada uma placa com quatro orifícios para posicionamento dos TLD-100, cuja espessura foi de $0,5 \mathrm{~cm}$. Os orifícios foram distribuídos em forma de cruz, cada um com o centro distante $2 \mathrm{~cm}$ do centro da placa. A placa para posicionamento dos TLD-100 pode ser vista na figura 23.

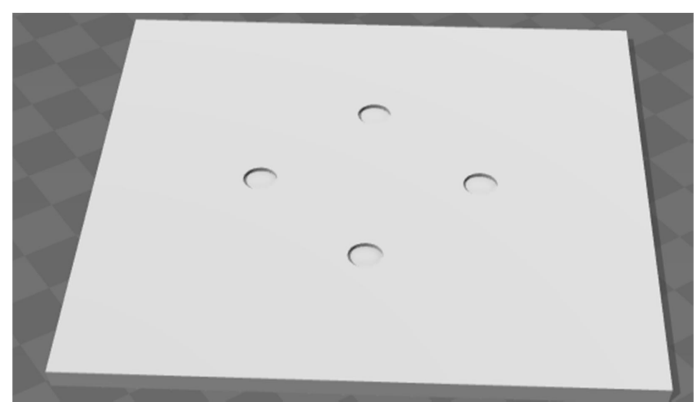

FIGURA 23. Placa para posicionamento dos dosímetros TL ("Porta TL") 
Abaixo da placa contendo os TLD-100 foi colocada uma placa (também impressa) com espessura de $2 \mathrm{~cm}$. Abaixo de toda estrutura foram posicionadas placas de Água Sólida cuja espessura final foi de $3 \mathrm{~cm}$.

No tocante às irradiações realizadas com Água Sólida, o procedimento de empilhamento de placas foi mantido. Abaixo das placas empilhadas foi posicionada uma camada de bolus de cera de abelha com espessura de 1,5 cm. Os TLD-100 foram acomodados na camada de bolus com o auxílio de uma cruz desenhada na superfície da mesma.

A organização dos TLD-100 nas irradiações com Água Sólida seguiu a mesma organização empregada nas irradiações do PLA e do ABS. Abaixo da estrutura foram posicionadas placas de Água Sólida cuja espessura final foi de $8 \mathrm{~cm}$. Os arranjos empregados nas irradiações podem ser visualizados na figura 24.
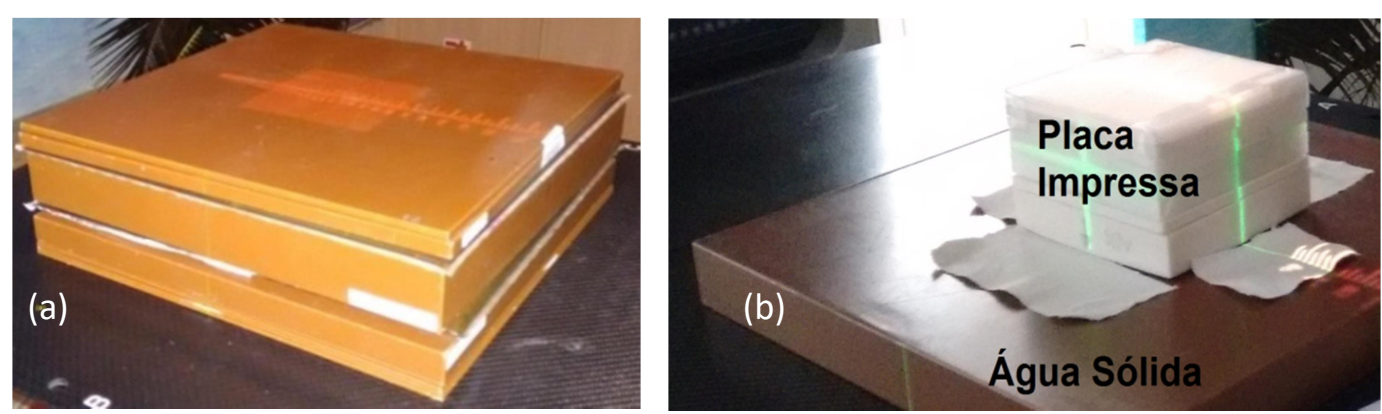

FIGURA 24. Arranjo das placas irradiadas - (a) Placas de Água Sólida; (b) Placas impressas UPP2 (no exemplo, ABS)

Para cada profundidade foi ajustada a SSD de modo a que essa sempre fosse mantida em $100 \mathrm{~cm}$. O marcador usado para ajuste da SSD pode ser visualizado na figura 25 .

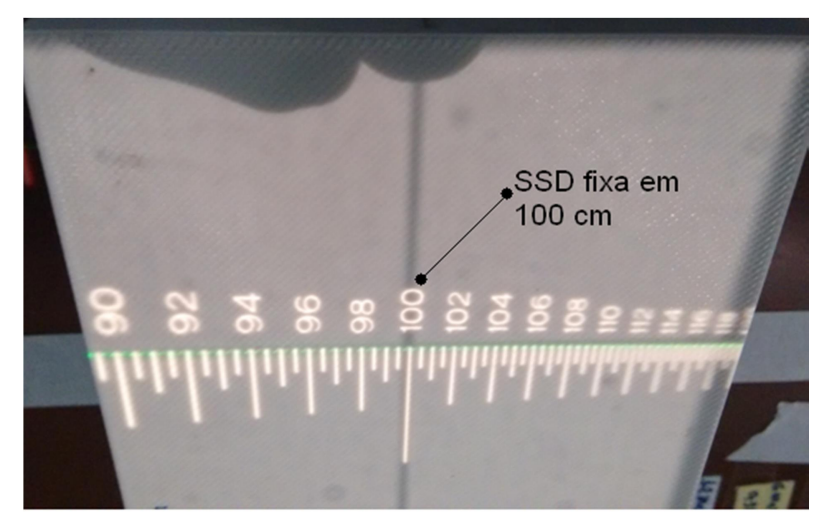

FIGURA 25. Marcador usado para ajuste da SSD. 
A cada nova profundidade, 4 TLD-100 ainda não irradiados foram posicionados, de modo a que fosse evitado o acúmulo da dose recebida por um mesmo dosímetro. As placas impressas foram irradiadas com um campo quadrado de lado $9,8 \mathrm{~cm}$ e as de Água Sólida foram irradiadas com um campo quadrado de lado $10 \mathrm{~cm}$.

Considerando que durante o trajeto (ida e volta): instituto de pesquisa/hospital, os dosímetros poderiam estar sujeitos à radiação de fundo (BG - background), foi reservado (para cada dia de irradiação) 2 dosímetros TL. A média das leituras obtidas por esses dois TLD's foi chamada “dose de BG"; sendo esse valor subtraído das leituras realizadas com os TLD's irradiados com o acelerador linear.

Visando avaliar as medições realizadas usando os dosímetros TL (LiF:Mg,Ti) foi realizado o planejamento do "tratamento" das placas irradiadas. Para que fosse possível realizar o planejamento, foi necessário realizar a tomografia computadorizada das placas impressas e dos objetos simuladores de Água Sólida (aqui chamados de placas de Água Sólida), seguindo sempre a mesma organização que seria aplicada nas irradiações. Um exemplo das placas sendo preparadas para a tomografia pode ser visto na figura 26.

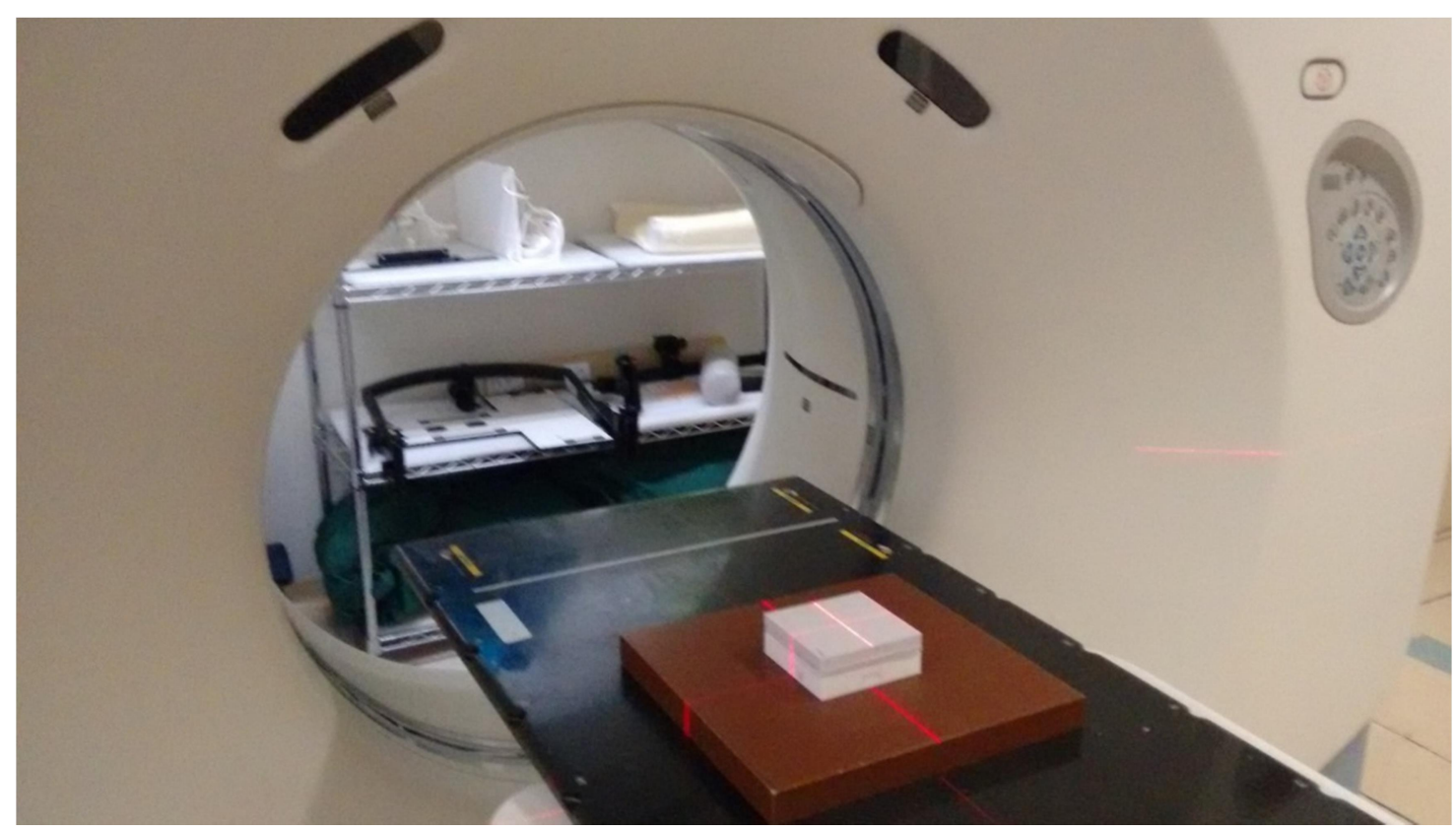

FIGURA 26. Arranjo experimental sendo preparado para tomografia computadorizada. 
Após a realização da tomografia computadorizada (CT) de cada material, os arquivos DICOM foram transferidos para o sistema de planejamento de tratamento Eclipse ${ }^{\mathrm{TM}}$ versão 13.6, para que fosse possível realizar o planejamento das irradiações experimentais no sistema.

Após terem sido carregados todos os arquivos DICOM no Eclipse ${ }^{\mathrm{TM}}$ foram "desenhadas" as estruturas do tratamento. As placas foram desenhadas como o corpo ("body") e os dosímetros TL foram desenhados como sendo os órgãos (“organ”).

Os tamanhos de campo que foram planejados no Eclipse ${ }^{\mathrm{TM}}$ foram um campo quadrado de lado 9,8 cm para o PLA e o ABS, para Água Sólida um campo quadrado de lado $10 \mathrm{~cm}$ (usado na medição experimental) e um campo quadrado de lado $9,8 \mathrm{~cm}$ (usado para comparativo com as placas impressas).

Para cada planejamento realizado foi estipulado: distância fonte-superfície igual a $100 \mathrm{~cm}$; dose de 100 unidades monitoras (MU - Monitor Unit) com uma taxa de dose $600 \mathrm{MU} / \mathrm{min}$; usando o mesmo acelerador empregado nas irradiações.

Primeiramente, o calculo de dose foi realizando empregado o Analytical Anisotropic Algorithm (AAA), que é um dos algoritmos de calculo de dose implementados no Eclipse ${ }^{\mathrm{TM}}$. Um exemplo da tela do Eclipse ${ }^{\mathrm{TM}}$, após o cálculo da dose, é mostrado na figura 27.

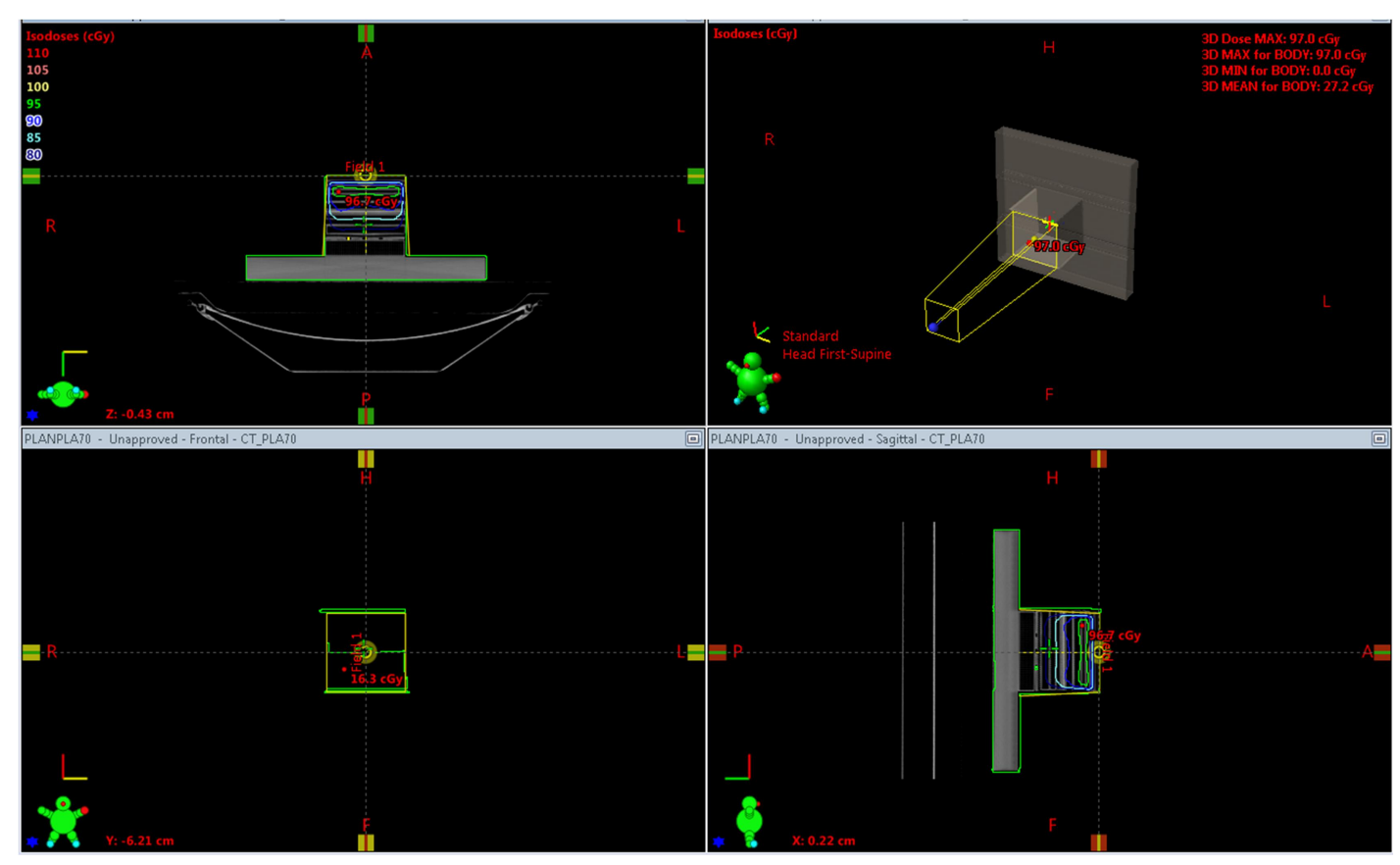

FIGURA 27. Planejamento da irradiação - Eclipse $^{\mathrm{TM}}$ versão 13.6 (no exemplo PLA) 
Após a realização de cada irradiação dos materiais (PLA, ABS e Água Sólida) e das respectivas leituras da resposta $\mathrm{TL}$, foi aplicado o fator de calibração obtido (para os $\mathrm{LiF}: \mathrm{Mg}, \mathrm{Ti}$ ) com o uso do Varian 6EX, sendo as doses obtidas em cGy.

Os valores de dose calculados com o dosímetro TL e com o sistema de planejamento Eclipse $^{\mathrm{TM}}$ foram comparados. Após o comparativo foi verificado que a diferença percentual entre as doses (TLD-100 e Eclipse ${ }^{\mathrm{TM}}$ ) para o ABS ultrapassaram 5\%. Por isso, foi refeito o planejamento, da irradiação das placas de ABS, utilizando o algoritmo de cálculo Acuros XB (AXB), o qual também se encontra implementado no Eclipse ${ }^{\mathrm{TM}}$.

Para os valores de dose obtidos foram realizados o cálculo de porcentagem de dose profunda e a diferença percentual com intuito de avaliar a equivalência entre o PLA e o ABS com a Água Sólida. 


\section{RESULTADOS E DISCUSSÕES}

\subsection{Seleção e calibração dos dosímetros}

A partir dos procedimentos descritos anteriormente (tópicos 4.5.2 à 4.5.4) foram obtidas as curvas de resposta TL em função da dose e os respectivos fatores de calibração. Na figura 28 é possível visualizar a curva de resposta TL em função da dose obtida na a seleção dos dosímetros de LiF:Mg,Ti (TLD-100) empregados neste trabalho. A diferença percentual entre a resposta TL do dosímetro individual e a resposta média do lote foi de $3 \%$.

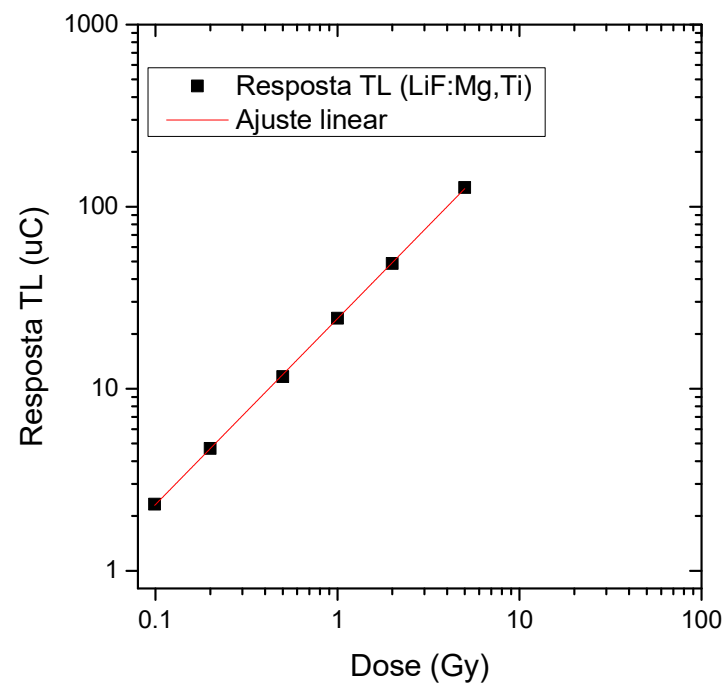

FIGURA 28. Curva de resposta em função da dose dos dosímetros TL

Após a realização do "teste-cego" que visava verificar a seleção dos dosímetros de LiF:Mg,Ti foi obtido um valor de dose calculado por meio dos TLD-100. A dose dada aos dosímetros foi de 312,92 cGy e o valor da dose obtidos pelos TLD's foi de 313,126 cGy. Os 
resultados apresentaram uma diferença percentual de $0,066 \%$, o que possibilitou validar a seleção dos dosímetros TL realizada.

A curva de resposta TL em função da dose obtida na seleção dos dosímetros de $\mathrm{CaSO}_{4}: \mathrm{Dy}$ pode ser vista na figura 29. A diferença percentual entre a resposta TL do dosímetro individual e a resposta média foi de $1 \%$.

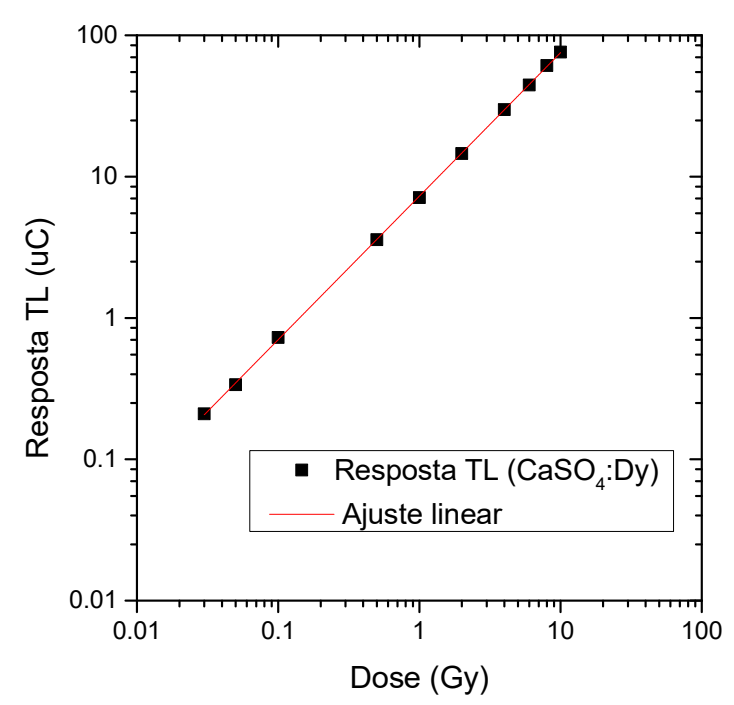

FIGURA 29. Curva de resposta TL em função da dose para radiação gama do ${ }^{60} \mathrm{Co}$

Conforme dito anteriormente, os dosímetros de $\mathrm{LiF}: \mathrm{Mg}$, Ti foram calibrados com um acelerador linear $6 \mathrm{MV}$ (LINAC Varian 6EX), por isso a diferença percentual entre a resposta TL do dosímetro individual e a resposta média do lote foi de 3\%. A curva de resposta TL em função da dose obtida para essa calibração pode ser vista na figura 30.

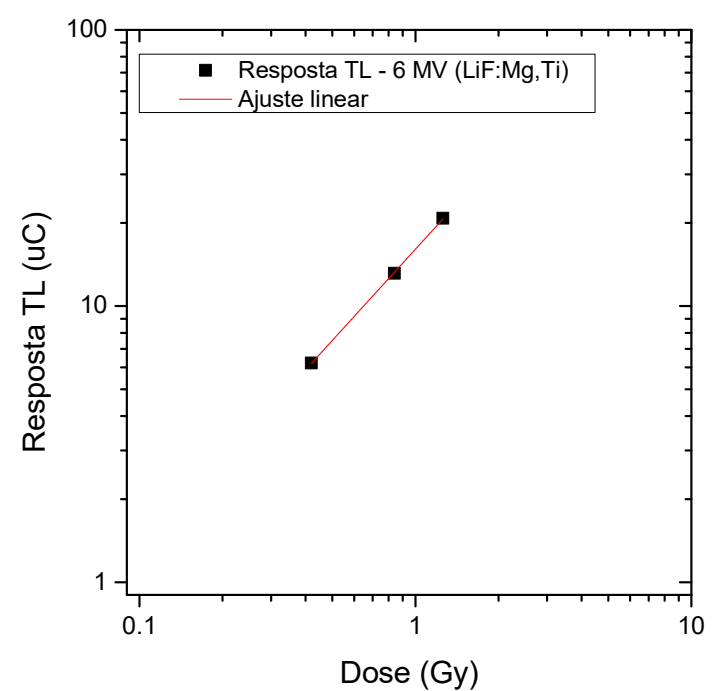

FIGURA 30. Curva de resposta TL em função da dose obtida com o LINAC Varian 6EX 


\subsection{Composição e densidade do material para simulação com MCNP5}

Após a caracterização dos materiais (descrita no tópico 4.6.1) havia, para o ABS, 17 átomos de hidrogênio, 15 átomos de carbono e 1 átomo de nitrogênio. No que se refere ao PLA foi verificado que havia 4 átomos de hidrogênio, 3 átomos de carbono e 2 átomos de oxigênio. Por tanto, as proporções calculadas, de cada elemento nos materiais estudados são:

- PLA: 5,6\% de hidrogênio; $50 \%$ de carbono; e 44,4\% de oxigênio;

- ABS: $8,1 \%$ de hidrogênio; $85,3 \%$ de carbono; e $6,6 \%$ de nitrogênio.

O método de Arquimedes foi utilizado para a obtenção da densidade, no entanto, foi notado que o método não é apropriado para relacionar a densidade de uma placa impressa real com um objeto simulado no MCNP5. Os resultados de densidade obtidos, a partir do método de Arquimedes, para a densidade do PLA e do ABS foram, respectivamente: $1,19 \mathrm{~g} / \mathrm{cm}^{3}$ e $0,548 \mathrm{~g} / \mathrm{cm}^{3}$.

Os valores de densidade para o PLA e para o ABS foram adaptados (aos valores obtidos pelo método de Arquimedes) para que as simulações com MCNP5 fossem condizentes com os valores experimentais. Os valores finais de densidade foram, respectivamente, para o PLA e para o ABS: $0,97 \mathrm{~g} / \mathrm{cm}^{3}$ e $0,82 \mathrm{~g} / \mathrm{cm}^{3}$.

\subsection{Coeficientes de Atenuação para PLA e ABS}

A tabela 4 apresenta o comparativo entre os resultados obtidos neste trabalho (empregando MCNP5) e os obtidos experimentalmente por Veneziani e colaboradores (2015).

TABELA 4 - Comparativo entre os valores obtidos empregando MCNP5 e os valores obtidos experimentalmente

\begin{tabular}{|c|c|c|c|c|c|c|c|c|}
\hline \multirow[b]{3}{*}{ Material } & \multicolumn{8}{|c|}{ Coeficiente de Atenuação $\left(\mathrm{mm}^{-1}\right)$} \\
\hline & \multicolumn{2}{|r|}{ RQR3 } & \multicolumn{2}{|r|}{ RQR 5} & \multicolumn{2}{|r|}{ RQR 8} & \multicolumn{2}{|r|}{ RQR 10} \\
\hline & Exp. & MCNP5 & Exp. & MCNP5 & Exp. & MCNP5 & Exp. & MCNP5 \\
\hline ABS & 0,02 & $0,0211 \pm 0,0001$ & 0,018 & $0,0185 \pm 0,0001$ & 0,016 & $0,0168 \pm 0,0001$ & 0,014 & $0,0149 \pm 0,00005$ \\
\hline PLA & 0,029 & $0,0287 \pm 0.0003$ & 0,024 & $0,0239 \pm 0,0003$ & 0,021 & $0,0208 \pm 0,0002$ & 0,017 & $0,0179 \pm 0,0001$ \\
\hline
\end{tabular}

Já eram esperadas diferenças entre os resultados obtidos por simulação e os obtidos experimentalmente, uma vez que as placas irradiadas experimentalmente e as simuladas eram diferentes no que diz respeito ao prenchimento, sendo classificadas como "quase-solidas" e totalmente preenchidas, respectivamente. 
As diferenças entre os resultados obtidos por simulação e experimentalmente indicam a importância dos espaços vazios (não preenchidos de PLA ou ABS), presentes nas placas impressas utilizadas experimentalmente, os quais podem influenciar a atenuação e/ou o espalhamento do feixe de radiação.

Os resultados obtidos com o MCNP5, quando empregados os valores de densidade calculados com o método de Arquimedes, foram muito distantes dos valores experimentais e por tanto foram descartados. Apenas como ilustração, vale citar o PLA cujo resultado foi um coeficiente de atenuação de $0,03493 \mathrm{~mm}^{-1}$.

Esse coeficiente de atenuação $\left(0,03493 \mathrm{~mm}^{-1}\right)$ resultaria em uma camada semirredutora de (aproximadamente) 19,84 cm. A camada semirredutora necessária, utilizando o coeficiente de atenuação experimental $\left(0,029 \mathrm{~mm}^{-1}\right)$ é de $23,9 \mathrm{~cm}$. Os valores, experimental e simulado, apresentam uma diferença de $4,06 \mathrm{~cm}$.

A necessidade de ajuste do valor da densidade encontrado pelo método de Arquimedes pode ser explicada devido ao MCNP5 atribuir o valor da densidade a um dado material que compõe um objeto. $\mathrm{O}$ método de Arquimedes, por outro lado, é capaz de determinar a densidade de um objeto por inteiro. No caso de um objeto impresso, o método de Arquimedes permiter determinar a densidade de uma peça impressa inteira, levando em conta as regiões preenchidas ou não por material impresso.

Outra fonte de incerteza para o método de Arquimedes (aplicado para a densidade de objetos impressos 3D) é a presença de espaços não preenchidos dentro de objetos impressos 3D. Oscilações na temperatura no sistema de aquecimento da impressora, possívelmente, vão afetar o modo como a impressora vai depor as camadas de material, para imprimir um objeto 3D. Dessa maneira (provavelmente) uma peça vai ser impressa com uma estrutura diferente de outra.

\subsection{Validação do modelo computacional da placa impressa "quase-sólida"}

Os coeficientes de atenuação, para PLA e ABS, que foram obtidos (experimentalmente e por simulação com MCNP5) para a validação do modelo computacional, podem ser vistos na tabela 5.

TABELA 5 - Coeficientes de atenuação para qualidade T-50a - PLA e ABS

\begin{tabular}{cccc}
\hline & \multicolumn{3}{c}{ Coeficiente de atenuação $\left(\mathrm{mm}^{-1}\right)$} \\
\hline Material & Experimental & MCNP5 ("Placa Cheia") & MCNP5 ("Placa Vazada") \\
PLA & 0,02556 & $0,02769 \pm 0,0004$ & $0,02555 \pm 0,00302$ \\
ABS & 0,01836 & $0,0199 \pm 0,0002$ & $0,01833+0,00144$ \\
\hline
\end{tabular}

A simulação de placas totalmente preenchidas ("Placa Cheia") foi realizada utilizando a mesma densidade e composição empregadas nas simulações com MCNP5 para o cálculo do coeficiente de atenuação do PLA e ABS. Os valores das densidades, empregadas nas simulações realizadas com o modelo computacional criado ("Placa Vazada") foram modificados de modo que o modelo computacional criado 
fosse condizente com os resultados experimentais. Os valores de densidade utilizados foram: $2 \frac{\mathrm{g}}{\mathrm{cm}^{3}} \mathrm{e}$ $2,44 \frac{\mathrm{g}}{\mathrm{cm}^{3}}$, respectivamente, para o ABS e o PLA.

Por meio da tabela 5 é possível verificar que a matriz criada para simulação com MCNP5, de placas impressas pela impressora UP Plus 2 no modo "quase-sólido", representa de maneira adequada as placas impressas, uma vez que segundo o LCI/GMR/IPEN a incerteza na medição experimental é de $\pm 3 \%$.

É possível notar que os coeficientes de atenuação obtidos experimentalmente são inferiores àqueles obtidos com a simulação das placas totalmente preenchidas ("Placa Cheia"); sendo um indicativo de que os espaços não preenchidos (pela impressora) influenciam a atenuação das placas.

\subsection{Fatores de correção para dependência energética do $\mathrm{CaSO}_{4}: \mathrm{Dy}$ - PLA versus PMMA}

As tabelas 6a e 6b apresentam, respectivamente, os valores de leitura e fatores de correção para dependência energética da resposta TL obtidos para o PMMA e para o PLA.

TABELA 6a - Resposta TL e fator de correção obtidos para placas de PMMA.

\begin{tabular}{cccc}
\hline Qualidades de Radiação & Energia $(\mathrm{keV})$ & Resposta TL $(\mathrm{uC})$ & Fator de dependência energética \\
\hline${ }^{60} \mathrm{Co}$ & 1250 & $1,80 \mathrm{E}-05$ & 1 \\
${ }^{137} \mathrm{Cs}$ & 660 & $2,03 \mathrm{E}-05$ & 1,13 \\
${ }^{\mathrm{N}} 150$ & 118 & $1,26 \mathrm{E}-05$ & 2,1 \\
RQR10 & 46,5 & $1,37 \mathrm{E}-04$ & 7,6 \\
RQR5 & 34 & $1,73 \mathrm{E}-04$ & 9,64 \\
RQR3 & 29,7 & $1,70 \mathrm{E}-04$ & 9,62 \\
\hline
\end{tabular}

Os fatores de correção de dependência energética apresentados nas tabelas $6 \mathrm{a}$ e $6 \mathrm{~b}$ foram obtidos por meio da razão da resposta TL pela dose para cada energia pela resposta TL respectiva a dose com ${ }^{60} \mathrm{Co}$. De posse desses valores, foi calculado, também para cada energia, o fator de correção por meio da equação 16.

$$
F_{\text {correção }}=\frac{R_{\frac{T L}{\text { dose }}}}{\frac{R_{T L_{60} C o}}{\text { dose }}}(16)
$$

Onde: $R_{\frac{T L}{d o s e}}$, representa razão da resposta TL pela dose para cada energia;

$R_{\frac{T L_{60} 0}{d o s e}}$, representa o valor obtido quando empregado a irradiação de referência com o ${ }^{60} \mathrm{Co}$ 
TABELA 6b - Resposta TL e fator de correção obtidos para placas de PLA.

\begin{tabular}{cccc}
\hline Qualidades de Radiação & Energia $(\mathrm{keV})$ & Resposta TL $(\mathrm{uC})$ & Fator de dependência energética \\
\hline${ }^{60} \mathrm{Co}$ & 1250 & $1,76 \mathrm{E}-05$ & 1 \\
${ }^{137} \mathrm{Cs}$ & 660 & $1,99 \mathrm{E}-05$ & 1,13 \\
$\mathrm{~N} 150$ & 118 & $1,22 \mathrm{E}-05$ & 2,09 \\
RQR10 & 46,5 & $1,29 \mathrm{E}-04$ & 9,36 \\
RQR5 & 34 & $1,63 \mathrm{E}-04$ & 10,29 \\
RQR3 & 29,7 & $1,82 \mathrm{E}-04$ & 10,4 \\
\hline
\end{tabular}

A Figura 31 apresenta as curvas de dependência energética da resposta TL do $\mathrm{CaSO}_{4}: \mathrm{Dy}$ empregando os dois tipos de placas.

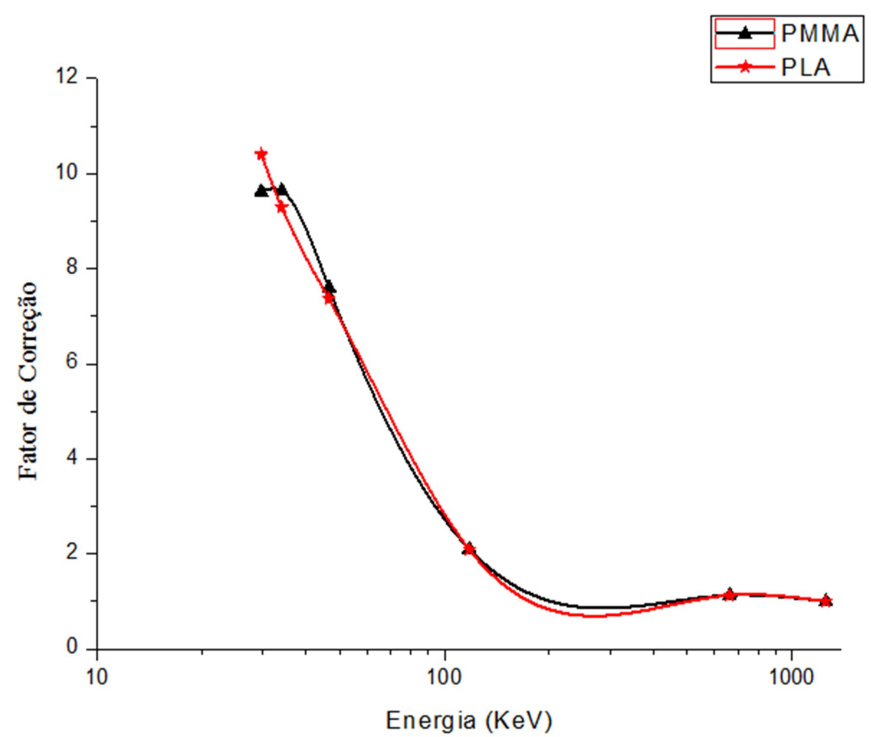

FIGURA 31. Curvas de dependência energética da resposta TL (em relação ao ${ }^{60} \mathrm{Co}$ ) do $\mathrm{CaSO}_{4}: \mathrm{Dy}$ empregando os dois tipos de placas.

Por meio do fator de calibração dos dosímetros $\mathrm{TL}\left(\mathrm{CaSO}_{4}\right.$ :Dy) foi realizada a conversão da resposta TL (uC) para a dose (mGy). Os valores de dose obtidos para os dosímetros irradiados, empregando as placas de PMMA e PLA, são mostrados na tabela 7. 
Tabela 7 - Doses calculadas empregando as placas de PMMA e PLA.

\begin{tabular}{cccc}
\hline \multicolumn{4}{c}{ Dose (mGy) } \\
\hline Qualidades de Radiação & PMMA & PLA & Diferença percentual \\
${ }^{60} \mathrm{Co}$ & $28,3 \pm 0,00040$ & $25,5 \pm 0,00039$ & 9,89 \\
${ }^{137} \mathrm{Cs}$ & $28,3 \pm 0,00045$ & $25,5 \pm 0,00035$ & 9,89 \\
${ }^{\mathrm{N} 150 *}$ & $9,4 \pm 0,00027$ & $8,48 \pm 0,00055$ & 9,79 \\
RQR10 & $28,3 \pm 0,00525$ & $25,5 \pm 0,00455$ & 9,89 \\
RQR5 & $28,3 \pm 0,00769$ & $25,5 \pm 0,01234$ & 9,89 \\
RQR3 & $28,3 \pm 0,00215$ & $25,5 \pm 0,00423$ & 9,89 \\
\hline${ }^{*}$ A qualidade N150 recebeu uma dose nominal de 10 mGy; as demais receberam uma dose nominal de 30 mGy.
\end{tabular}

Os valores das doses contidos na tabela 7 foram normalizados com a dose nominal de $30 \mathrm{mGy}$ de radiação gama do ${ }^{60} \mathrm{Co}$ (fonte radioativa de referência), tendo sido calculada (para cada qualidade de radiação) a diferença percentual entre os valores para o PMMA e o PLA, por meio da equação 17 , resultando em diferenças menores que $10 \%$.

$$
D i f_{\%}=\left[\frac{D_{P M M A}-D_{P L A}}{D_{P M M A}}\right] * 100(17)
$$

Conforme o manual do fabricante a malha impressa não é totalmente sólida, de modo a existirem espaços não preenchidos por PLA. É possível notar, na tabela 7, que as doses avaliadas para as placas de PLA são inferiores àquelas obtidas para o PMMA.

Nas tabelas $6 \mathrm{a}$ e $6 \mathrm{~b}$ os fatores de correção para a dependência energética nas qualidades de raios $\mathrm{X}$ diagnóstico (exceto $\mathrm{RQR} 3$ ) mostram que o PMMA, com a espessura adequada para o equilíbrio eletrônico para radiação do ${ }^{60} \mathrm{Co}$, apresenta fatores de dependência energética sempre maiores que para o PLA.

Essa diferença é um demonstrativo de que a espessura de $3 \mathrm{~mm}$ de PLA não é suficiente para fornecer condição de equilíbrio eletrônico para radiação do ${ }^{60} \mathrm{Co}$, com consequente sub estimativa da dose.

Para a qualidade RQR 3, há o indicativo de que com uma energia baixa do feixe $(29,7 \mathrm{keV})$, e considerando a qualidade da impressão utilizada, a placa de PLA impressa irá apresentar uma atenuação diferenciada, provocando dessa forma uma maior dependência energética da resposta TL do $\mathrm{CaSO}_{4}: \mathrm{Dy}$. 
Desse modo, é necessário o uso cauteloso e uma melhor avaliação das espessuras das placas de PLA impressas, de modo a que seja corrigida a influência da qualidade da impressão na equivalência do PLA ao polimetilmetacrilato (PMMA).

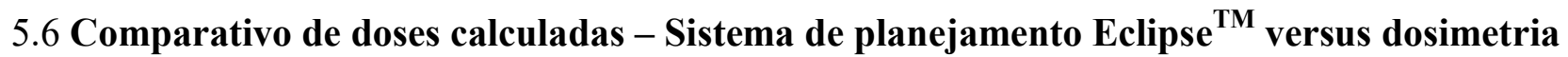 termoluminescente}

A tabela 8 mostra os valores das doses obtidas pelos TLD's e pelo Eclipse ${ }^{\text {TM. }}$ quando usado o Anisotropic Analytical Algorithm (AAA).

TABELA 8 - Valores das doses obtidas pelos TLD's e pelo Eclipse $\mathrm{TM}^{\mathrm{TM}}$

\begin{tabular}{|c|c|c|c|c|c|c|c|}
\hline \multirow[b]{3}{*}{$\begin{array}{l}\text { Profundidade } \\
\text { (cm) }\end{array}$} & \multicolumn{7}{|c|}{ Dose (cGy) } \\
\hline & \multicolumn{3}{|c|}{ Água Sólida } & \multicolumn{2}{|c|}{ PLA } & \multicolumn{2}{|c|}{ ABS } \\
\hline & TLD & $\begin{array}{c}\text { Eclipse } \\
\left(10 \times 10 \mathrm{~cm}^{2}\right)\end{array}$ & $\begin{array}{c}\text { Eclipse* } \\
\left(9,8 \times 9,8 \mathrm{~cm}^{2}\right)\end{array}$ & TLD & Eclipse & TLD & Eclipse \\
\hline 1,5 & $97,845 \pm 1,967$ & $96,900 \pm 0,041$ & $96,700 \pm 0,071$ & $97,118 \pm 2,220$ & $95,925 \pm 0,131$ & $91,052 \pm 1,748$ & $93,275 \pm 0,085$ \\
\hline 3,5 & $88,718 \pm 2,320$ & $90,475 \pm 0,025$ & $90,300 \pm 0,041$ & $91,933 \pm 0,936$ & $91,225 \pm 0,075$ & $89,411 \pm 1,033$ & $90,950 \pm 0,087$ \\
\hline 5 & $82,771 \pm 1,735$ & $84,050 \pm 0,029$ & $83,850 \pm 0,029$ & $85,135 \pm 2,203$ & $86,125 \pm 0,048$ & $83,274 \pm 1,003$ & $85,900 \pm 0,071$ \\
\hline 7 & $76,062 \pm 0,714$ & $76,000 \pm 0,041$ & $75,775 \pm 0,048$ & $77,664 \pm 2,007$ & $76,675 \pm 0,075$ & $75,627 \pm 2,018$ & $79,700 \pm 0,071$ \\
\hline
\end{tabular}

Com os valores da tabela 8 foi calculado a diferença percentual entre os resultados obtidos pelo LiF:Mg,Ti e pelo Eclipse ${ }^{\mathrm{TM}}$. O calculo foi feito a partir da equação 18.

$$
\text { Diferença percentual }=\left[\frac{\left(D_{T L D}-D_{\text {Eclipse }}\right)}{\left(D_{\text {Eclipse }}\right)}\right] * 100
$$

Onde: $D_{T L D}$, representa o valor de dose obtido pelo TLD;

$D_{\text {Eclipse }}$, representa o valor de dose obtido pelo Eclipse ${ }^{\mathrm{TM}}$.

As diferenças percentuais (aproximadamente) são mostradas na tabela 9.

TABELA 9 - Diferença percentual entre os valore de dose para TLD e para Eclipse ${ }^{\mathrm{TM}}$

\begin{tabular}{cccc}
\hline \multicolumn{4}{c}{ Diferença percentual } \\
\hline $\begin{array}{c}\text { Profundidade } \\
(\mathrm{cm})\end{array}$ & $\begin{array}{c}\text { Água Sólida } \\
\left(10 \mathrm{x} 10 \mathrm{~cm}^{2}\right)\end{array}$ & PLA & ABS \\
1,5 & 0,975 & 1,244 & 2,383 \\
3,5 & 1,942 & 0,776 & 1,692 \\
5 & 1,522 & 1,150 & 3,058 \\
7 & 0,081 & 1,290 & 5,111 \\
\hline
\end{tabular}


A partir da tabela 9 é possível verificar que as doses obtidas com o uso dos TLD's são aceitáveis, uma vez que a diferença percentual não ultrapassou os $5 \%$ recomendados pela literatura; isso considerando as respostas do PLA e da Água Sólida. No tocante aos resultados obtidos com o ABS, foi necessária uma nova abordagem, uma vez que a diferença percentual ultrapassou os $5 \%$ recomendados na literatura.

Em um trabalho publicado por Robinson (2008) foi avaliada a capacidade do AAA de considerar corretamente a presença de não homogeneidade em geometrias simples. Foi concluído que o AAA sobrestima a dose em regiões de heterogeneidade de baixa densidade e subestima a dose em regiões de heterogeneidade com alta densidade.

Diante disso, foi refeito o planejamento, empregando dessa vez o algoritmo de calculo Acuros XB, também presente no Eclipse ${ }^{\mathrm{TM}}$.

\subsubsection{Diferença percentual da dose - PLA versus Água Sólida}

O cálculo da diferença percentual da dose entre o PLA e a Água Sólida (campo 10x10 $\mathrm{cm}^{2}$ ) foi realizado com os valores da dose obtidos pelos TLD's. No tocante ao comparativo realizado entre o PLA e a Água Sólida (campo 9,8x9,8 $\mathrm{cm}^{2}$ ) foram utilizados os valores obtidos pelos TLD's e pelo Eclipse ${ }^{\mathrm{TM}}$, respectivamente. Para ambos os comparativos calculados foi utilizada a equação 19.

$$
\text { Diferença percentual }=\left[\frac{\left(D_{P L A}-D_{\text {Água Sólida }}\right)}{\left(D_{\text {Água Sólida }}\right)}\right] * 100(19)
$$

Onde: $D_{P L A}$, representa as doses para o PLA;

$D_{\text {Água Sólida }}$, representa as doses para a Água Sólida.

As diferenças percentuais obtidas com a equação 19 são mostradas na tabela 10.

TABELA 10 - Diferença percentual das doses do PLA e da água sólida.

\begin{tabular}{ccc}
\hline Profundidade $(\mathrm{cm})$ & PLA versus Água Sólida $\left(10 \times 10 \mathrm{~cm}^{2}\right)$ & PLA versus Água Sólida $\left(9,8 \times 9,8 \mathrm{~cm}^{2}\right)$ \\
\hline 1,5 & 0,742 & 0,433 \\
3,5 & 3,623 & 1,808 \\
5 & 2,857 & 1,533 \\
7 & 2,107 & 2,493 \\
\hline
\end{tabular}

\subsubsection{Percentagem de dose profunda - PLA versus Água Sólida}

Com os valores da dose (tabela 8) foi calculada a porcentagem de dose profunda. Vale ressaltar que as doses utilizadas para a Água Sólida $\left(10 \times 10 \mathrm{~cm}^{2}\right)$ foram as obtidas pelos TLD's e para a Água Sólida 
$\left(9.8 \times 9.8 \mathrm{~cm}^{2}\right)$ os valores utilizados foram os calculados pelo Eclipse ${ }^{\mathrm{TM}}$. Os valores de porcentagem de dose profunda obtidos podem ser visualizados na tabela 11 .

TABELA 11 - Porcentagem de dose profunda

\begin{tabular}{cccc}
\hline $\begin{array}{c}\text { Profundidade } \\
(\mathrm{cm})\end{array}$ & $\begin{array}{c}\text { Água Sólida } \\
\left(10 \times 10 \mathrm{~cm}^{2}\right)\end{array}$ & $\begin{array}{c}\text { Água Sólida } \\
\left(9,8 \times 9,8 \mathrm{~cm}^{2}\right)\end{array}$ & PLA \\
\hline 1,5 & 100 & 100 & 100 \\
3,5 & 90,673 & 93,382 & 94,660 \\
5 & 84,594 & 86,711 & 87,662 \\
7 & 77,737 & 78,361 & 79,969 \\
\hline
\end{tabular}

Utilizando a tabela 11 foi calculada a diferença percentual entre os valores de porcentagem de dose profunda para o PLA, Água Sólida $\left(10 \times 10 \mathrm{~cm}^{2}\right)$ e Água Sólida $\left(9.8 \times 9.8 \mathrm{~cm}^{2}\right)$. Esse cálculo foi realizado por meio da equação 20 .

$$
\text { Diferença percentual }=\left[\frac{\left(\% \text { dose }_{\text {material }}-\% \text { dose }_{\text {Água Sólida }}\right)}{\left(\% \text { dose }_{\text {Água Sólida }}\right)}\right] * 100(20)
$$

Onde: \%dose $e_{\text {material }}$, representa a porcentagem da dose, em sua respectiva profundidade, para o PLA;

$\%$ dose $_{\text {Água Sólida }}$, representa a porcentagem de dose, em sua respectiva profundidade, para a Água Sólida.

Os resultados calculados, pela equação 20, podem ser vistos na tabela 12 .

TABELA 12 - Diferença percentual da percentagem de dose profunda do PLA e da água sólida.

\begin{tabular}{ccc}
\hline Profundidade $(\mathrm{cm})$ & $\begin{array}{c}\text { PLA versus Água Sólida } \\
\left(10 \times 10 \mathrm{~cm}^{2}\right)\end{array}$ & $\begin{array}{c}\text { PLA versus Água Sólida } \\
\left(9,8 \times 9,8 \mathrm{~cm}^{2}\right)\end{array}$ \\
\hline 1,5 & 0 & 0 \\
3,5 & 4,398 & 1,369 \\
5 & 3,626 & 1,096 \\
7 & 2,871 & 2,052 \\
\hline
\end{tabular}

Os resultados mostrados na tabela 12 indicam que o PLA equivale a Água Sólida. Vale lembrar que o PLA foi irradiado com um campo quadrado $\left(9,8 \times 9,8 \mathrm{~cm}^{2}\right)$; tamanho de campo com qual foi obtido melhor proximidade com os resultados referente à Água Sólida. 


\subsubsection{Valores de dose calculados pelo algoritmo de cálculo Acuros XB para o ABS}

Na tabela 13 é possível encontrar os valores de dose obtidos por dosimetria TL e pelo AXB, para o ABS.

TABELA 13 - Valores de dose (cGy) obtidos por dosimetria TL e pelo algoritmo de calculo AXB, para placas de ABS.

\begin{tabular}{ccc}
\hline & \multicolumn{3}{c}{ Doses (cGy) } \\
\hline & \multicolumn{3}{c}{ ABS } \\
Profundidade $(\mathrm{cm})$ & $91,052 \pm 1,748$ & Eclipse (AXB) \\
1,5 & $89,411 \pm 1,033$ & $91,450 \pm 0,065$ \\
3,5 & $83,274 \pm 1,003$ & $88,650 \pm 0,029$ \\
5 & $75,627 \pm 2,018$ & $84,900 \pm 0,091$ \\
7 & & $77,925 \pm 0,025$ \\
\hline
\end{tabular}

A diferença percentual entre os valores mostrados na tabela 13 foi calculada pela equação 18 . Os resultados obtidos são mostrados na tabela 14 .

TABELA 14 - Diferença percentual entre os valores obtidos

\begin{tabular}{cc}
\hline Profundidade $(\mathrm{cm})$ & Diferença Percentual \\
\hline 1,5 & 0,435 \\
3,5 & 0,859 \\
5 & 1,916 \\
7 & 2,949 \\
\hline
\end{tabular}

\subsubsection{Diferença percentual de dose - ABS versus Água Sólida}

O calculo da diferença percentual da dose entre o ABS e a Água Sólida (campo 10x10 $\mathrm{cm}^{2}$ ) foi realizado com os valores da dose obtidos pelos TLD's. No tocante ao comparativo realizado entre o ABS e a Água Sólida (campo 9,8 x 9,8 $\mathrm{cm}^{2}$ ) foram utilizados os valores obtidos pelos TLD's e pelo Eclipse ${ }^{\mathrm{TM}}$ (Anisotropic Analytical Algorithm), respectivamente. Os comparativos foram calculados utilizando a equação 19 (adaptada para o ABS). As diferenças percentuais obtidas podem ser vistas na tabela 15 .

TABELA 15 - Diferença percentual das doses do ABS e da Água Sólida.

\begin{tabular}{ccc}
\hline Profundidade $(\mathrm{cm})$ & $\begin{array}{c}\text { ABS versus Água Sólida } \\
\left(10 \times 10 \mathrm{~cm}^{2}\right)\end{array}$ & $\begin{array}{c}\text { ABS versus Água Sólida } \\
\left(9.8 \times 9.8 \mathrm{~cm}^{2}\right)\end{array}$ \\
\hline 1,5 & 6,942 & 5,841 \\
3,5 & 0,781 & 0,984 \\
5 & 0,607 & 0,688 \\
7 & 0,572 & 0,196 \\
\hline
\end{tabular}




\subsubsection{Percentagem de dose profunda - ABS versus Água Sólida}

Com os valores da dose foi calculada a porcentagem de dose profunda. Vale ressaltar que as doses utilizadas para a Água Sólida $\left(10 \times 10 \mathrm{~cm}^{2}\right)$ foram a obtidas pelos TLD's e para a Água Sólida $\left(9,8 \times 9,8 \mathrm{~cm}^{2}\right)$ os valores utilizados foram os calculados pelo Eclipse ${ }^{\mathrm{TM}}$ (Anisotropic Analytical Algorithm). Para o ABS os valores empregados foram os obtidos pelos TLD's. Os valores obtidos podem ser vistos na tabela 16.

TABELA 16 - Porcentagem de dose profunda

\begin{tabular}{cccc}
\hline $\begin{array}{c}\text { Profundidade } \\
(\mathrm{cm} 2)\end{array}$ & $\begin{array}{c}\text { Água Sólida } \\
\left(10 \times 10 \mathrm{~cm}^{2}\right)\end{array}$ & $\begin{array}{c}\text { Água Sólida } \\
\left(9.8 \times 9.8 \mathrm{~cm}^{2}\right)\end{array}$ & ABS \\
\hline 1,5 & 100 & 100 & 100 \\
3,5 & 90,673 & 93,382 & 98,198 \\
5 & 84,594 & 86,711 & 91,457 \\
7 & 77,737 & 78,361 & 83,059 \\
\hline
\end{tabular}

Utilizando a tabela 16 foi calculada a diferença percentual entre os valores de porcentagem de dose profunda para o ABS, Água Sólida $\left(10 \times 10 \mathrm{~cm}^{2}\right)$ e Água Sólida $\left(9,8 \times 9,8 \mathrm{~cm}^{2}\right)$. Para que esse calculo fosse realizado, foi utilizada a equação 20 (adaptada para o ABS). Os resultados obtidos podem ser vistos na tabela 17.

TABELA 17 - Diferença percentual da percentagem de dose profunda do ABS e da Água Sólida.

\begin{tabular}{ccc}
\hline Profundidade $(\mathrm{cm})$ & $\begin{array}{c}\text { ABS versus Água Sólida } \\
\left(10 \times 10 \mathrm{~cm}^{2}\right)\end{array}$ & $\begin{array}{c}\text { ABS versus Água Sólida } \\
\left(9.8 \times 9.8 \mathrm{~cm}^{2}\right)\end{array}$ \\
\hline 1,5 & 0 & 0 \\
3,5 & 8,3 & 5,158 \\
5 & 8,113 & 5,473 \\
7 & 6,846 & 5,995 \\
\hline
\end{tabular}

Diante do exposto na tabela 17 o ABS aparenta não ter equivalência com a Água Sólida. Vale lembrar que o ABS foi irradiado com um campo quadrado $\left(9,8 \times 9,8 \mathrm{~cm}^{2}\right)$; tamanho de campo com qual foi obtido menor diferença percentual com os resultados referentes à Água Sólida. 


\section{CONCLUSÃO}

Foram desenvolvidas simulações utilizando MCNP5 para calculo do coeficiente de atenuação de placas impressas 3D irradiadas por diversos feixes de raios $\mathrm{X}$ com qualidades de radiodiagnóstico. Com as simulações com MCNP5 foi verificado que a presença de espaços não preenchidos em placas impressas apresenta influência na atenuação de um dado feixe de radiação.

O modelo computacional criado de uma placa impressa 3D pela impressora UP Plus 2, demonstra que a metodologia empregada foi eficiente e que há um indicativo da influência de espaços não preenchidos em uma placa impressa 3D.

Resultados experimentais obtidos indicam que modo de impressão pode ser empregado de modo a influenciar a atenuação de um feixe em determinada qualidade de radiação, devendo ser analisada a qualidade de impressão empregada na impressão 3D bem como a qualidade de radiação utilizada.

As simulações computacionais realizadas com o sistema de planejamento Eclipse ${ }^{\mathrm{TM}}$ demonstraram que a metodologia de "empilhar placas", empregada nos testes com qualidade de radioterapia, pode acarretar em sobreposição de camadas com posterior erro no calculo da dose. Esse fato (provavelmente) se deve à estrutura interna das placas impressas, quando submetidas à tomografia computadorizada acarretar em uma alternância entre material impresso e ar, levando a uma má estimativa do espalhamento/absorção da radiação.

No tocante aos resultados obtidos com qualidades de raios $\mathrm{X}$ em qualidades de radioterapia, foi mostrado um indicativo de equivalência entre o PLA impresso (com a qualidade de impressão “quase-sólida”) e objetos simuladores de Água Sólida no que diz respeito à deposição de dose em profundidade.

No entanto, os resultados obtidos com qualidade de radioterapia, para o ABS impresso, indicou que o mesmo (com a qualidade de impressão "quase-sólida") não apresenta equivalência com objetos simuladores de Água Sólida no que diz respeito à deposição de dose em profundidade 
Os resultados obtidos para o PLA e ABS impressos 3D e para Água Sólida para qualidade de radioterapia indicam que usar um mesmo material impresso para compor objetos simuladores de órgãos e estruturas ósseas poderá acarretar em uma distribuição de dose incorreta, uma vez que o PLA aparenta ter equivalência com a Água Sólida e o ABS aparenta não ter equivalência com a Água Sólida

É necessário avaliar o desenvolvimento de órgãos específicos ou de um objeto simulador antropomórfico empregando materiais impressos diversos ou qualidades de impressão diversas.

Para aplicação da impressão 3D no desenvolvimento de objetos simuladores na prática clínica é necessário estudar a influência das alterações climáticas na impressão, pois a impressora 3D UP Plus emprega sistema de aquecimento para confecção de objetos, sendo necessário estudar também o tempo de "vida útil" da impressora 3D, pois o mau funcionamento da impressora poderá acarretar em objetos simuladores com dimensões incorretas. 
REFERENCIAS

AMERICAN ASSOCIATION OF PHYSICISTS IN MEDICINE. A protocol for clinical reference dosimetry of high-energy photon and electron beams. 1999.

AMERICAN CANCER SOCIETY. Cancer Facts $\&$ Figures. Atlanta, 2014. Disponível em: $<$ http://www.cancer.org/research/cancerfactsstatistics/cancerfactsfigu res2014/>. Acesso em: $02 \mathrm{dez} 2015$.

BARBOSA, Patrícia de O. Implementação do controle de qualidade para sistemas de planejamento de tratamento em radioterapia nas avaliações locais do PQRT/INCA. 2011. Dissertação (Mestrado) - Universidade Federal do Rio de Janeiro, Rio de Janeiro. 88 p.

BATISTA, Bernardo J. B. Avaliação de dosímetros termoluminescentes para uso em radioterapia com fótons de alta energia. 2011. Dissertação (Mestrado) - Universidade de São Paulo, São Paulo. 96 p.

BERGER, T.; HAJEK, M.. TL-efficiency: Overview and experimental results over the years. Radiation Measurements, v. 43, n. 2/6, p.146-156, 2007.

BOGART, J.A.; GUNDERSON, L.L.; TEPPER, J.E. Clinical Radiation Oncology, 4. ed. Elsevier, 2016.

BRASIL. MINISTÉRIO DA SAÚDE/ (INCA) INSTITUTO NACIONAL DE CÂNCER. ABC do Câncer: abordagens básicas para o controle do câncer. Thuler, L. C. S. (Org.). $2^{\mathrm{a}}$ ed., 129 p., Rio de Janeiro, 2012. Disponível em: $<$ http://www1.inca.gov.br/inca/Arquivos/livro_abc_2ed.pdf $>$. Acesso em: 11 dez. 2015.

BUENO, Gisele O. V. Proposta de procedimentos para evitar erros em radioterapia baseados em lições aprendidas de exposições acidentais. 2007. Dissertação (Mestrado) - Instituto de Pesquisas Energéticas e Nucleares, São Paulo. 69 p.

BUSHBERG, J.T.; SEIBERT, J.A.; LEIDHOLDT, E.M.; BOONE, J.M. The Essential Physics of Medical Imaging. 3 ed. Philadelphia: Lippincott Williams \& Wilkins, 2012

CAMPOS, L. L; LIMA, M.F. Dosimetric properties of $\mathrm{CaSO}_{4}:$ Dy Teflon pellets produced at IPEN. Rad. Prot. Dosim., v. 14, n.4, p.333-335, 1986. 
CAMPOS, L. L.. Termoluminescência de materiais e sua aplicação em dosimetria da radiação. Cerâmica, v. 44, n. 290, 1998. Disponível em <http://www.scielo.br/scielo.php?script=sci_arttext\& pid $=$ S036669131998000600007\&lng=pt\&nrm=iso > . Acesso em: 07 setembro 2015.

CAVALIERI, T. A.; CASTRO, V. A.; SIQUEIRA, P. T. D.. Uso do MCNP para comparação das respostas de dose depositada nos TLD 100, TLD 600 e TLD 700 em campos de irradiação devido a fontes de 60Co e 241AmBe. Revista Brasileira de Física Médica, v. 6, n. 2, p.91-94, 2012.

CUNICO, Marlon W. M. Desenvolvimento de nova tecnologia de manufatura aditiva baseado em formação seletiva de compósito. 2013. Tese (Doutorado) - Escola de Engenharia de São Carlos, São Paulo. 290 p.

DANCE, D.R.; CHRISTOFIDES, S.; MAIDMENT, A.D.A.; McLean, I.D.; NG, K.H. (Ed.). Diagnostic Radiology Physics: A Handbook for Teachers and Students. Vienna: International Atomic Energy Agency, 2014.

DeWerd, L.A.; KISSICK, M. (Ed.). The Phantoms of Medical and Health Physics: Devices for Research and Development.. New York: Springer. 2014.

Elekta. Monaco ${ }^{\circledR}$.[s.d.]. Disponível em: $<$ http://www.elekta.com/healthcare-professionals/products/e lekta-software/treatment-planning-software/planning-software/monaco.html>. Acesso em: $02 \mathrm{fev}$ 2016

Elekta. $\mathrm{XiO}^{\circledR}$.[s.d.] Disponível em: $<\mathrm{http} / /$ www.elekta.com/healthcare-professionals/products/elekta -software/treatment-planning-software/planning-software/xio.html>. Acesso em: 02 fev 2016

EVANS, B. Practical 3D printers: The Science and Art of 3D Printing. Apress, 2012.

FRANCHETTI, S. M. M.; MARCONATO, J. C.. Polímeros biodegradáveis: uma solução parcial para diminuir a quantidade dos resíduos plásticos. Química Nova, v. 29, n. 4, p. 811-816, 2006 . Disponível em: $<$ http://www.scielo.br/scielo.php?script=sci_arttext\&pid=S0100-404220060004003 $1 \& \operatorname{lng}=$ en\&nrm=iso $>$. Acesso em 13 jan 2016.

FURETTA, C. Handbook of Thermoluminescence. World Scientific Publishing Co. Pte. Ltd., 2003.

GARLOTTA, D. A Literature Review of Poly(Lactic Acid). Journal of Polymers and the Environment, v. 9, n 2, p. 63-84, 2001.

GIGLIOLI, Milena. Avaliação da distribuição da dose absorvida em radioterapia com campos irregulares e alargados. 2012. Dissertação (Mestrado) - Instituto de Pesquisas Energéticas e Nucleares, São Paulo. 130 p.

GOITEIN, M. Radiation Oncology: A Physicist's-Eye View. New York: Springer, 2008. 
HIEMENZ, J. 3D printing with fdm: how it works. Stratasys Inc. [s.d.] Disponível em: $<$ http://www.usglobalimages.stratasys.com/Main/Secure/White\%20Papers/Rebranded/SSYS_WP_3 d_printing_with_fdm.pdf?v=635393106532802826> Acesso em:20 dez 2015

HOROWITZ, Y.S.; MOSCOVITCH, M. Highlights and pitfalls of 20 years of application of computerised glow curve analysis to thermoluminescence research and dosimetry. Radiation Protection Dosimetry, v. 153, n. 1, p.1-22, 2012

HOSPITAL ISRAELITA ALBERT EINSTEIN. Câncer benigno e maligno. 2013. Disponível em: $<$ http://www.einstein.br/einstein-saude/em-dia-com-a-saude/Paginas/cancer-benigno-emaligno.aspx $>$. Acesso em: $01 \mathrm{dez} 2015$

(IAEA)INTERNATIONAL ATOMIC ENERGY AGENCY. Absorbed Dose Determination in External Beam Radiotherapy: An International Code of Practice for Dosimetry Based on Standards of Absorbed Dose to Water. Viena, 2005.

(IAEA)INTERNATIONAL ATOMIC ENERGY AGENCY. Radiation protection and safety of radiation sources : international basic safety (GSR. Part. 3). Vienna, 2014.

(ICRU)INTERNATIONAL COMISSION ON RADIATION UNITS AND MEASUREMENTS. Report 48, Phantoms and Computational Models in Therapy, Diagnosis and Protection. Bethesda, 1992.

(IEC)INTERNATIONAL ELETROTECHNICAL COMMISSION. Medical Diagnostic X-ray Equipment - Radiation Conditions for use in the Determination of Characteristics. 2013 (IEC 61267, 2005.)

(INCA)INSTITUTO NACIONAL DE CÂNCER. Radioterapia.[s.d.]. Disponível em:<http://www. inca.gov.br/conteudo_view.asp?ID=100>. Acesso em: 23 novembro 2015.

INTERNATIONAL ORGANIZATION FOR STANDARDIZATION/ AMERICAN SOCIETY FOR TESTING AND MATERIALS. Standard Practice for Use of a Thermoluminescence-Dosi metry System (TLD System) for Radiation Processing. 2013. (ISO/ASTM 51956:2013)

(IUPAC)INTERNATIONAL UNION OF PURE AND APPLIED CHEMISTRY. IUPAC Periodic Table of the Elements. v. 28 november 2016. Disponível em: $<$ https://www.iupac.org/cms/wpcontent/uploads/2015/07/IUPAC_Periodic_Table-28Nov16.jpg>. Acesso em: 08 dez. 2016.

KAIRN, T.; CROWE, S. B.; MARKWELL, T.. Use of 3D Printed Materials as Tissue-Equivalent Phantoms. IFMBE Proceedings, v. 51,p.728-731, 2015. DOI: 10.1007/978-3-319-19387-8_179.

KHAN, F. M. The Physics Of Radiation Therapy. 3. ed. Philadelphia: Lippincot, William e Wilkins, 2003

LANDI, T.R.L. Estudo do efeito da radiação ionizante por feixe de elétrons sobre o terpolímero acrilonitrila butadieno estireno - ABS. 2003. Dissertação (Mestrado) - Instituto de Pesquisas Energéticas e Nucleares, São Paulo. 78 p. 
LEROY, C. Radiation interaction in matter and principles of detection In NUCLEAR PHYSICS METHODS AND ACCELERATORS IN BIOLOGY AND MEDICINE: FIFTH INTERNATIONAL SUMMER SCHOOL ON NUCLEAR PHYSICS METHODS AND ACCELERATORS IN BIOLOGY AND MEDICINE. July 06-15, 2009, Bratislava. AIP Conference Proceedings, v. 1204, n. 3, 2010.

MAIA, Ana F; JÚNIOR, Edvaldo de S.; SANTOS, Laélia P. B. C. dos; MACEDO, Marcelo A.; ATTIE, Márcia R.P.; VALERIO, Mario E.G. Apostila de LABORATÓRIO DE FÍSICA A. São Cristovão: Universidade Federal de Sergipe/Departamento de Física, 2016.

MARQUES, K. Manufatura aditiva: o futuro do mercado industrial de fabricação e inovação. EESC-USP. 2014. Disponível:<http://www.eesc.usp.br/portaleesc/index.php?option=com_content \&view=article\&id=1934:manufatura-aditiva-o-futuro-do-mercado-industrial-de-fabricacao-einovacao\&catid=115\&Itemid=164>. Acesso em:20 dez 2015.

MATSUSHIMA, L.C. Avaliação da resposta de detectores termoluminescentes na dosimetria de feixes clínicos utilizando diferentes objetos simuladores. 2010. Dissertação (Mestrado) Instituto de Pesquisas Energéticas e Nucleares, São Paulo. 96 p.

MAZALI, Italo O. Determinação da Densidade de Sólidos pelo Método de Arquimedes. Campinas: Laboratório de Química do Estado Sólido, 2005

MCKEEVER, S.W.S..; CHEN, R.. Luminescence models. Radiation Measurements, v. 27, n. 5/6, p.625-661, 1997

(NIH/NIBIB)NATIONAL INSTITUTES OF HEALTH/NATIONAL INSTITUTE OF BIOMEDICAL IMAGING AND BIOENGINEERING. Computed Tomography. [s.d.]. Disponível em: $<\quad$ https://www.nibib.nih.gov/science-education/science-topics/computedtomography-ct>. Acesso: 31 jan 2016.

NUNES, M. G. Avaliação do desempenho dos detectores termoluminescentes de caso4:dy e lif:mg,ti na dosimetria de feixes clínicos de életrons. 2008. 93 p. Dissertação (Mestrado) Instituto de Pesquisas Energéticas e Nucleares, São Paulo. 93 p.

OBERHOFER, M.; SCHARMANN, A. Applied Thermoluminescence dosimetry. Ispra, Itália: Adam Hilger Ltd (Commission of the European Comunnitties), 1979.

OKUNO, E. Efeitos biológicos das radiações ionizantes: acidente radiológico de Goiânia. Estudos Avançados., v. 27, n. 77, p. 185-200, 2013. Disponível em: <http://www.scielo.br/scielo.php?script =sci_arttext\&pid=S0103-40142013000100014\&lng=en\&nrm=iso $>$. Acesso em 17 nov. 2015.

OKUNO, E.; YOSHIMURA, E. M. Física das Radiações. São Paulo: Oficina de Textos, 2010.

OLIVEIRA, Camila T. de. Desenvolvimento de uma metodologia para calibração de câmaras de ionização de placas paralelas em feixes de raios $x$ de energia baixa em termos de dose absorvida em água. 2015, Dissertação (Mestrado) - Instituto de Pesquisas Energéticas e Nucleares, São Paulo. 99 p. 
PAWLICKI, T.; SCANDERBEG, D.J.; STARKSCHALL, G. Hendee's Radiation Therapy Physics. 4. ed. Hoboken: Wiley Blackwell, 2016.

PELOWITZ, D.B. MCNPX ${ }^{\text {TM }}$ USER'S MANUAL: Versions 2.7.0. Los alamos: Los Alamos National Laboratory, 2011. (LA-CP-11-00438 ).

PEREIRA, Marcelo O. Metodologia de obtenção do coeficiente de atenuação de massa em matrizes biológicas. 2011. Tese (Doutorado) - Instituto Alberto Luiz Coimbra de Pós-Graduação e Pesquisa de Engenharia (COPPE), Rio de Janeiro. 140 p.

Philips. Pinnacle ${ }^{3}$.[s.d.]. Disponível em: $<$ http://www.healthcare.philips.com/main/products/ros/pro ducts/pinnacle3/>. Acesso em: 02 fev 2016

PODGORSAK, E. B. Radiation oncology physics: a handbook for teachers and students. Viena: International Atomic Energy Agency, 2005.

PODGORSAK, E.B. Radiation Physics for Medical Physicists. Berlin: Springer-Verlag Berlin Heidelberg, 2010.

POLI, Maria E. R. Definição do volume de planejamento do alvo (PTV) e seu efeito na radioterapia. 2007. Tese (Doutorado) - Instituto de Pesquisas Energéticas e Nucleares, São Paulo. $182 \mathrm{p}$

REED, A.B. The history of radiation use in medicine. Journal of Vascular Surgery, v. 53, n. 1, p. 3S-5S, 2011. Supplmeent.

ROBINSON, D. Inhomogeneity correction and the analytic anisotropic algorithm. J Appl Clin Med Phys., v.9, n. 2, p.112-122, 2008.

ROMANS, L.E. Computed tomography for technologists: a comprehensive text. Philadelphia: Lippincott Williams \& Wilkins, 2011.

RUTKOWSKI, J. V.; LEVIN, C.B. Acrylonitrile-Butadiene-Styrene Copolymers (ABS): Pyrolysis and Combustion Products and theirToxicity-A Review of the Literature. Fire and Materials, v. 10, p. 93-105, 1986.

SCAFF, L. A. M. Física na Radioterapia - A base analógica de uma era digital. Parte 1. São Paulo: Editora Projeto Saber, 2010

SCHLEGEL, W.; BORTFELD, Thomas; GROSU, Anca-ligia. New Tecnologies in Radiation Oncology. Berlin: Springer Berlin - Heidelberg, 2006.

SHUlTIS, J.K.; FAW, R.E. An MCNP Primer. Manhattan: Kansas State University,2011. 
SISTEMA DE INFORMAÇÕES AMBULATORIAIS/SISTEMA ÚNICO DE SAÚDE. Oncologia: Bases Técnicas. 21a ed. Brasília-DF. 2015. Disponível em: < http://www1.inca.gov.br/inca/Arquivos/manualoncologia21aedicao14092015.pdf $>$. Acesso: 01 dez. 2015.

SILVA, Rosemeire Evangelista da. Dosimetria com materias radiocrômicos em feixes de elétrons acelerados - processos de irradiação com doses altas. 2000. Dissertação (Mestrado) Instituto de Pesquisas Energéticas e Nucleares, São Paulo. . 133 p.

SYMONDS, P.; DEEHAN, C.; MILLS, J.A.; MEREDITH, C. (Ed.). Walter and Miller's Textbook of Radiotherapy: Radiation Physics, Therapy and Oncology. 7 ed. Churchill Livingstone, 2012.

TURNER, J. E. Atoms, Radiation, and Radiation Protection. 3. ed. Weinheim: Wiley-vch Verlag Gmbh \& Co., 2007.

(USNRC)UNITED STATES NUCLEAR REGULATORY COMISSION. Uses of Radiation. 2014 Disponível em: $<$ http://www.nrc.gov/about-nrc/radiation/around-us/uses-radiation.html $>$. Acesso em: 23 nov . 2015.

UP! 3D Brasil. UP! User Manual. Disponível em:< http://www.bcstecnologia.com.br/cariboost_files/UP_Plus_2_User_Manual-PT_BRV2.pdf>. Acesso em:01 nov 2015

Varian Medical Systems (a). Eclipse Photon and Electron Algorithms Reference Guide.[s.d.]. Disponível em: < https://varian.force.com> Acesso em: 02 mai 2016

Varian Medical Systems (b). Eclipse ${ }^{\text {TM }}$ Treatment Planning System. [s.d.]. Disponível em: $<$ https://www.varian.com/oncology/products/software/treatment-planning/eclipse-treatmentplanning-system.> Acesso em: 02 fev 2016

Varian Medical Systems (c). Eclipse Photon and Electron Instructions for Use. [s.d.]. Disponível em: $<$ https://varian.force.com> Acesso em: 02 mai 2016

VENEZIANI, G. R.; CORREA, E.L.; POTIENS, M.P.A.; CAMPOS, L.L.. Attenuation coefficient determination of printed abs and pla samples in diagnostic radiology standard beams. In: $8^{\circ}$ Congresso Brasileiro de Metrologia. 29 novembro à 4 de dezembro, 2015. Bento Gonçalves, RS

WILliamS, J. R.; THWAiTeS, D. I. Radiotherapy Physics in Practice. Oxford: University Press, 2000.

X5 MONTE CARLO TEAM. MCNP: A General Monte Carlo N-Particle Transport Code, Version 5. Los Alamos: Los Alamos National Laboratory, 2003. Volume I: Overview and Theory.

X5 MONTE CARLO TEAM. MCNP: A General Monte Carlo N-Particle Transport Code, Version 5. Los Alamos: Los Alamos National Laboratory, 2003. Volume II: User's Guide. 
YORIYAZ, H. Método de Monte Carlo: Princípios e aplicações em Física Médica. Revista Brasileira de Fisica Medica, v. 3, p. 141-149, 2009

YOSHIMURA, E.M. Física das Radiações: interação da radiação com a matéria. Revista Brasileira de Física Médica, v.3, n.1, p.57-67, 2009.

ZEISS. Scanning Electron Microscopes.[s.d.]. Disponível em:<http://www.zeiss.com/microscopy/ en_de/products/scanning-electron-microscopes.html>. Acesso em: 19 ago 2016

3D Printing Systems. UP PLUS 2: User Manual. Disponível em: $<$ http://3dprintingsystems.com/do wnload/UP\%20Plus\%202\%203D\%20Printer\%20Manual.pdf>. Acesso em:01 nov 2015 